UNIVERSIDADE DE SÃO PAULO

FACULDADE DE ZOOTECNIA E ENGENHARIA DE ALIMENTOS

PALMER VICENTE PULLA HUILLCA

Propriedades superficiais de filmes à base de gelatina 
PALMER VICENTE PULLA HUILLCA

Propriedades superficiais de filmes à base de gelatina

Dissertação apresentada à Faculdade de Zootecnia e Engenharia de Alimentos da Universidade de São Paulo, como parte dos requisitos para a obtenção do Título de Mestre em Ciências do programa de pós-graduação em Engenharia de Alimentos.

Área de concentração: Ciências da Engenharia de Alimentos.

Orientador: Prof. Paulo José do Amaral Sobral. 
Dados Internacionais de Catalogação na Publicação

Serviço de Biblioteca e Informação da Faculdade de Zootecnia e Engenharia de Alimentos da Universidade de São Paulo

\footnotetext{
Huillca Pulla, Palmer Vicente

Propriedades surperficiais de filmes à base de gelatina / Palmer Vicente Huillca Pulla. -- Pirassununga, 2015 .

$83 \mathrm{f}$.

Dissertação (Mestrado) -- Faculdade de Zootecnia e Engenharia de Alimentos - Universidade de São Paulo. Departamento de Engenharia de Alimentos.

Área de Concentração: Ciências da Engenharia de Alimentos.

Orientador: Prof. Dr. Paulo José do Amaral Sobral.

1. Filme de gelatina 2. Ângulo de contato

3. Molhabilidades 4. Coeficiente de espalhamento

5. Energia livre superficial I. Título.
} 


\section{Propriedades superficiais de filmes à base de gelatina}

Dissertação apresentada à Faculdade de Zootecnia e Engenharia de Alimentos da Universidade de São Paulo, como parte dos requisitos para a obtenção do Título de Mestre em Ciências do programa de pós-graduação em Engenharia de Alimentos.

Área de concentração: Ciências da Engenharia de Alimentos.

Data de aprovação:

\section{Banca Examinadora:}

Paulo José do Amaral Sobral - Presidente da Banca Examinadora

Prof. Titular da Faculdade de Zootecnia e Engenharia de Alimentos da Universidade de São Paulo - Orientador

Rosemary Aparecida de Carvalho

Prof. Associada da Faculdade de Zootecnia e Engenharia de Alimentos da Universidade de São Paulo

Milena dos Reis Martelli

Dra. da Faculdade de Filosofia, Ciências e Letras de Ribeirão Preto da Universidade de São Paulo 


\section{DEDICATÓRIA}

Com todo meu amor para Minha amada Família: Meus pais Maria Elena e Agripino, meus irmãos Jorge, Mily e María Elena, por seu amor incondicional e apoio nos momentos mais difíceis e por fazer possível a realização do meu sonho.

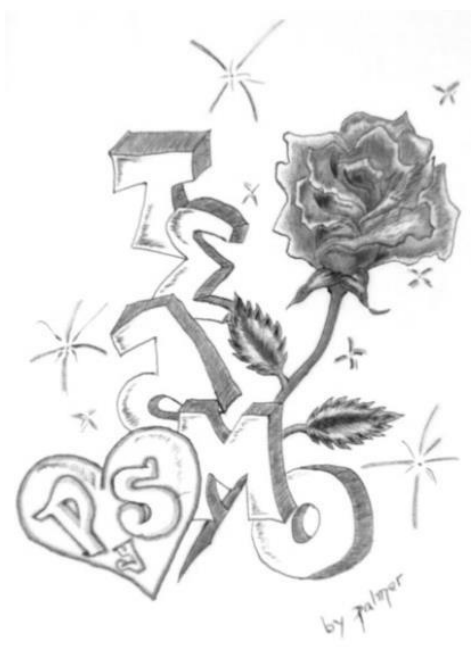

A minha noiva Katherine Sareth, por todo seu amor, por estar presente em cada momento desta jornada além da distancia, por todo seu apoio, por sua confiança e por tentar tirar sempre um sorriso de mim, TE AMO. 
Talvez não tenha conseguido fazer o melhor, mas lutei para que o melhor fosse feito. Não sou o que deveria ser, mas graças a Deus, não sou o que era antes.

Martin Luther King.

Se não puder voar, corra. Se não puder correr, ande. Se não puder andar, rasteje, mas continue em frente de qualquer jeito.

Martin Luther King. 


\section{AGRADECIMENTO}

A Deus pelas bênçãos, por dar-me as forças para puder concluir com bem esta etapa da minha vida, e por dar-me o maior presente que um ser humano pode ter, a sua família.

Às mulheres da minha vida, minha mãe Maria Elena e minha noiva Katherine Sareth, por todo seu amor.

Ao Programa Nacional de Becas y Créditos Educativos (PRONABEC) do governo Peruano, pela bolsa de mestrado outorgada.

À Faculdade de Zootecnia e Engenharia de Alimentos (FZEA) da Universidade de São Paulo por acolher-me.

Ao meu Orientador, Prof. Dr. Paulo José do Amaral Sobral, pela paciência, amizade, compreensão e por dar-me a mão no momento mais difícil.

Aos meus amigos da Pós-graduação Roger, Gerardo, Heber, Santiago, Sandra, Julio Colivet, Julio Guerra, Diana, Ylianita, Kiupsy, pela amizade, pelo seu tempo e as risadas compartilhadas neste tempo.

Aos técnicos: Rodrigo Lourenço, Mônica Bittante e Carla Mônaco pela sua ajuda no uso dos equipamentos.

Aos meus colegas e amigos do Laboratório de Tecnologia de Alimentos: Germán, Gisele, Jeannine, Carla (Kakau), Christian, Luís, Flavia, Laura, Daniel, Ilyes, Lucas, Tiara, David, pela sua amizade, agradável companhia e sua ajuda.

Ao Prof. Dr. Jorge Lizardo Diaz Calle pela sua ajuda e tempo.

À seção de Pós-graduação, Layla Denófrio e funcionários, que sempre me atenderam com muita amabilidade.

Ao Comitê de Relações Internacionais, Prof. Dr. Raul Franzolin e Clélia de Godoy, pelas saídas com o grupo de estrangeiros.

A todas aquelas pessoas que me acompanharam de alguma maneira por esta etapa da minha vida...

Muito obrigado a todos... Gracias Totales...!!! 


\section{RESUMO}

PULLA HUILLCA, P.V. Propriedades superficiais de filmes à base de gelatina. 2015. 83 f. Dissertação (Mestrado) - Faculdade de Zootecnia e Engenharia de Alimentos, Universidade de São Paulo, Pirassununga, 2015.

O objetivo do presente trabalho foi caracterizar as propriedades superficiais de filmes à base de gelatina. Para o qual foram elaborados filmes de: (i) Gelatina plastificado com glicerol (G) (gelatina: $5 \mathrm{~g} / 100 \mathrm{~g}$ SFF; glicerol: $30 \mathrm{~g} / 100 \mathrm{~g}$ de gelatina), (ii) Gelatina reforçado com montmorilhonita (G/MMT) (gelatina: 5 g/100 g SFF; glicerol: 30 g/100 g de gelatina; MMT: $5 \mathrm{~g} / 100 \mathrm{~g}$ de gelatina) e Gelatina plastificado com citrato de acetiltributila (G/ATB) (gelatina: 5 g/100 g SFF; ATB: 50 g/100 de gelatina; lecitina de soja: 60 g/100 g de ATB; etanol: 20 $\mathrm{g} / 100 \mathrm{~g} \mathrm{SFF}$ ). Os filmes foram produzidos mediante o uso de um aplicador automático de filmes "Spreading". Logo, os filmes foram submetidos a testes para determinação da espessura, umidade e propriedades óticas (brilho, cor e opacidade). Também foi caracterizada a microestrutura por microscopia eletrônica de varredura (MEV) e microscopia de força atômica (AFM); às imagens obtidas por MEV foi aplicado um analise de imagem mediante o programa Image J, para obter o valor da dimensão fractal (DF). Depois foram caracterizadas as propriedades superficiais de ângulo de contato (AC), molhabilidade ou coeficiente de espalhamento $\left(\mathrm{S}_{\mathrm{e}}\right)$, e energia livre superficial (ELS) mediante a medida do ângulo de contato pelo método da gota séssil (água: $5 \mu \mathrm{L}$ e 1-Bromonaftaleno: $3 \mu \mathrm{L}$ ). Para o cálculo da ELS também foi aplicado o método de Owens-Wendt. Estas caracterizações foram feitas em ambos os lados do filme, lado ar e lado placa. A natureza do filme de G/ATB influenciou na umidade e as propriedades óticas, enquanto que os filmes de G e G/MMT apresentaram características similares. Em relação à microestrutura e rugosidade, o filme de $\mathrm{G}$ apresentou a superfície mais homogênea e lisa, contrario ao observado no filme de G/MMT, que apresentou a maior rugosidade seguida do filme de G/ATB. Foi observado que houve uma relação entre os valores de rugosidade e DF. De acordo com o valor do AC, os filmes apresentaram um caráter hidrofóbico, pois seus valores foram superiores a $65^{\circ}$ (em ambos os lados dos filmes), na seguinte ordem: G/MMT > G > G/ATB; sendo que o $S_{e}$ seguiu a mesma tendência. Cabe mencionar também que não foi encontrada uma correlação significativa entre os valores de $\mathrm{AC}$ e rugosidade. Em função dos valores de $\mathrm{AC}, \mathrm{S}_{\mathrm{e}}$ e ELS (especificamente a componente polar), o filme de G/ATB apresentou o menor caráter hidrofóbico, pois apresentou menores 
valores de $\mathrm{AC}$ e maiores valores de $\mathrm{S}_{\mathrm{e}}$ em comparação com os outros dois filmes. Os valores da componente polar da G/ATB foram os maiores, explicando de melhor maneira o caráter menos hidrofóbico deste filme. Pode-se concluir que os filmes à base de gelatina elaborados no presente trabalho têm propriedades hidrofóbicas $\left(\mathrm{AC}>65^{\circ}\right)$, sendo a $\mathrm{G} / \mathrm{MMT}$ o filme com melhores características hidrofóbicas.

Palavras-chave: Filme de gelatina, ângulo de contato, molhabilidade, coeficiente de espalhamento, energia livre superficial. 


\begin{abstract}
PULLA HUILlCA, P.V. Surface properties of gelatin-based films. 2015. 83 f. M. Sc. Dissertation - Faculdade de Zootecnia e Engenharia de Alimentos, Universidade de São Paulo, Pirassununga, 2015.
\end{abstract}

The aim of this study was to characterize the surface properties of gelatin-based films. For which, films were produced as following: gelatin plasticized with glycerol (gelatin: $5 \mathrm{~g} / 100 \mathrm{~g}$ SFF; glycerol: $30 \mathrm{~g} / 100 \mathrm{~g}$ of gelatin), gelatin reinforced with montmorillonite (gelatin: 5 g/100 g SFF; glycerol: $30 \mathrm{~g} / 100$ of gelatin; montmorillonite: $5 \mathrm{~g} / 100 \mathrm{~g}$ of gelatin), and gelatin plasticized with acetyltributyl citrate (gelatin: $5 \mathrm{~g} / 100 \mathrm{~g}$ SFF; acetyltributyl citrate: $50 \mathrm{~g} / 100$ of gelatin, soy lecithin: $60 \mathrm{~g} / 100 \mathrm{~g}$ acetyltributyl citrate; ethanol: $20 \mathrm{~g} / 100 \mathrm{~g}$ SFF). The films were produced by using an automatic film applicator "Spreading". Then, the films were tested for determining thickness, humidity and optical property (gloss, color and opacity). Also the microstructure was characterized by scanning electron microscopy (SEM) and atomic force microscopy (AFM); in the images obtained by SEM it was applied image analysis using Image $\mathrm{J}$ program, to get the value of the fractal dimension (FD). After, the surface properties of contact angle (CA), wettability or spreading coefficient $\left(\mathrm{C}_{\mathrm{s}}\right)$ and surface free energy (SFE) were characterized by measuring the contact angle by the method of the sessile drop (water: 5 $\mu \mathrm{L}$, 1-Bromonaphthalene: $3 \mu \mathrm{L}$ ). For the calculation of the ELS, it was also applied the method of Owens-Wendt. These characterizations were made on both sides of the film (air side and plate side). The nature of the G/ATB film influenced the moisture and optical properties, while the films of $\mathrm{G}$ and G/MMT showed similar values. With regard to microstructure and roughness, the $\mathrm{G}$ film presented a more homogeneous and smooth surface, contrary to that was observed in films of G/MMT, who presented the highest roughness followed by G/ATB film. It was observed that there was a relationship between the roughness values and DF. According to the value of the CA, the three films had a hydrophobic character, because their values were above $65^{\circ}$ (on both sides of the film), in the following order: G/MMT > G > G/ATB; the $\mathrm{C}_{\mathrm{s}}$ followed the same trend. It should be also mentioned that a significant correlation between the values of $\mathrm{CA}$ and the roughness was found. According to the values of CA, $\mathrm{C}_{\mathrm{s}}$ and SFE (specifically the polar component), the films of G/ATB had the lowest hydrophobicity, because had lower $\mathrm{CA}$ values and higher $\mathrm{C}_{\mathrm{s}}$ values, as compared to the other two films. The values of the polar component of the film G/ATB were higher, which 
explains better the less hydrophobic character of this film. It can be concluded that the gelatin-based films produced in this work have hydrophobic properties $\left(\mathrm{CA}>65^{\circ}\right)$, being the film G/MMT which showed better hydrophobic characteristics.

Keywords: Gelatin film, contact angle, wettability, spreading coefficient, surface free energy. 


\section{Lista de Figuras}

Figura 1 - Ângulo de contato de um líquido sobre uma superfície sólida e representação da tensão superficial nas três fases de ponto de contato.

Figura 2 - Uma gotícula colocado sobre uma superfície sólida pode (a) espalhar-se (baixo ângulo de contato, alta molhabilidade), ou (b) contrair-se (alto ângulo de contato, baixa molhabilidade)

Figura 3- Aplicador automático de filmes do Laboratório de Tecnologia de Alimentos .........26

Figura 4 - Fluxograma para a produção do filme de Gelatina com glicerol............................27

Figura 5 - Homogeneizador mecânico UT ultraturrax (T25, IKA) .......................................2 28

Figura 6 - Fluxograma para a produção do filme de Gelatina/MMT ...................................... 30

Figura 7 - Fluxograma para a produção do filme de Gelatina/ATB ....................................... 32

Figura 8 - Fluxograma para a caracterização dos filmes à base de gelatina............................. 33

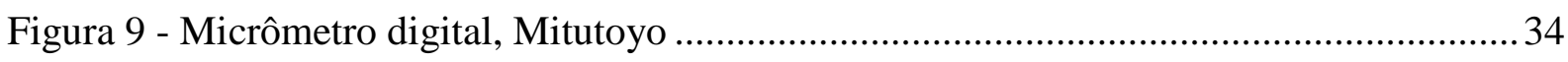

Figura 10 - Pesa filtros para a determinação da umidade ...................................................... 35

Figura 11 - Colorímetro (HunterLab, modelo Miniscan XE)................................................ 36

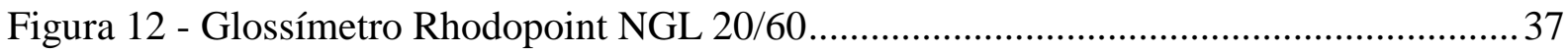

Figura 13 - Microscópio eletrônico de varredura (HITACHI TM3000) .................................. 38

Figura 14 - Microscópio de força atômica (Solver Next, NT-MDT, Russia) .......................... 38

Figura 15 - Gráfico de log de contagem de caixa contra log de tamanho de caixa obtido mediante o algoritmo SDBC, onde a pendente representa a dimensão fractal da imagem ...... 41

Figura 16 - Tensiômetro óptico (Attension, Theta Lite Optical Tensiometer)........................42

Figura 17 - Filmes à base de gelatina, A: Gelatina, B: Gelatina/MMT e C: Gelatina/ATB .... 45

Figura 18 - Micrografias de MEV do filme de Gelatina: Lado ar (a), Lado placa (b), seção

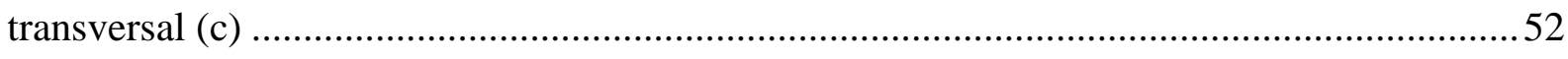

Figura 19 - Micrografias de MEV do filme de Gelatina/MMT: Lado ar (a), Lado placa (b), seção transversal (c).

Figura 20 - Micrografias de MEV do filme de Gelatina/ATB: Lado ar (a), Lado placa (b), seção transversal (c).

Figura 21 - Micrografias de AFM dos filmes à base de gelatina: Gelatina (a, b, g, h),

Gelatina/MMT (c, d, i, j), Gelatina/ATB (e, f, k, l)....

Figura 22 - Relação Dimensão fractal (DF) - Rugosidade $\left(R_{a}, R_{q}\right)$ para os filmes à base de gelatina (G: Gelatina; G/MMT: Gelatina/MMT; G/ATB: Gelatina/ATB): Lado ar (a), Lado placa (b) 
Figura 23 - Ilustração simplificada da matriz do filme de gelatina sem (a) e com óleo essencial (b) na presença de surfactante

Figura 24 - Valores de Trabalho de Adesão, $\mathrm{W}_{\mathrm{a}}(\mathrm{mN} / \mathrm{m})$ e Coeficiente de Espalhamento, $\mathrm{S}_{\mathrm{e}}$ $(\mathrm{mN} / \mathrm{m})$ para os filmes à base de gelatina, lado ar e lado placa 67

Figura 25 - Imagens das gotas de água capturadas imediatamente depois da deposição da gota $\left(\mathrm{t}_{0}\right)$, depois de $30 \mathrm{~s},\left(\mathrm{t}_{30}\right)$ e depois de $60 \mathrm{~s}\left(\mathrm{t}_{60}\right)$ de análise 68

Figura 26 - Cinética do ângulo de contato e seu ajuste para os filmes à base de gelatina .71

Figura 27 - Valores de ângulos de contato e rugosidade dos filmes à base de gelatina 73 


\section{Lista de Tabelas}

Tabela 1 - Equações dos parâmetros texturais a partir das imagens na escala de cinzas com o algoritmo GLCM

Tabela 2 - Tensão superficial $\left(\gamma_{\mathrm{L}}\right)$ e seus componentes polar $\left(\gamma^{\mathrm{P}}\right)$ e dispersa $\left(\gamma^{\mathrm{D}}\right)$ dos líquidos

Tabela 3 - Espessura media dos filmes à base de gelatina .....................................................46

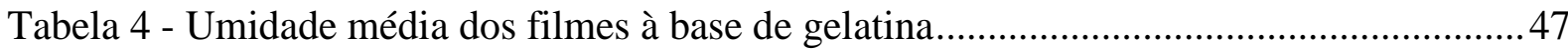

Tabela 5 - Parâmetros de cor $\left(\mathrm{L}^{*}, \mathrm{a}^{*}, \mathrm{~b}^{*}\right)$, diferença de cor $\left(\Delta \mathrm{E}^{*}\right)$ e opacidade dos filmes à base de gelatina, lado "ar" e lado "placa"

Tabela 6 - Valores de brilho $\left(20^{\circ}\right.$ e $\left.60^{\circ}\right)$ para os filmes à base de gelatina, lado "ar" e lado "placa"

Tabela 7 - Valores de rugosidade $\mathrm{R}_{\mathrm{a}}(\mathrm{nm}), \mathrm{R}_{\mathrm{q}}(\mathrm{nm})$ para os filmes à base de gelatina, lado "ar" e lado "placa"

Tabela 8 - Parâmetros de textura extraídos das micrografias de MEV dos filmes à base de gelatina

Tabela 9 - Dados de ângulo de contato $(\theta)$, trabalho de adesão $\left(\mathrm{W}_{\mathrm{a}}\right)$ e coeficiente de espalhamento $\left(\mathrm{S}_{\mathrm{e}}\right)$ dos filmes a base de gelatina para um tempo de 60 segundos.

Tabela 10 - Variação do ângulo de contato da gota de água sobre os filmes de gelatina durante o período de avaliação de 60 segundos

Tabela 11 - Parâmetros de ajuste da eq. (17) para a cinética de ângulo de contato dos filmes e valores da primeira derivada das curvas ajustadas .70

Tabela 12 - Correlação entre os valores de Rugosidade e Ângulo de contato 74

Tabela 13 - Valores de energia livre superficial $\left(\gamma_{S}\right)$ e seus componentes polar $\left(\gamma_{S}{ }^{\mathrm{P}}\right)$ e dispersa $\left(\gamma_{\mathrm{S}}{ }^{\mathrm{D}}\right)(\mathrm{mN} / \mathrm{m})$ mediante o método de Owens e Wendt para os filmes à base de gelatina 


\section{Sumário}

1. INTRODUÇÃ

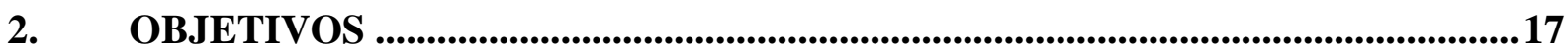

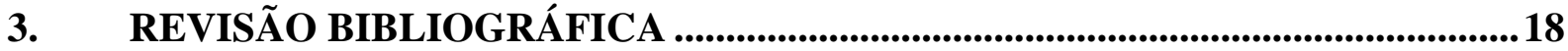

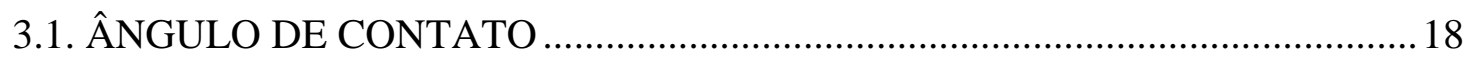

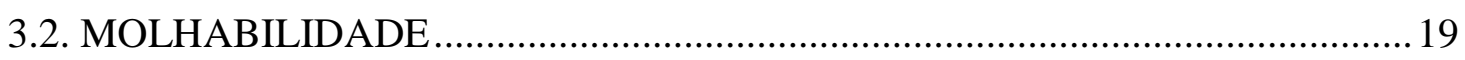

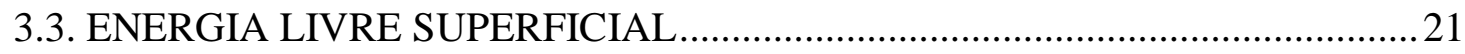

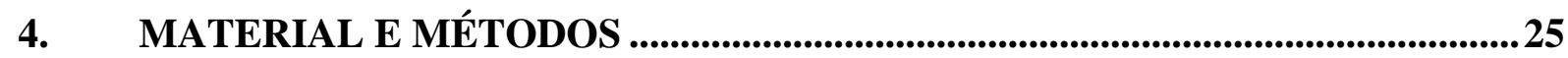

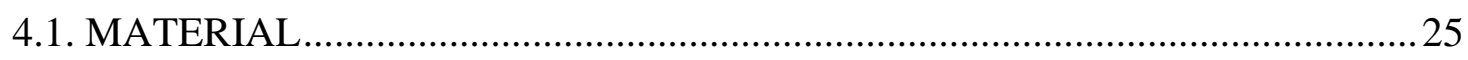

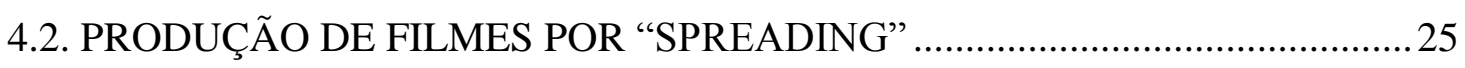

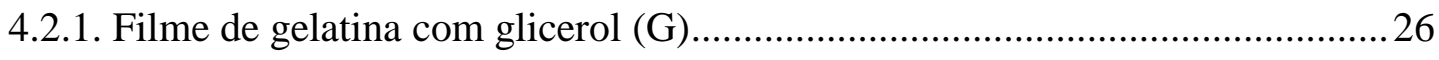

4.2.2. Filme de gelatina com montmorilhonita (G/MMT) .................................... 28

4.2.3. Filme de gelatina com citrato de acetiltributila (G/ATB) ............................... 31

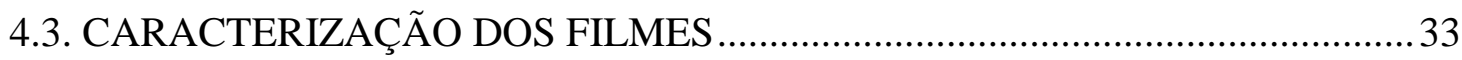

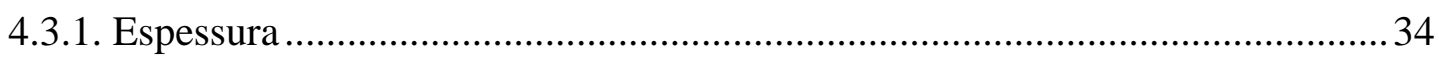

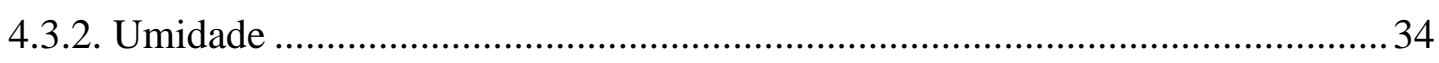

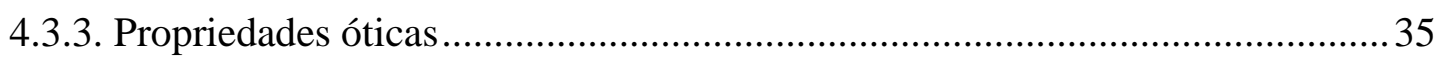

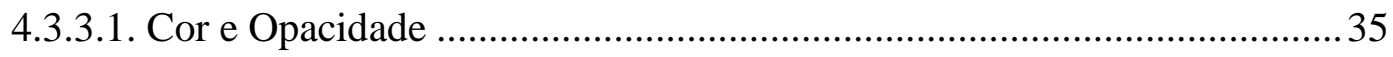

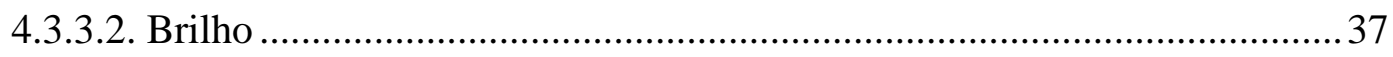

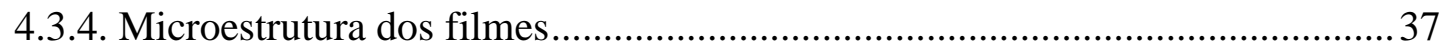

4.3.4.1. Microscopia eletrônica de varredura (MEV) ......................................... 37

4.3.4.2. Microscopia de força atômica (AFM) ................................................... 38

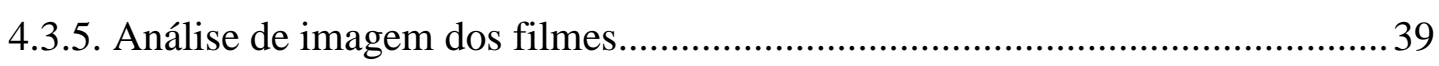

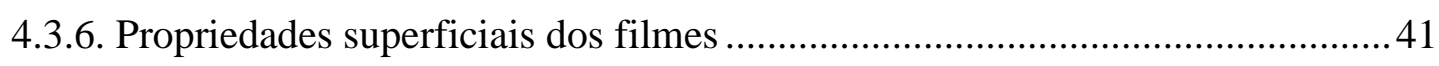

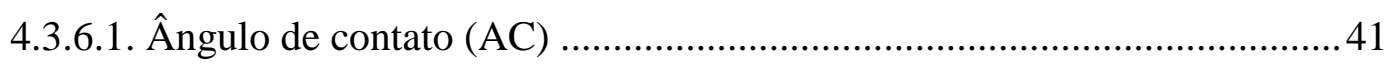

4.3.6.2. Molhabilidade ou Coeficiente de Espalhamento (Se) ............................ 42

4.3.6.3. Modelagem da cinética do ângulo de contato........................................ 43

4.3.6.4. Energia livre superficial ............................................................. 43

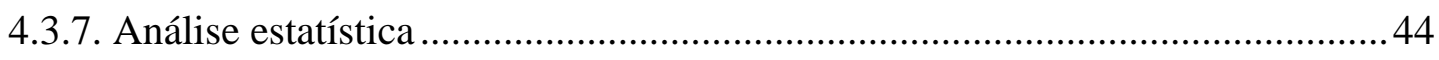

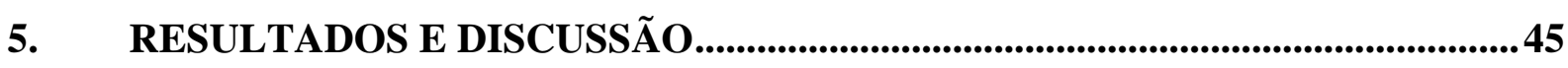

5.1. CARACTERIZAÇÃO DOS FILMES ........................................................... 45

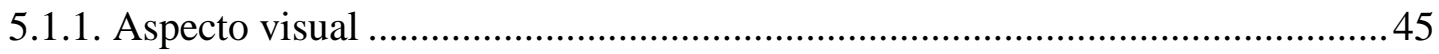

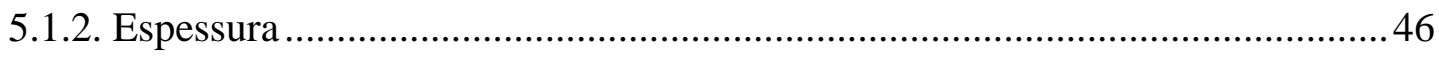

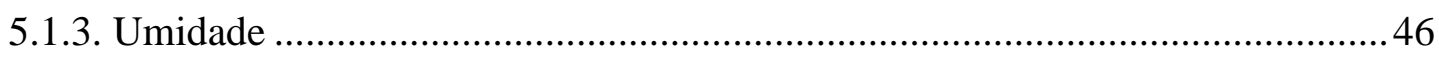


5.1.4. Propriedades óticas.

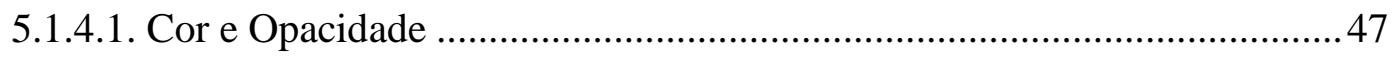

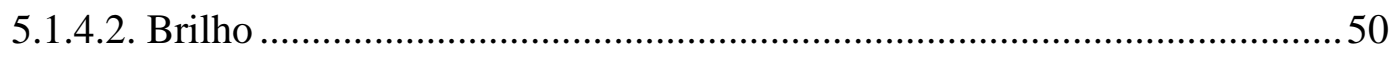

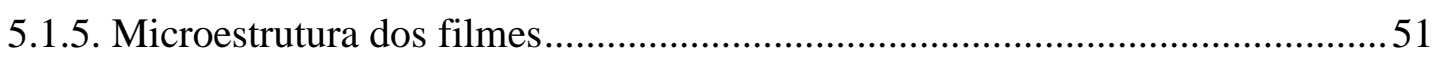

5.1.5.1. Microscopia eletrônica de varredura (MEV) ..........................................52

5.1.5.2. Microscopia de força atômica (AFM) ................................................. 55

5.1.6. Análise de imagem dos filmes....................................................................58

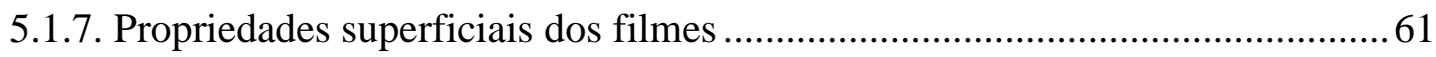

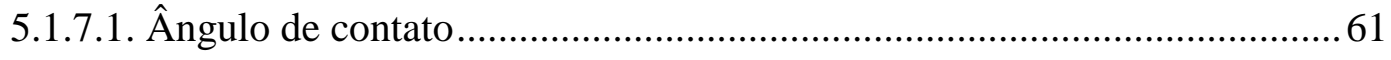

5.1.7.2. Molhabilidade ou Coeficiente de Espalhamento $\left(S_{\mathrm{e}}\right)$...........................65 65

5.1.7.3. Modelagem da cinética do ângulo de contato.........................................6 68

5.1.7.4. Correlação entre o ângulo de contato e a rugosidade ............................... 72

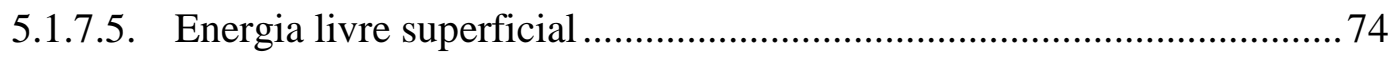

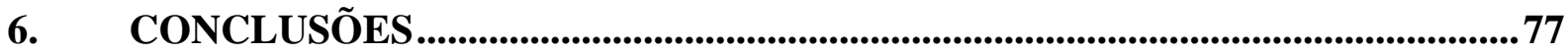

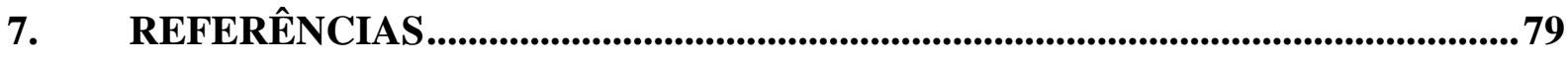




\section{INTRODUÇÃO}

A gelatina é uma proteína capaz de formar uma rede tridimensional, com zonas de junções intermoleculares microcristalinas e a desidratação deste sistema podem produzir filmes quebradiços (ARVANITOYANNIS, 2002). Assim, a adição de um plastificante é necessária para impedir esse caráter quebradiço, possibilitando a formação de um material fino e flexível (SOBRAL et al., 2001).

Em função de sua excelente propriedade filmogênica, a gelatina tem sido amplamente utilizada em estudos sobre filmes comestíveis e/ou biodegradáveis, isso aliado à produção mundial em larga escala e baixo custo. Flaker et al. (2015), Jongjareonrak et al. (2006), Sobral et al. (2001), Thomazine, Carvalho e Sobral (2005) e Vanin et al. (2005), entre outros, estudaram as propriedades físicas e funcionais de filmes a base de gelatina, em função da origem da gelatina, do tipo e concentração de plastificantes, das condições de secagem, da espessura dos filmes, ou da incorporação de nanopartículas.

O conhecimento da energia livre superficial dos sólidos tem uma grande importância tecnológica para todos os fenômenos interfaciais, já que é um parâmetro muito útil nos estudos dos processos de adsorção e molhabilidade. A tensão superficial é de fato criticamente importante em muitas aplicações industriais, incluindo a indústria de embalagem, polímeros (operações de revestimento), farmácia e biomedicina. Em geral, as propriedades de superfície afetam todos os campos relacionados com os mecanismos de molhabilidade e adesão. A caracterização das propriedades da superfície, e especialmente dos componentes da energia livre superficial dos sólidos, são considerados como a chave para se compreender os mecanismos que envolvem interações sólido-líquido, tais como a molhabilidade e o espalhamento (KARBOWIAK; DEBEAUFORT; VOILLEY, 2006). 
Compreender os fenômenos de molhabilidade representa uma boa maneira de melhorar e desenvolver novas superfícies e interfaces, isso porque permite que se altere artificialmente a compatibilidade de um material com as outras fases. Dessa forma, a indústria de embalagens pode utilizar da compreensão desses fenômenos para caracterizar melhor seus produtos finais. Principalmente quando se trata do desenvolvimento de novas técnicas de produções e produtos, tais como filmes e coberturas comestíveis (KARBOWIAK; DEBEAUFORT; VOILLEY, 2006).

Porém, não existe um método direto para determinar as propriedades superficiais de filmes. Como alternativa, têm-se medidas indiretas, como as medidas de ângulo de contato, que combinada a um enfoque teórico podem caracterizar as superfícies de materiais.

O laboratório de Tecnologia de Alimentos (LTA) da FZEA/USP, onde foi realizado o presente trabalho, tem uma longa experiência na elaboração de filmes à base de gelatina com diferentes propriedades, mas as propriedades superficiais desses filmes ainda não foram estudadas mais profundamente e, além disso, na literatura não se encontram muitas informações acerca dessas propriedades. Assim, esta tese teve por objetivo caracterizar as propriedades superficiais (ângulo de contato, molhabilidade e energia livre superficial) de filmes à base de gelatina, visando a importância desses parâmetros na indústria de embalagem e mais ainda na caracterização de novas superfícies de filmes à base de biopolímeros. 


\section{OBJETIVOS}

O objetivo geral deste trabalho foi à caracterização das propriedades superficiais de diferentes filmes à base de gelatina.

Para isso os objetivos específicos foram:

$\checkmark$ Elaboração de filmes à base de gelatina (filme de gelatina plastificado com glicerol, filme de gelatina reforçado com montmorilhonita e filme de gelatina plastificado com citrato de acetiltributila).

$\checkmark$ Caracterização dos filmes enquanto a espessura, umidade, propriedade ótica (brilho, cor e opacidade) e microestrutura.

$\checkmark$ Analise de imagem das micrografias da superfície dos filmes obtidos mediante microscopia de varredura (MEV) pelo uso do programa Image J.

$\checkmark$ Determinação do ângulo de contato, molhabilidade (coeficiente de espalhamento) e energia livre superficial dos filmes. 


\section{REVISÃO BIBLIOGRÁFICA}

\section{1. ÂNGULO DE CONTATO}

O ângulo de contato é definido basicamente como o ângulo entre a superfície sólida e a tangente traçada na superfície da gota, que passa através do ponto triplo da atmosfera líquido-sólido (Figura 1). O ângulo de contato é então uma medida das tendências de interação presentes entre a gota de um líquido e uma superfície sólida. É a medida entre as forças que fazem com que um líquido se espalhe uma superfície sólida ou, ao contrário, conserve a formação de uma gota para reduzindo ao mínimo sua própria área. Este fenômeno depende da magnitude relativa das forças moleculares que existem dentro do líquido (coesivo) e entre o líquido e o sólido (adesivo) (KARBOWIAK et al., 2006).

Figura 1 - Ângulo de contato de um líquido sobre uma superfície sólida e representação da tensão superficial nas três fases de ponto de contato

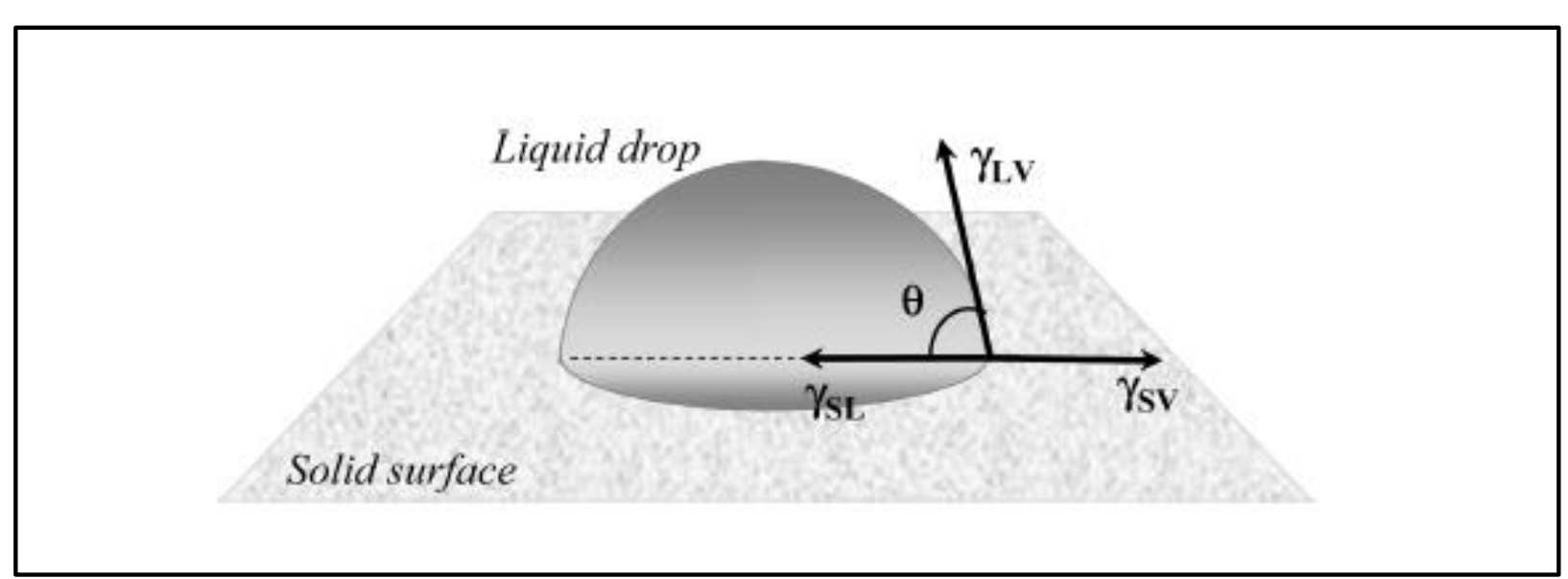

Fonte: Karbowiak et al. (2006).

O ângulo de contato foi definido como um fenômeno de molhabilidade originalmente nos inicios de 1800 para superfícies sólidas, não porosas, não absorventes, para o qual a leitura foi tomada no equilíbrio. Em 1805, Young (KARBOWIAK et al., 2006) descreveu-o 
como uma relação que indica a tensão superficial num ponto da linha de contato de três fases, entre uma fase sólida $\mathrm{S}$, lisa, rígida, um líquido L e seu vapor V; o qual é mostrado na eq.(1).

$$
\gamma_{\mathrm{LV}} * \cos \theta=\gamma_{\mathrm{SV}}-\gamma_{\mathrm{SL}}
$$

Onde: $\gamma_{\mathrm{LV}}, \gamma_{\mathrm{SV}}$ e $\gamma_{\mathrm{SL}}$ são as tensões superficiais (ou energia livre por unidade de área) das interações líquido-vapor, sólido-vapor e sólido-líquido e $\theta$ é o ângulo de contato.

\subsection{MOLHABILIDADE}

A molhabilidade ou coeficiente de espalhamento $\left(S_{\mathrm{e}}\right)$ representa a habilidade de um determinado líquido de se espalhar sobre uma superfície sólida (RIBEIRO et al., 2007). A molhabilidade $\left(\mathrm{S}_{\mathrm{e}}\right)$ de um sólido por um líquido é obtida considerando o equilíbrio entre as forças adesivas (trabalho de adesão: $\mathrm{W}_{\mathrm{a}}$ ) do líquido sobre o sólido e as forças coesivas do líquido (trabalho de coesão: $\mathrm{W}_{\mathrm{c}}$ ), cujo valor pode ser negativo ou zero. Quanto mais perto de zero, a superfície é mais molhável. Cada uma destas forças atua de maneira diferente. Enquanto as forças adesivas $\left(\mathrm{W}_{\mathrm{a}}\right)$ fazem com que o líquido se espalhe sobre uma superfície plana, as forças coesivas $\left(\mathrm{W}_{\mathrm{c}}\right)$ provocam a contração da gotícula (RAMÍREZ et al., 2012).

A molhabilidade envolve a interação entre um líquido e um sólido. Quando a gotícula de um líquido é depositada sobre uma superfície sólida, podem acontecer dois comportamentos (Figura 2). No primeiro caso, a superfície sólida esta bem molhada pelo líquido e o ângulo de contato, é baixo (Figura 2a). No segundo caso, o sólido é pouco molhado e o ângulo de contato é alto (Figura 2b) (CHOI et al., 2002). 
Figura 2 - Uma gotícula colocado sobre uma superfície sólida pode (a) espalhar-se (baixo ângulo de contato, alta molhabilidade), ou (b) contrair-se (alto ângulo de contato, baixa molhabilidade)

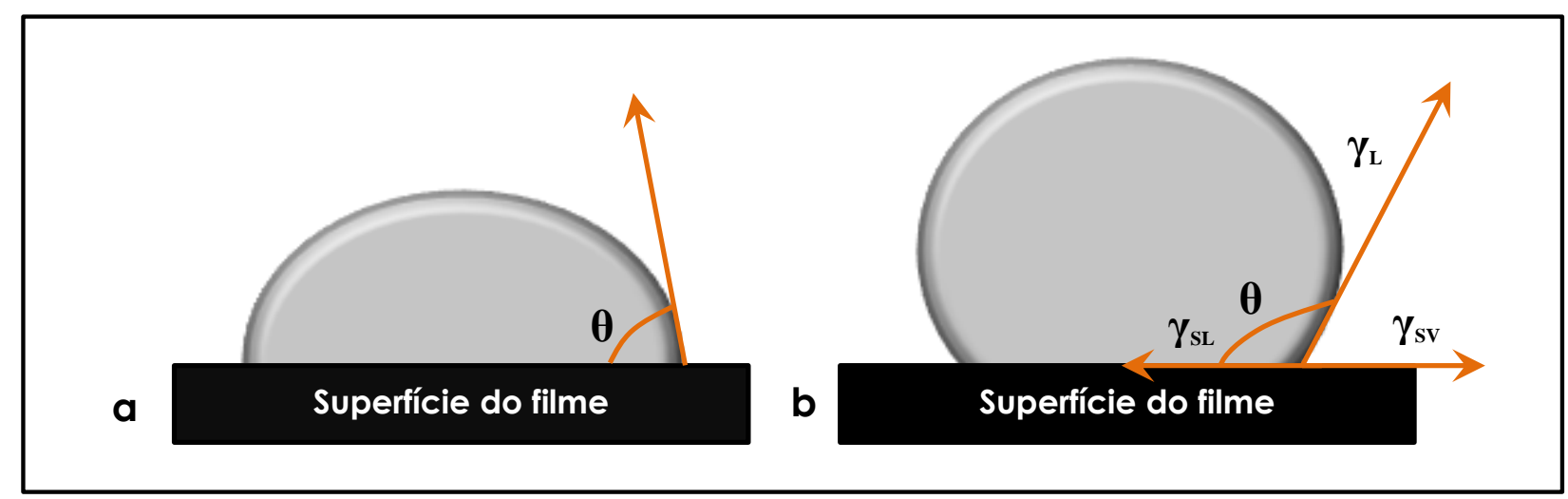

Fonte: Choi et al. (2002).

O coeficiente de espalhamento $\left(S_{e}\right)$ é definido pela eq.(2) (ANDRADE et al., 2014).

$$
\mathrm{S}_{\mathrm{e}}=\mathrm{W}_{\mathrm{a}}-\mathrm{W}_{\mathrm{c}}
$$

Onde $\mathrm{W}_{\mathrm{a}}$ e $\mathrm{W}_{\mathrm{c}}$ são o trabalho de adesão e coesão, definidos pela eq.(3) e eq.(4) respectivamente, $\gamma_{\mathrm{LV}}$ é a tensão superficial entre o líquido-vapor, e $\theta$ é o ângulo de contato de equilíbrio.

$$
\mathrm{W}_{\mathrm{a}}=\gamma_{\mathrm{LV}} *(1+\cos \theta)
$$

$$
\mathrm{W}_{\mathrm{c}}=2 * \gamma_{\mathrm{LV}}
$$

O trabalho de adesão e o coeficiente de espalhamento podem ser utilizados para prever a aderência dos materiais. A aderência dos materiais pode representar um dos fatores que 
afetam a adesão do filme no produto, no processo de recobrimento (KARBOWIAK et al., 2006).

\subsection{ENERGIA LIVRE SUPERFICIAL}

A energia livre superficial é uma grandeza termodinâmica que descreve o estado de equilíbrio dos átomos na camada superficial dos materiais. Esta quantidade de energia é específica para cada substância. Reflete o estado específico de desequilíbrio nas interações intermoleculares presentes na interface de dois meios. A energia livre superficial é o trabalho necessário para a criação de uma nova unidade de superfície, enquanto se separa duas fases em equilíbrio (RUDAWSKA; JACNIACKA, 2009).

Para Packham (2003), o conceito básico de energia superficial é o excesso de energia associado com a presença de uma superfície, o qual é expresso por unidade de área. Segundo Karbowiak, Debeaufort e Voilley (2006), a energia livre superficial é frequentemente denominada "tensão superficial”, "tensão interfacial", "energia interfacial” ou "energia livre interfacial". Assim, esses autores indicam que a tensão superficial é a energia livre superficial dividida pela área sobre a qual é aplicada a energia.

A unidade internacional da tensão superficial é Newton por metro [N/m] (equivalente à Joule por metro quadrado $\left.-\left[\mathrm{J} / \mathrm{m}^{2}\right]\right)$. No entanto, é frequentemente expressa em $\mathrm{mN} / \mathrm{m}$, ou em outras unidades, como $\mathrm{mJ} / \mathrm{m}^{2}$, ergs $/ \mathrm{cm}^{2}$ ou dinas $/ \mathrm{cm}^{1}$.

A energia livre superficial de um sólido esta estreitamente ligada às interações que um sólido é capaz de realizar. Portanto, o conhecimento desse parâmetro permite a compreensão e a predição dos fenômenos que podem acontecer na interface nos sistemas líquido-vaporsólido. No entanto, a energia livre superficial não pode ser medida diretamente como para um 
líquido. Então, diferentes métodos podem ser utilizados para estimar a energia livre superficial de um sólido a partir da medida do ângulo de contato.

Existem alguns métodos que podem ser utilizados para calcular a energia livre superficial, sendo exemplos destes: o método de Zisman (KUREK et al., 2013), o método de Owens-Wendt (KUJAWA et al., 2014) e o método van Oss-Chaudhury (vOCG) (ANDRADE et al., 2014).

O método de Owens-Wendt é um dos mais utilizados para determinar a energia livre superficial de filmes e outras superfícies (BENBETTAÏEB et al., 2015; GUETTLER; MORESOLI; SIMON, 2013; KUREK et al., 2013; SLAVUTSKY; BERTUZI, 2015). Dessa forma, neste trabalho foi utilizado o método de Owens-Wendt para a determinação da energia livre superficial dos filmes à base de gelatina (GUETTLER; MORESOLI; SIMON, 2013; KUJAWA et al., 2014).

A energia livre superficial e suas componentes polar e dispersa podem ser calculadas a partir da determinação do ângulo de contato de um líquido sobre uma superfície sólida, com a equação de Young (eq.5). Estas informações obtidas com o auxílio do método de OwensWendt, fornecem a energia livre interfacial sólido-líquido, que é expressa como a média geométrica da interação polar e dispersa entre as duas fases (eq.6).

$$
\gamma_{\mathrm{L}} * \cos \theta=\gamma_{\mathrm{S}}-\gamma_{\mathrm{SL}}
$$

$$
\gamma_{\mathrm{SL}}=\gamma_{\mathrm{S}}+\gamma_{\mathrm{L}}-2 * \sqrt{\left(\gamma_{\mathrm{S}}^{\mathrm{D}} * \gamma_{\mathrm{L}}^{\mathrm{D}}\right)}-2 * \sqrt{\left(\gamma_{\mathrm{S}}^{\mathrm{P}} * \gamma_{\mathrm{L}}^{\mathrm{P}}\right)}
$$


Substituindo $\gamma_{S L}$ na equação de Young, se obtém a eq.(7), onde $\gamma_{L}$ é a tensão superficial do líquido $(\mathrm{mN} / \mathrm{m}), \gamma_{L}^{\mathrm{D}}(\mathrm{mN} / \mathrm{m})$ e $\gamma_{\mathrm{S}}^{\mathrm{D}}(\mathrm{mN} / \mathrm{m})$ são as componentes dispersas do líquido e do sólido, respectivamente, e $\gamma_{\mathrm{L}}^{\mathrm{P}}(\mathrm{mN} / \mathrm{m})$ e $\gamma_{\mathrm{S}}^{\mathrm{P}}(\mathrm{mN} / \mathrm{m})$ são as componentes polares do líquido e do sólido, respectivamente.

$$
\gamma_{\mathrm{L}} *(\cos \theta+1)=2\left(\sqrt{\left(\gamma_{\mathrm{S}}^{\mathrm{D}} * \gamma_{\mathrm{L}}^{\mathrm{D}}\right)}+\sqrt{\left(\gamma_{\mathrm{S}}^{\mathrm{P}} * \gamma_{\mathrm{L}}^{\mathrm{P}}\right)}\right)
$$

Reorganizando-se a eq.(7) para calcular a energia livre superficial do sólido $\left(\gamma_{\mathrm{s}}\right)$, as eq.(8) e eq.(9) podem ser aplicadas. A eq.(8) descreve a $\gamma^{\mathrm{D}}$, e a eq.(9) descreve a $\gamma^{\mathrm{P}}{ }_{\text {s. }}$

$$
\left(\gamma_{\mathrm{S}}^{\mathrm{D}}\right)^{0.5}=\frac{\gamma_{\text {L.apolar }} *\left(\cos \theta_{\text {L.apolar }}+1\right)-\gamma_{\text {L.polar }} *\left(\cos \theta_{\text {L.polar }}+1\right) \sqrt{\frac{\gamma_{\text {L.apolar }}^{\mathrm{P}}}{\gamma_{\text {L.polar }}^{\mathrm{P}}}}}{2\left[\sqrt{\gamma_{\text {L.apolar }}^{\mathrm{D}}}-\sqrt{\left.\gamma_{\text {L.apolar }}^{\mathrm{P}} * \frac{\gamma_{\text {L.apolar }}^{\mathrm{D}}}{\gamma_{\text {L.apolar }}^{\mathrm{P}}}\right]}\right.}
$$

$$
\left(\gamma_{\mathrm{S}}^{\mathrm{P}}\right)^{0.5}=\frac{\gamma_{\mathrm{L} . \text { polar }} *\left(\cos \theta_{\mathrm{L} . \text { polar }}+1\right)-2 * \sqrt{\gamma_{\mathrm{S}}^{\mathrm{D}} * \gamma_{\mathrm{L} . \text { polar }}^{\mathrm{D}}}}{2 * \sqrt{\gamma_{\mathrm{L} . \text { polar }}^{\mathrm{P}}}}
$$

Onde $\gamma_{L}, \gamma_{L}^{D}, \gamma_{L}^{P}$ e $\theta$ com subíndice "L.apolar" e "L.polar" são valores de tensão superficial, componente dispersa, componente polar e ângulo de contato para um líquido apolar e polar, respectivamente. 
A energia livre superficial do sólido $\left(\gamma_{\mathrm{s}}\right)$ (eq.10) pode ser determinada como a soma da componente polar $\left(\gamma_{\mathrm{s}}^{\mathrm{P}}\right)$ e a componente dispersa do sólido $\left(\gamma_{\mathrm{s}}^{\mathrm{D}}\right)$.

$$
\gamma_{\mathrm{S}}=\gamma_{\mathrm{S}}^{\mathrm{D}}+\gamma_{\mathrm{S}}^{\mathrm{P}}
$$




\section{MATERIAL E MÉTODOS}

\subsection{MATERIAL}

Para o desenvolvimento deste estudo, utilizou-se como biopolímero, a gelatina de pele suína do tipo A (260 Bloom/40 Mesh) fornecida pela empresa GELITA do Brasil Ltda. (São Paulo, Brasil), e os plastificantes: glicerol bidestilado (Synth, Brasil) e citrato de acetil tributila (Aldrich). Foram utilizados também lecitina de soja (E 322, Caramuru, São Simão GO) e etanol (Dinâmica, Ltda.). A nanopartícula usada foi a montmorillonita (Nanomer ${ }^{\circledR}$ Clay, PGV, Sigma). Os líquidos padrões utilizados para a medida do ângulo de contato foram água ultrapura, e o 1-Bromonaftaleno (Sigma-Aldrich 97\%).

\subsection{PRODUÇÃO DE FILMES POR "SPREADING”}

Os filmes foram elaborados pela técnica "spreading", que consiste na dispersão das soluções formadora de filmes (SFF) numa placa de acrílico $\left(780 \mathrm{~cm}^{2}\right)$ usando um aplicador automático de filmes (Model Speed II, TKB Erichsen) (Figura 3) sob as seguintes condições de operação: altura do espalhador foi mantida em $1,5 \mathrm{~mm}$, a velocidade do espalhamento foi fixada em $35 \mathrm{~mm} / \mathrm{s}$, a temperatura do suporte foi mantida a $20{ }^{\circ} \mathrm{C}$. Esta temperatura, assim como a temperatura das soluções formadoras de filmes $\left(26^{\circ} \mathrm{C}\right)$, foi definida de acordo com os resultados dos ensaios reológicos (JORGE et al. 2014). 
Figura 3- Aplicador automático de filmes do Laboratório de Tecnologia de Alimentos

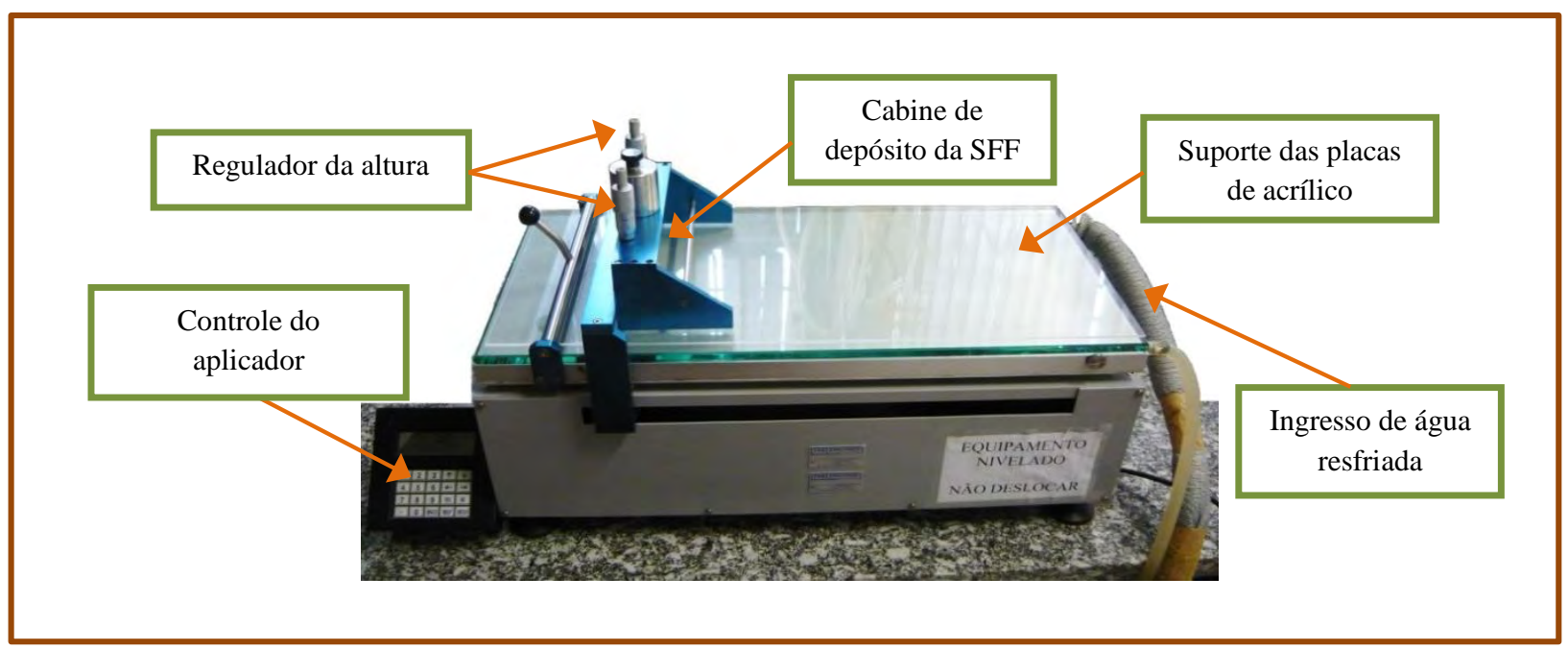

Fonte: Própria autoria.

\subsubsection{Filme de gelatina com glicerol (G)}

A solução formadora de filme (SFF) foi preparada com uma concentração de gelatina de $5 \mathrm{~g}$ de gelatina/100 $\mathrm{g}$ de SFF e uma concentração de plastificante de $30 \mathrm{~g}$ de glicerol/100 $\mathrm{g}$ de gelatina. A gelatina foi hidratada a $25{ }^{\circ} \mathrm{C}$ por 30 minutos e solubilizada a $70{ }^{\circ} \mathrm{C}$ por 15 minutos, em banho termostático (Marconi, modelo MA 179), seguido de 5 minutos em banho ultrassônico (Unique, modelo MaxiClean 1400) a $60{ }^{\circ} \mathrm{C}$ para remoção de bolhas de ar. $\mathrm{Na}$ sequência, a solução permaneceu 13 minutos no banho termostático e então o plastificante foi adicionado e a massa final da solução formadora de filme foi corrigida com água destilada. Em seguida, a solução foi homogeneizada mantendo-a no banho termostático $\left(70{ }^{\circ} \mathrm{C}\right)$ por mais 2 minutos sob agitação mecânica, e então, colocada em banho ultrassônico a $60{ }^{\circ} \mathrm{C}$ por mais 10 minutos (Figura 4).

Na sequência, a solução formadora de filme foi resfriada $\left(26{ }^{\circ} \mathrm{C}\right)$ e dispersa na placa de acrílico utilizando o aplicador automático de filmes (Figura 3) acoplado a um banho ultratermostatizado (Marconi, modelo MA 184/20), para o controle da temperatura da 
superfície de espalhamento. Os filmes foram obtidos após secagem em estufa com circulação de ar forçado (Marconi, modelo MA 035), a $30{ }^{\circ} \mathrm{C}$ por 24 horas.

Figura 4 - Fluxograma para a produção do filme de Gelatina com glicerol

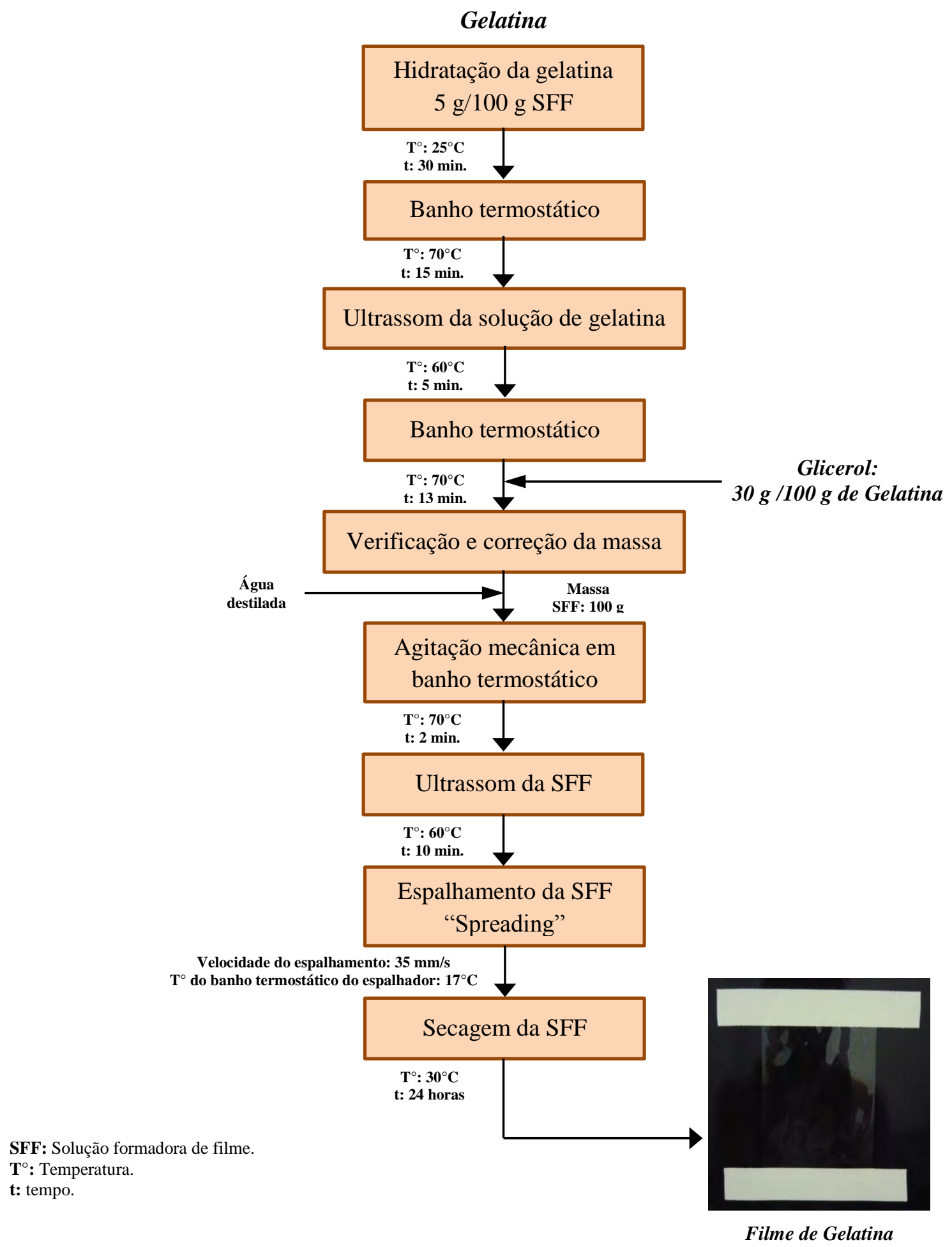

Fonte: Própria autoria. 
4.2.2. Filme de gelatina com montmorilhonita (G/MMT)

Inicialmente, as partículas de montmorillonita (MMT) foram dispersas em água destilada (1g/100 g de água) a $20000 \mathrm{rpm}$ durante 30 minutos, utilizando-se um homogeneizador mecânico UT ultraturrax (T25, IKA) (Figura 5). Em seguida, essa dispersão de MMT foi mantida em repouso por 18 horas para permitir a hidratação das nanopartículas (FLAKER et al., 2015).

Figura 5 - Homogeneizador mecânico UT ultraturrax (T25, IKA)

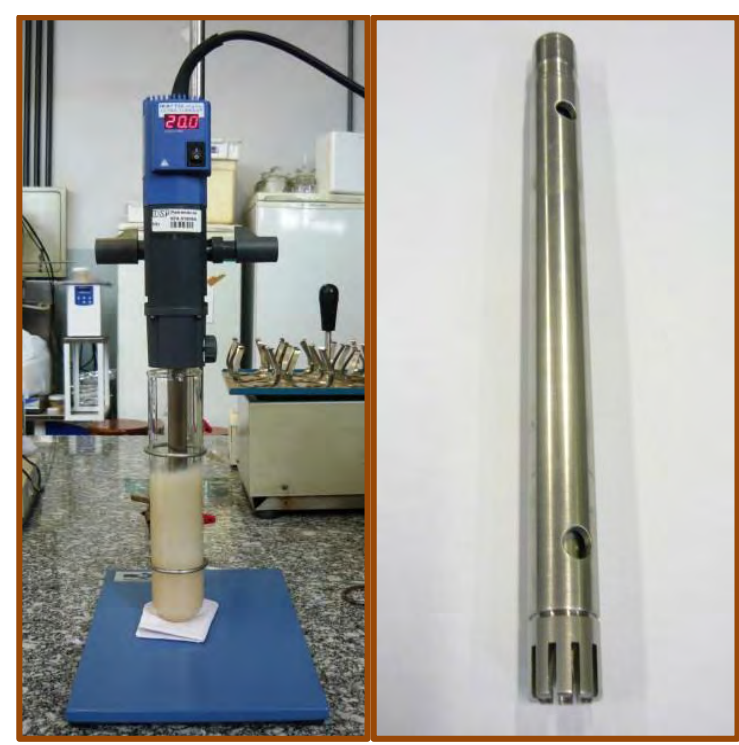

Fonte: Própria autoria.

O filme de gelatina reforçado com MMT foi preparado de acordo com o descrito em 4.2.1. (5 g de gelatina/100 g SFF e $30 \mathrm{~g}$ de glicerol/100 g de gelatina), até a mistura da solução de gelatina com o glicerol. Nesta SFF, foi adicionada a dispersão de MMT a uma concentração de $5 \mathrm{~g}$ de MMT/100 g de gelatina. Em seguida, a SFF foi homogeneizada sob agitação mecânica num banho termostático $\left(70{ }^{\circ} \mathrm{C} / 2\right.$ minutos). Após a homogeneização, a SFF foi mantida em banho ultrassônico a $60{ }^{\circ} \mathrm{C}$ por 10 minutos, sendo depois resfriada até a 
temperatura adequada para o seu espalhamento em placas de acrílico $\left(26^{\circ} \mathrm{C}\right)$. E finalmente os filmes foram obtidos após secagem das SFF em estufa a $30{ }^{\circ} \mathrm{C}$ por 24 horas (Figura 6). 
Figura 6 - Fluxograma para a produção do filme de Gelatina/MMT

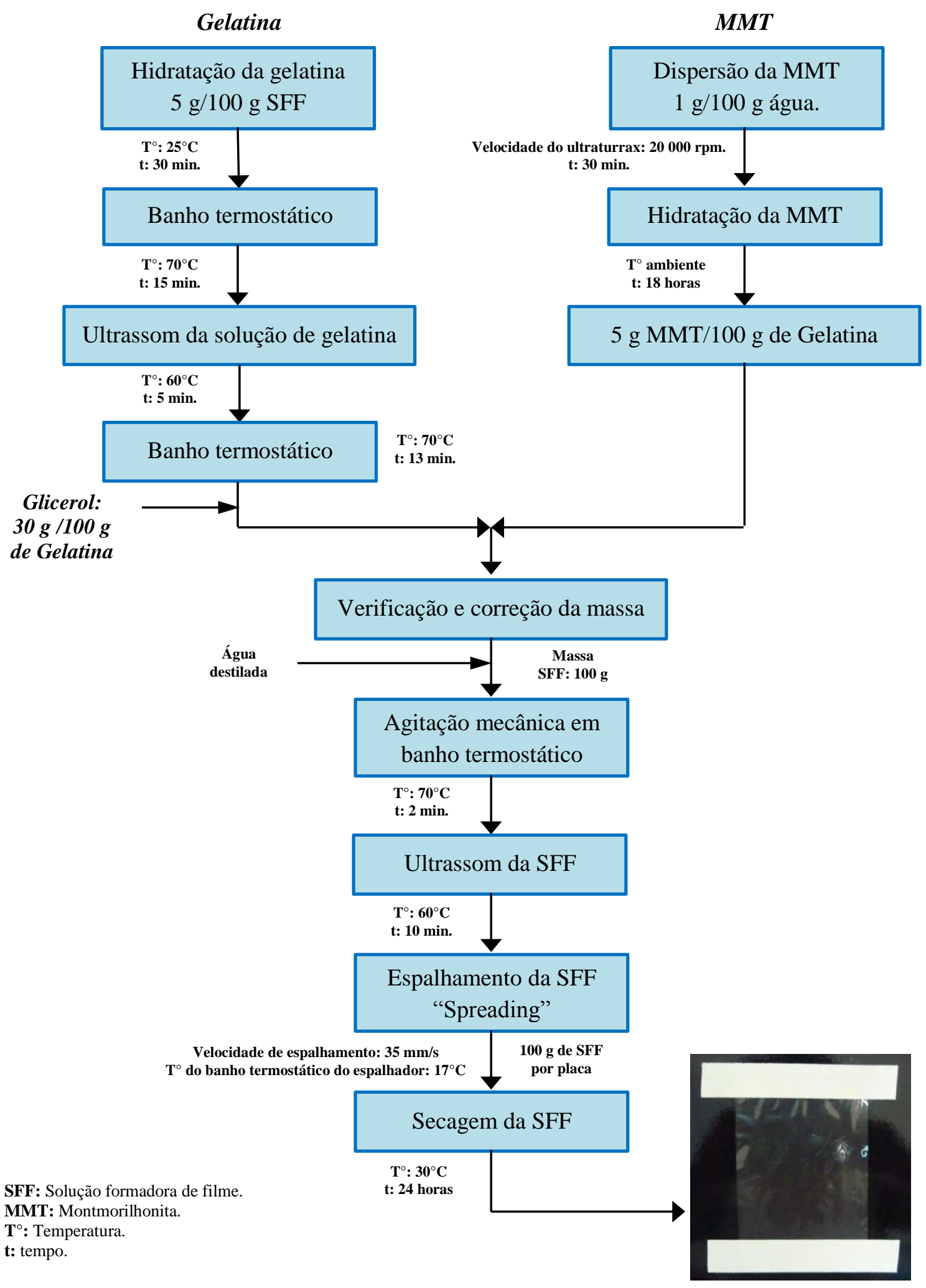

Fonte: Própria autoria. 
4.2.3. Filme de gelatina com citrato de acetiltributila (G/ATB)

A SFF foi preparada com uma concentração de gelatina de $5 \mathrm{~g}$ de gelatina/100 $\mathrm{g}$ de SFF, uma concentração de citrato de acetiltributila (ATB), como plastificante, de $50 \mathrm{~g}$ de ATB/100 g de gelatina, e $60 \mathrm{~g}$ de lecitina de soja/100 g de ATB (CARVALHO, 2009).

A gelatina foi hidratada em água destilada a $25^{\circ} \mathrm{C}$ por 30 minutos e solubilizada a 70 ${ }^{\circ} \mathrm{C}$ por 15 minutos em banho termostático (Marconi, modelo MA 179). O plastificante e a lecitina de soja foram misturados com etanol (20 g/100 g SFF) e mantidos sob agitação mecânica por 2 horas a temperatura ambiente. No final desse período, a gelatina solubilizada foi adicionada à mistura e posteriormente foi homogeneizado num homogeneizador mecânico UT ultraturrax (T25, IKA) a 22.500 rpm, durante 6 minutos. Após a homogeneização, a SFF foi mantida em banho ultrassônico a $60{ }^{\circ} \mathrm{C}$ por 10 minutos (para reduzir as bolhas de ar), sendo depois resfriada até a temperatura adequada para o seu espalhamento em placas de acrílico $\left(26^{\circ} \mathrm{C}\right)$. Os filmes foram obtidos após secagem das SFF em estufa $\left(30^{\circ} \mathrm{C} / 24\right.$ horas $)$ (Figura 7). 
Figura 7 - Fluxograma para a produção do filme de Gelatina/ATB

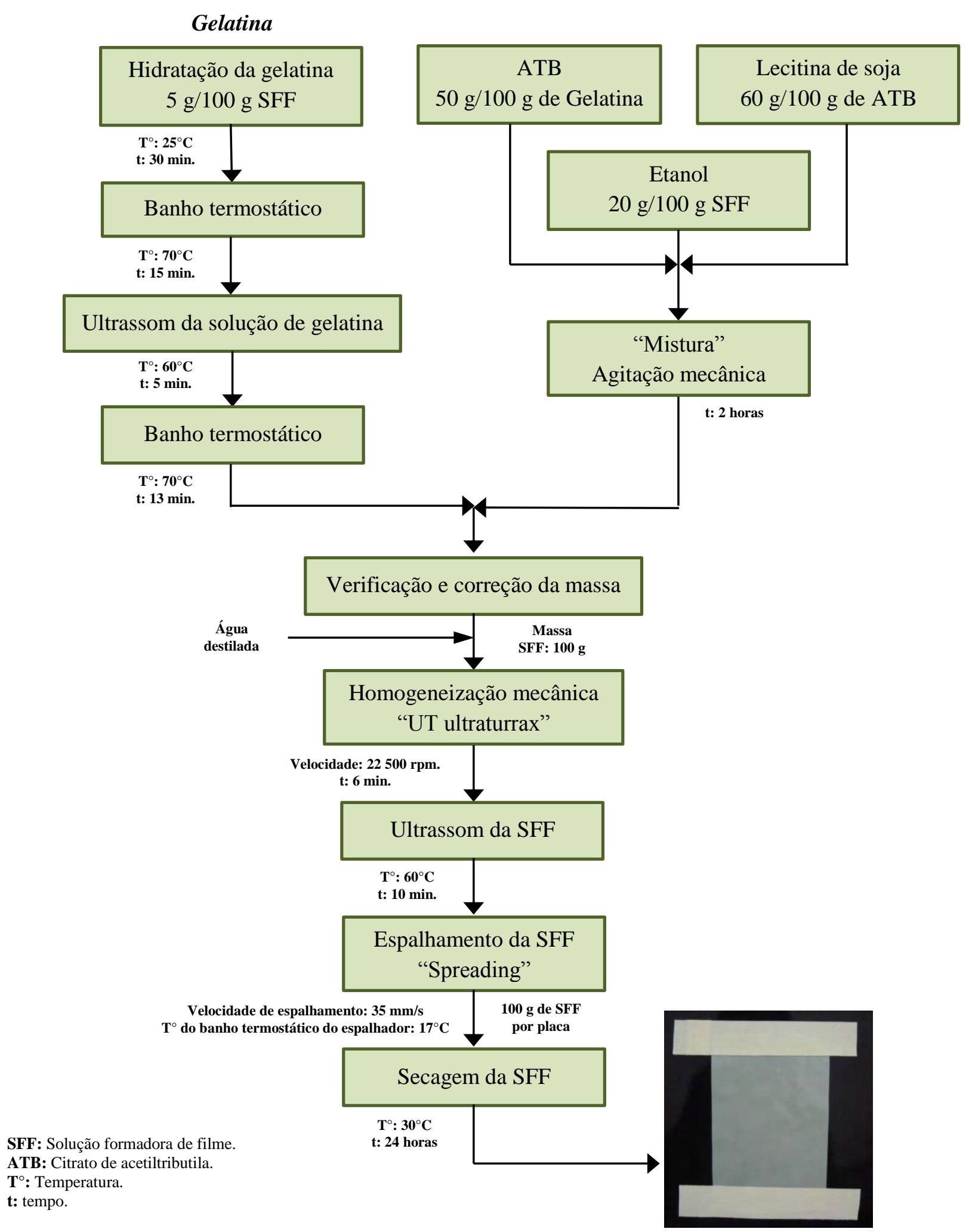

Filme de Gelatina/ATB

Fonte: Própria autoria. 


\subsection{CARACTERIZAÇÃO DOS FILMES}

Antes da caracterização dos filmes, eles foram acondicionados em dessecadores contendo uma solução saturada de $\mathrm{NaBr}$ (58 \% de umidade relativa) ou sílica gel (dependendo da caracterização a ser feita) (Figura 8) à $25^{\circ} \mathrm{C}$, por um período de 7 dias.

Figura 8 - Fluxograma para a caracterização dos filmes à base de gelatina

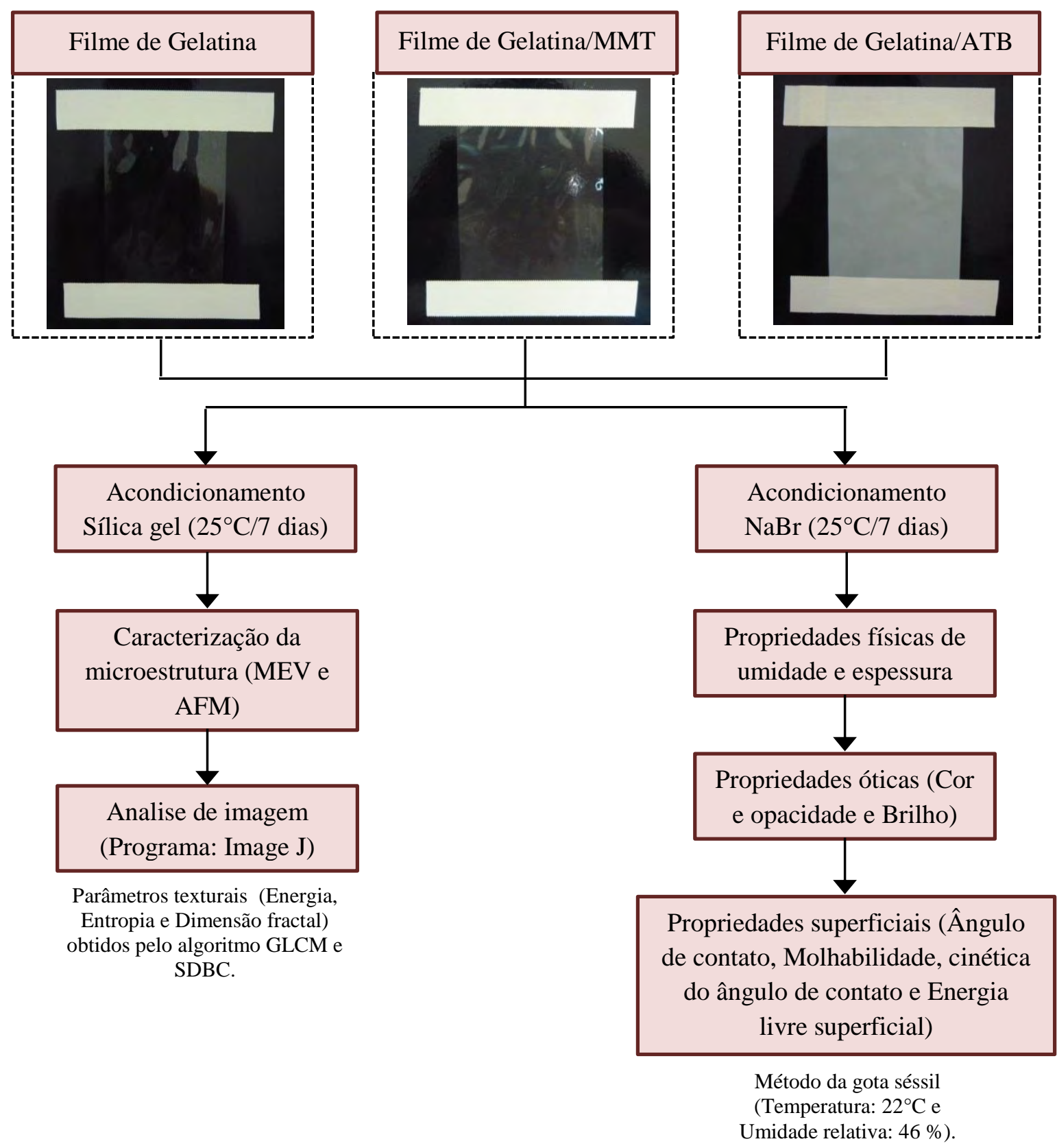

Fonte: Própria autoria. 


\subsubsection{Espessura}

A espessura dos filmes foi determinada utilizando-se um micrômetro digital (Mitutoyo, Osaka, Japão) com um diâmetro de sonda de 6,4 mm e uma sensibilidade de 0,001 mm (Figura 9). A espessura foi calculada como o valor da média aritmética de dez medidas feitas aleatoriamente ao longo de cada amostra.

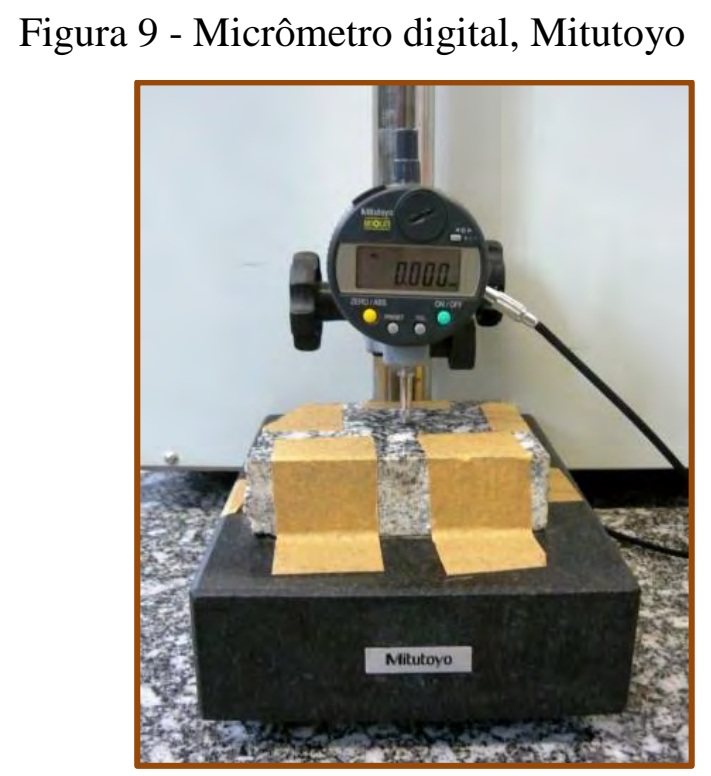

Fonte: Própria autoria.

\subsubsection{Umidade}

A umidade do filmes foi determinada de acordo com a metodologia proposta por Gontard, Guilbert e Cuq (1992). Amostras de filmes (discos de $2 \mathrm{~cm}$ de diâmetro) foram colocadas em pesa filtros e levadas à estufa a $105{ }^{\circ} \mathrm{C}$ por 24 horas (Figura 10). A umidade foi calculada com a eq.(11).

$$
\mathrm{U}(\%)=\left(\frac{\mathrm{m}_{\mathrm{i}}-\mathrm{m}_{\mathrm{f}}}{\mathrm{m}_{\mathrm{i}}}\right) * 100
$$


Onde: $\mathrm{m}_{\mathrm{i}}$ e $\mathrm{m}_{\mathrm{f}}$ são a massa inicial e final em gramas (depois do secagem) dos discos respectivamente.

Figura 10 - Pesa filtros para a determinação da umidade

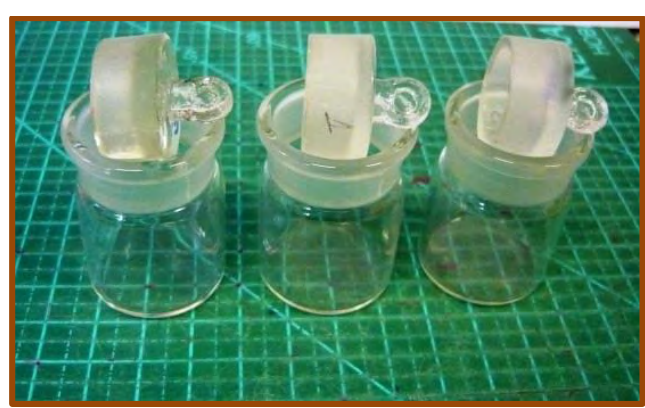

Fonte: Própria autoria.

\subsubsection{Propriedades óticas}

\subsubsection{Cor e Opacidade}

A cor dos filmes foi determinada com um colorímetro (HunterLab, modelo Miniscan XE) usando a lâmpada D65 (luz do dia) com ângulo visual de $10^{\circ}$ e uma célula de medição com uma abertura de $30 \mathrm{~mm}$ (Figura 11). Os filmes foram colocados sobre uma placa branca padrão e os parâmetros $L^{*}, a^{*}$ e $b^{*}$ foram medidos. A diferença de cor $\left(\Delta E^{*}\right)$ foi calculada com a eq.(12) (GENNADIOS et al., 1994). 
Figura 11 - Colorímetro (HunterLab, modelo Miniscan XE)

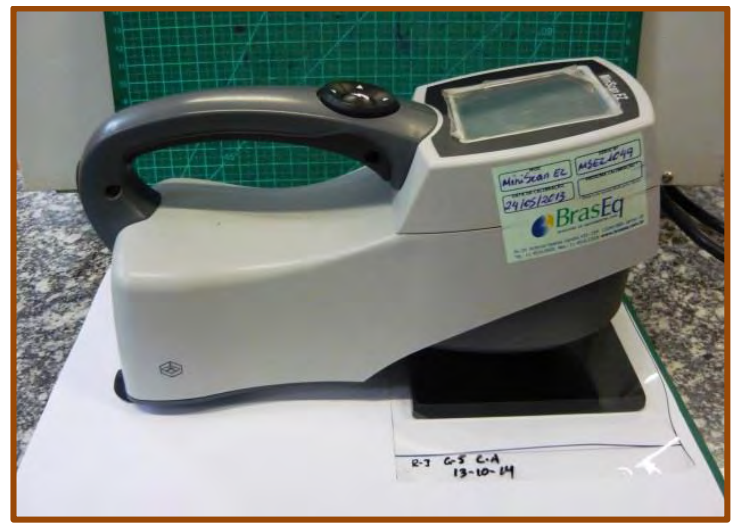

Fonte: Própria autoria.

$$
\Delta \mathrm{E}^{*}=\sqrt{\left(\Delta \mathrm{L}^{*}\right)^{2}+\left(\Delta \mathrm{a}^{*}\right)^{2}+\left(\Delta \mathrm{b}^{*}\right)^{2}}
$$

Onde: $\Delta \mathrm{L}^{*}=\mathrm{L}^{*}$ amostra $-\mathrm{L}^{*}$ padrão $(93,79) ; \Delta \mathrm{a}^{*}=\mathrm{a}^{*}$ amostra - a padrão $(-1,03) ; \Delta \mathrm{b}^{*}=$ $b^{*}$ amostra - $b^{*}$ padrão $(1,64)$.

A opacidade do filme foi determinada segundo método HunterLab (SOBRAL, 2000), utilizando-se o mesmo aparelho da medida de cor, operado em modo refletância. A opacidade (Y) da amostra foi calculada como a relação entre a opacidade da amostra colocada sobre o padrão preto $\left(\mathrm{Y}_{\mathrm{p}}\right)$ e a opacidade da amostra colocada sobre o padrão branco $\left(\mathrm{Y}_{\mathrm{b}}\right)$, conforme a eq.(13).

$$
\mathrm{Y}=\frac{\mathrm{Y}_{\mathrm{p}}}{\mathrm{Y}_{\mathrm{b}}}
$$

O cálculo da opacidade foi realizado pelo programa Universal Software 3.2 (Hunterlab Associates Laboratory). A opacidade assim medida (entre 0 e 100\%) apresenta escala arbitraria. 


\subsubsection{Brilho}

O brilho do filme foi determinado mediante o uso de um glossímetro Rhodopoint NGL 20/60 (Figura 12), nos ângulos de $20^{\circ}$ e $60^{\circ}$ (VILLALOBOS et al., 2005). Foram feitas 10 medidas aleatórias sobre a superfície dos filmes (lado ar e lado placa). As medidas foram realizadas em triplicata.

Figura 12 - Glossímetro Rhodopoint NGL 20/60

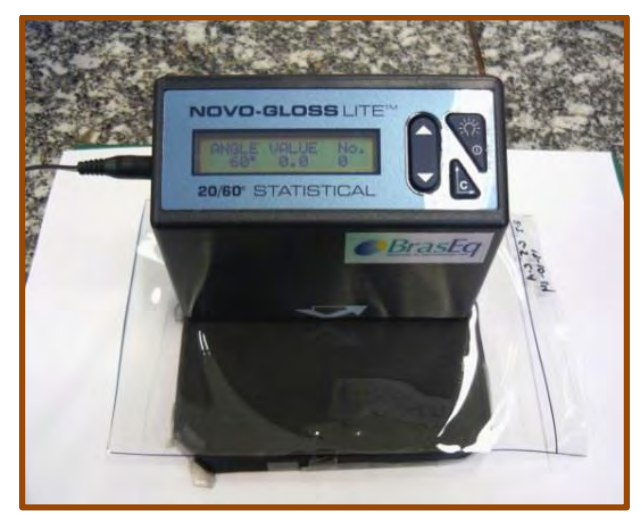

Fonte: Própria autoria.

\subsubsection{Microestrutura dos filmes}

4.3.4.1. Microscopia eletrônica de varredura (MEV)

A microestrutura dos filmes foi analisada utilizando-se um microscópio eletrônico de varredura (MEV) (HITACHI TM3000; Tóquio, Japão) (Figura 13) com uma fonte de elétrons de tungstênio a $5 \mathrm{kV}$ (superfície) e $15 \mathrm{kV}$ (seção transversal) sem tratamento prévio. Ambas as superfícies foram analisadas, lado ar e lado placa, assim como a seção transversal dos filmes que foram previamente fraturados, após imersão em nitrogênio líquido. 
Figura 13 - Microscópio eletrônico de varredura (HITACHI TM3000)

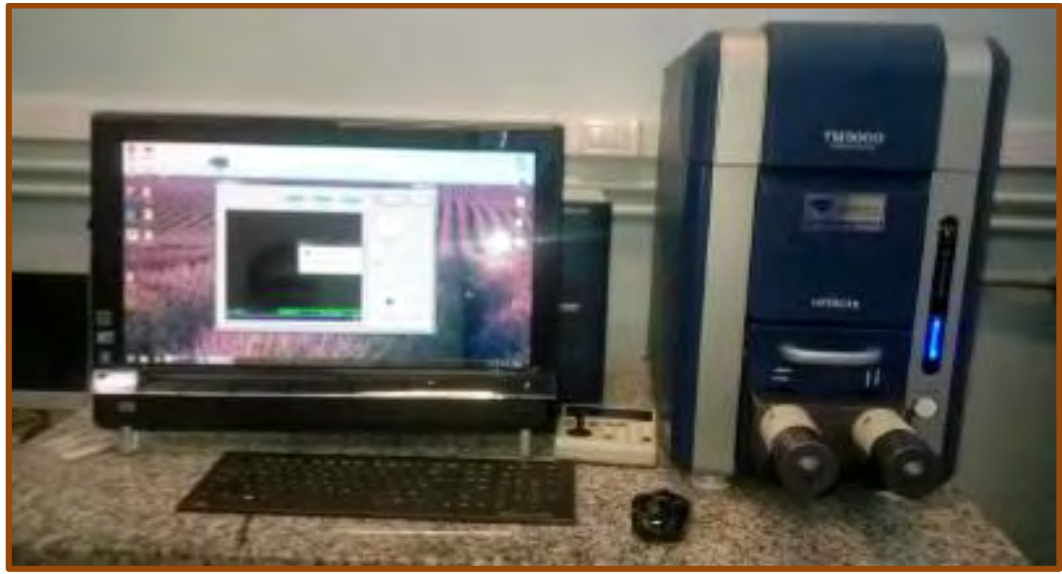

Fonte: Própria autoria.

\subsubsection{Microscopia de força atômica (AFM)}

A nanoestrutura superficial dos filmes foi analisada utilizando um microscópio de força atômica (Solver Next, NT-MDT, Russia) (Figura 14), onde foram obtidas imagens em 3D para determinar a topografia e rugosidade das superfícies (lado ar e lado placa). A nanoestrutura foi caracterizada utilizando-se a ponteira TAP $150 \mathrm{AL}-\mathrm{G}$, com uma frequência de ressonância de $150 \mathrm{kHz}$, força de contato de $5 \mathrm{~N} / \mathrm{m}$ e velocidade de varredura de $0,5 \mathrm{~Hz}$.

Figura 14 - Microscópio de força atômica (Solver Next, NT-MDT, Russia)

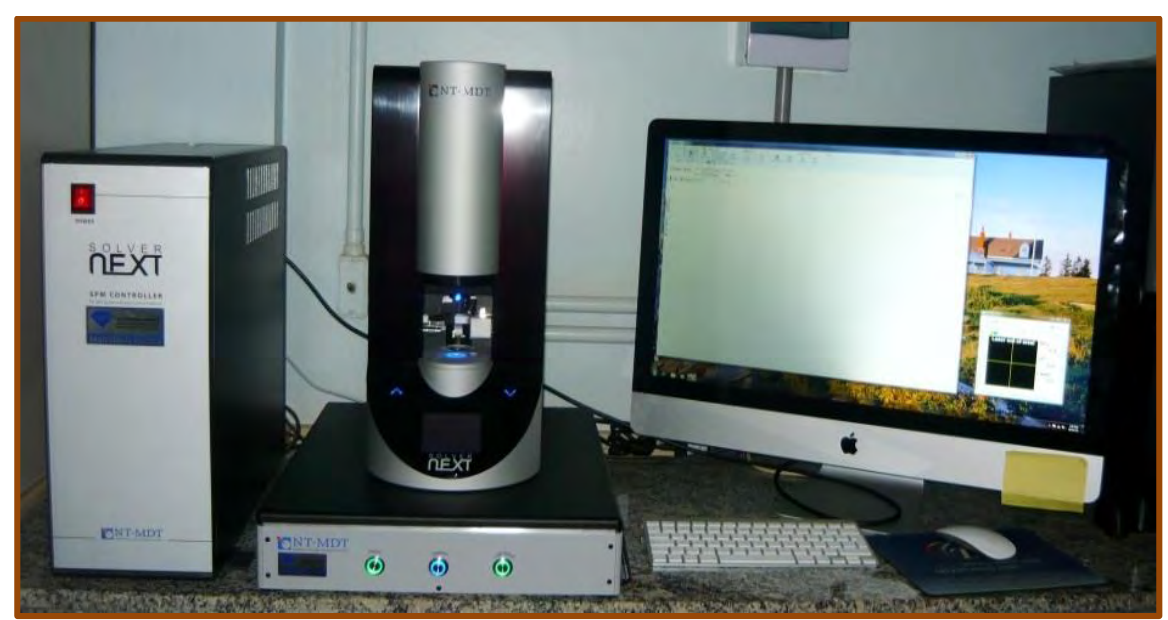

Fonte: Própria autoria. 


\subsubsection{Análise de imagem dos filmes}

A análise de imagem foi aplicada para caracterizar quantitativamente a microestrutura da superfície dos filmes à base de gelatina (lado ar e lado placa). A textura de uma imagem é uma característica representada pelo arranjo espacial dos níveis de cinzas dos pixels da imagem. Neste trabalho, três parâmetros de textura foram selecionados para estudo: Energia, Entropia e Dimensão Fractal.

As imagens dos filmes analisadas foram as imagens obtidas por MEV. Estas imagens foram obtidas já em escala de cinzas diretamente do equipamento; posteriormente os algoritmos de Matriz de Co-Ocorrência na escala de cinzas (Gray-Level Co-Occurrence Matrix - GLCM) e de Contagem de Caixas de Deslocamento Diferencial (Shifting Differential Box Counting - SDBC) foram aplicados para obter os parâmetros de textura a partir das imagens em escala de cinzas (ARZATE-VÁZQUEZ et al., 2012). A metodologia de processamento de imagens foi feita usando o programa livre Image J v1.34s (NATIONAL INSTITUTES HEALTH, BETHESDA, MD, USA).

Segundo Arzate-Vázquez et al. (2012), o algoritmo GLCM foi aplicado para calcular os parâmetros de textura de energia e entropia. Estes parâmetros foram calculados a uma distância entre pixels “d” igual a 1 e com um ângulo de deslocamento “ $\theta$ ” de $0^{\circ}$. A Tabela 1 apresenta as equações (eq.14 e eq.15) de textura extraídas a partir das imagens na escala de cinza. 
Tabela 1 - Equações dos parâmetros texturais a partir das imagens na escala de cinzas com o algoritmo GLCM

\begin{tabular}{lc}
\hline Parâmetro de textura & \multicolumn{1}{c}{ Equação } \\
\hline Energia & $\sum_{\mathrm{ij}} \mathrm{P}_{\mathrm{d} \theta}(\mathrm{i}, \mathrm{j})^{2}$ \\
Entropia & $-\sum_{\mathrm{ij}} \mathrm{P}_{\mathrm{d} \theta}(\mathrm{i}, \mathrm{j}) \log \left(\mathrm{P}_{\mathrm{d} \theta}(\mathrm{i}, \mathrm{j})\right)$ \\
\hline
\end{tabular}

Fonte: Arzate-Vázquez et al. (2012).

A energia mede a uniformidade de textura da imagem e é um parâmetro oposto a entropia. A entropia mede a desordem e a aleatoriedade das imagens e pode ser usada para caracterizar a textura da imagem e é um indicativo da complexidade dentro de uma imagem, portanto, imagens complexas terão altos valores de entropia. Esses dois parâmetros de textura foram extraídos das imagens obtidas pelo MEV com o plug-ing GLCM Texture incluído no programa Image J. E, a textura fractal foi avaliada pela lei da potência para obter sua dimensão fractal (DF), usando o algoritmo de Contagem de Caixas de Deslocamento Diferencial. A dimensão fractal foi estimada com o uso do programa Image $\mathbf{J}$ com o plug-in SDBC. Calculou-se a dimensão fractal a partir de uma tangente de um gráfico, onde plotou-se o log da contagem de caixas contra o log de tamanho de caixa (Figura 15) com a eq.(16):

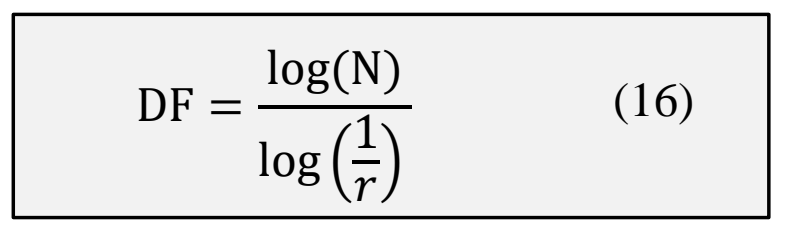

Onde $N$ representa o número de caixas e $r$ o tamanho da caixa. O parâmetro DF é uma medida diretamente relacionada com o grau de rugosidade da superfície. Para imagens em escala de cinzas 2D, valores entre 2 e 3 de dimensão fractal podem ser obtidos, portanto, o valor de dimensão fractal para uma superfície rugosa é maior que para uma superfície lisa. 
Este parâmetro foi estimado para todas as imagens na escala de cinzas obtida pela técnica de MEV.

Figura 15 - Gráfico de log de contagem de caixa contra log de tamanho de caixa obtido mediante o algoritmo SDBC, onde a pendente representa a dimensão fractal da imagem

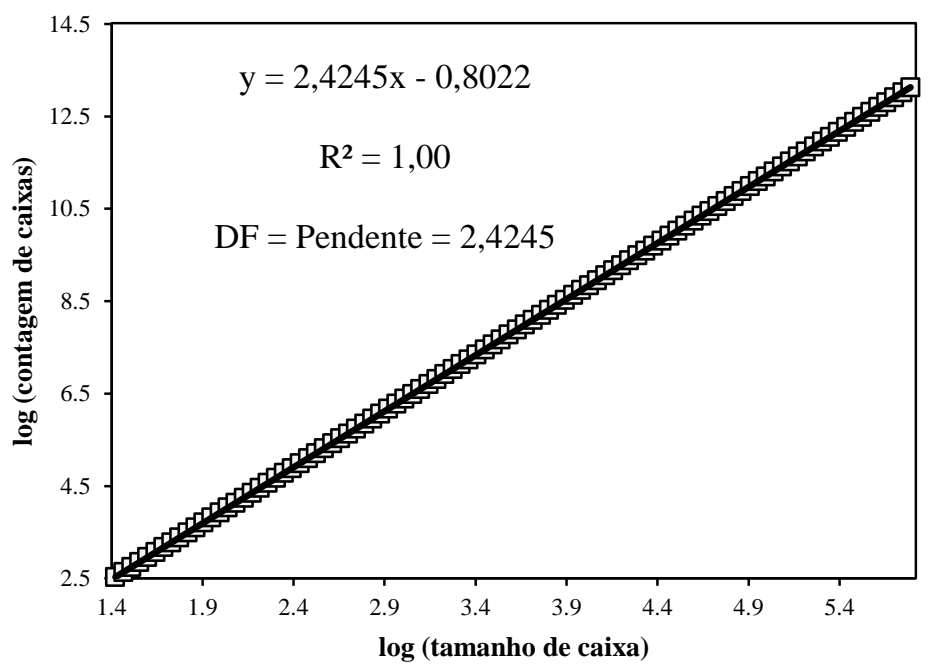

Fonte: Própria autoria.

\subsubsection{Propriedades superficiais dos filmes}

\subsubsection{1. Ângulo de contato (AC)}

A medida do ângulo de contato (AC) foi feita pelo método da gota séssil (ANDRADE et al., 2014; FARRIS et al., 2011; FERREIRA et al., 2015; KARBOWIAK et al., 2006; KUREK et al., 2013; WIĄCEK, 2015; YIN et al., 2014), onde uma gota do líquido padrão (água Mili-Q) foi colocado sobre a superfície do filme. A medição foi realizada utilizando-se um tensiômetro óptico (Attension, Theta Lite Optical Tensiometer) (Figura 16) equipado com o software de análise de imagem Attension Theta (Versao 4.1.9.8).

Uma gota de água Mili-Q $(5 \mu \mathrm{L})$ foi depositada sobre a superfície do filme em ambos os lados (lado ar e lado placa) com ajuda de uma seringa de precisão (Temperatura de $22{ }^{\circ} \mathrm{C}$ e 
umidade relativa de $46 \%$ ), sendo o valor do AC calculado como a média do ângulo de ambos os lados da gota de água, medidos num intervalo de tempo de 60 segundos. Cada valor do AC foi a média de 15 medidas do ângulo da gota do liquido padrão sobre a superfície do filme (3 x $2 \mathrm{~cm}$ ). O efeito da evaporação foi avaliado sobre uma superfície de referência impermeável: polietileno de baixa densidade (PBD) (KARBOWIAK et al., 2006).

Figura 16 - Tensiômetro óptico (Attension, Theta Lite Optical Tensiometer)

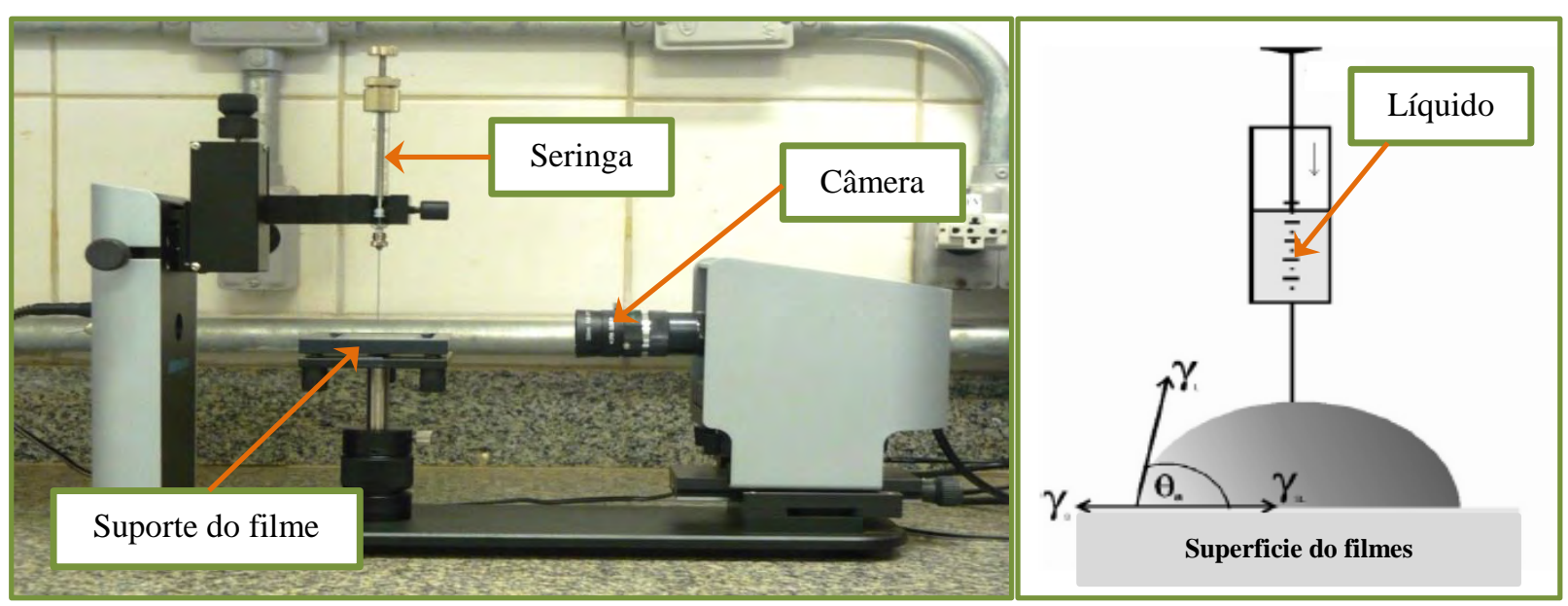

Fonte: Própria autoria.

4.3.6.2. Molhabilidade ou Coeficiente de Espalhamento (Se)

A molhabilidade da superfície do filme é representada pelo coeficiente de espalhamento $\left(\mathrm{S}_{\mathrm{e}}\right)$ (eq.2), e foi avaliada a partir da medida do AC baseado no método da gota séssil. Sendo $\mathrm{S}_{\mathrm{e}}$ a diferença entre o trabalho de adesão $\left(\mathrm{W}_{\mathrm{a}}\right)$ (eq.3) e o trabalho de coesão $\left(\mathrm{W}_{\mathrm{c}}\right)$ (eq.4) (AGNIESZKA, 2015; ANDRADE et al., 2013; KARBOWIAK; DEBEAUFORT; VOILLEY, 2006; KUREK et al., 2013), conforme as equações 2, 3 e 4. Onde $\gamma_{L}$, é a tensão superficial da água $(72.8 \mathrm{mN} / \mathrm{m})$ (Tabela 2) e $\theta$ é o AC da água. $\mathrm{O}$ valor do coeficiente de espalhamento só pode ser negativo ou zero como máximo valor. 
4.3.6.3. Modelagem da cinética do ângulo de contato

Para descrever a cinética do AC da gota de água sobre a superfície dos filmes de gelatina uma abordagem semi-empírica foi utilizada, conforme proposto por Farris et al. (2011), onde a eq.(17) foi ajustada aos dados experimentais do AC. O ajuste não linear da curva foi feito mediante a ferramenta SOLVER do Microsoft Excel (2010). A primeira derivada da função $\partial \theta / \partial t$ foi depois obtida para avaliar a taxa de evolução do ângulo de contato $\left({ }^{\circ} \mathrm{s}^{-1}\right)$.

$$
\theta_{\mathrm{t}}=\theta_{0} \operatorname{Exp}\left(\mathrm{k} * \mathrm{t}^{\mathrm{n}}\right)
$$

Onde, $\theta_{\mathrm{t}}$ é o ângulo de contato no tempo t, $\theta_{0}$ é o ângulo de contato inicial calculado, "k" medida da taxa de variação do ângulo de contato, "n", são os fenômenos de absorção e difusão, tomando "n" o valor de 1 ou 0 , no caso de absorção pura e espalhamento puro, respectivamente.

\subsubsection{Energia livre superficial}

A energia livre superficial, e suas componentes polar e dispersa, foram determinadas a partir da medida do AC utilizando água Mili-Q (5 $\mu \mathrm{L}$ ) (líquido polar) e 1-bromonaftaleno (3 $\mu$ ) (líquido apolar) sobre a superfície dos filmes, com ajuda do método de Owens-Wendt (GUETTLER; MORESOLI; SIMON, 2013: KUJAWA et al., 2014; KUREK et al, 2013), descrito nas equações 8,9 e 10. A eq.(8) descreve a componente dispersa $\left(\gamma_{\text {s }}^{D}\right)$, a eq.(9) 
descreve a componente polar $\left(\gamma_{s}^{\mathrm{P}}\right)$. E finalmente a energia livre superficial do filme $\left(\gamma_{\mathrm{s}}\right)$ (eq.10) foi estimada como a soma da $\gamma_{s}^{\mathrm{P}}$ e $\gamma^{\mathrm{D}}{ }_{s}$.

Os valores da tensão superficial e as componentes polar e dispersa dos líquidos padrões (Água Mili-Q e 1-Bromonaftaleno) utilizados para a determinação da energia livre superficial dos filmes à base de gelatina estão apresentados na Tabela 2.

Tabela 2 - Tensão superficial $\left(\gamma_{\mathrm{L}}\right)$ e seus componentes polar $\left(\gamma^{\mathrm{P}}\right)$ e dispersa $\left(\gamma^{\mathrm{D}}\right)$ dos líquidos

\begin{tabular}{lccc}
\hline Liquido $^{\prime}$ & $\gamma_{\mathrm{L}}(\mathrm{mN} / \mathrm{m})$ & $\gamma^{\mathrm{P}}(\mathrm{mN} / \mathrm{m})$ & $\gamma^{\mathrm{D}}(\mathrm{mN} / \mathrm{m})$ \\
\hline Água $^{\mathrm{a}}$ & 72,8 & 21,8 & 51,0 \\
1-Bromonaftaleno $^{\mathrm{b}}$ & 44,4 & 44,4 & 0,0 \\
\hline
\end{tabular}

Fonte: (a) Kurek et al. (2013); (b) Ribeiro et al. (2007).

\subsubsection{Análise estatística}

Os resultados experimentais foram submetidos à analise de variância e as médias foram comparadas através do teste múltiplo de Tukey no intervalo de $95 \%$ de confiança, usando o programa estatístico STATGRAPHICS Centurion 16.1. 


\section{RESULTADOS E DISCUSSÃO}

\subsection{CARACTERIZAÇÃO DOS FILMES}

\subsubsection{Aspecto visual}

Os filmes à base de gelatina apresentaram uma boa aparência visual, homogeneidade e ausência de partículas insolúveis na sua superfície (Figura 17).

Figura 17 - Filmes à base de gelatina, A: Gelatina, B: Gelatina/MMT e C: Gelatina/ATB

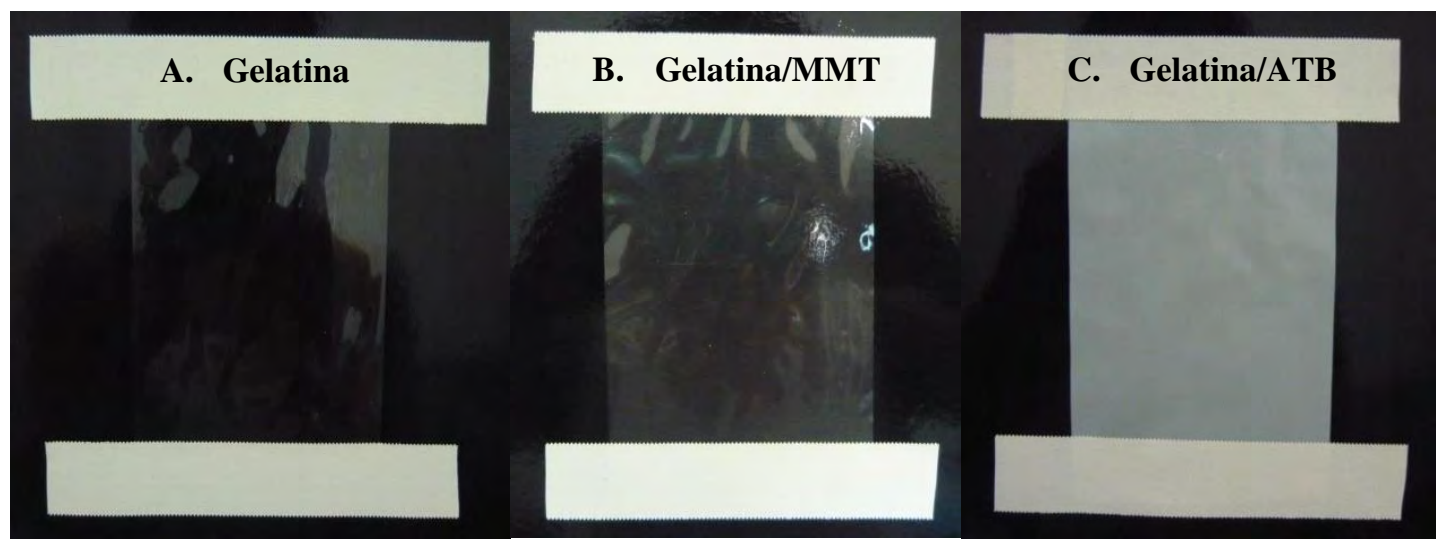

Fonte: Própria autoria.

Tanto o filme de gelatina plastificado com glicerol, como o filme de gelatina/MMT apresentaram-se brilhantes e transparentes, já o filme de Gelatina/ATB apresentou uma coloração amarelada e certa opacidade, devido à presença do plastificante ATB na forma de gotículas, que alteram as propriedades óticas do material (VILLALOBOS et al., 2005). 


\subsubsection{Espessura}

A espessura é um parâmetro importante a ser controlado na produção de filmes (SOBRAL, 2000), pois exerce influência direta em diversas propriedades, como a permeabilidade ao vapor de água, propriedades mecânicas, cor e opacidade.

Na Tabela 3 encontram-se o valor médio da espessura dos filmes de gelatina. Não foi observada diferença estatística significativa $(p>0,05)$ entre os três filmes, cuja espessura ficou em torno de $0,078 \mathrm{~mm}$.

Tabela 3 - Espessura media dos filmes à base de gelatina

\begin{tabular}{ll}
\hline Filmes & Espessura $(\mathbf{m m})$ \\
\hline Gelatina & $0,077 \pm 0,001^{\mathrm{a}}$ \\
Gelatina/MMT & $0,080 \pm 0,000^{\mathrm{a}}$ \\
Gelatina/ATB & $0,076 \pm 0,001^{\mathrm{a}}$ \\
\hline
\end{tabular}

Letras minúsculas diferentes, na mesma coluna, indicam diferença estatisticamente significativa $(\mathrm{p}<0,05)$ entre as medias, obtidas pelo teste de Tukey, utilizando-se o software STATGRAPHICS Centurion 16.1.

Fonte: Própria autoria.

\subsubsection{Umidade}

Na Tabela 4 estão apresentados os valores médios da umidade para os filmes à base de gelatina. Observou-se que só o filme de Gelatina/ATB (Umidade=10,6 \%) apresentou diferença significativa $(\mathrm{p}<0,05)$ dos outros filmes, cuja umidade permaneceu em torno de 17\%. O baixo valor de umidade da gelatina/ATB pode ser atribuído à presença do plastificante ATB, que tem um caráter hidrofóbico, ou seja, esse filme foi menos sensível à umidade ambiental. 
Tabela 4 - Umidade média dos filmes à base de gelatina

\begin{tabular}{lc}
\hline Filmes & Umidade $(\%)$ \\
\hline Gelatina & $16,5 \pm 1,1^{\mathrm{a}}$ \\
Gelatina/MMT & $17,7 \pm 0,4^{\mathrm{a}}$ \\
Gelatina/ATB & $10,6 \pm 0,2^{\mathrm{b}}$ \\
\hline Letras minúsculas diferentes na mesma coluna indicam diferença estatisticamente significativa $(\mathrm{p}<0,05)$ entre as \\
medias, obtidas pelo teste de Tukey, utilizando-se o software STATGRAPHICS Centurion 16.1. \\
Fonte: Própria autoria.
\end{tabular}

Os maiores valores de umidade para os filmes de Gelatina e Gelatina/MMT é consequência da higroscopicidade da matriz filmogênica (SOBRAL et al., 2001). A gelatina é um biopolímero que tem alta quantidade de aminoácidos polares que conferem um caráter higroscópico à essa proteína (SOBRAL; HABITANTE, 2001). Além disso, o glicerol utilizado como plastificante nos dois filmes, é altamente higroscópico (BERGO; MORAES; SOBRAL, 2013; SOBRAL et al., 2001; THOMAZINE; CARVALHO; SOBRAL, 2005).

\subsubsection{Propriedades óticas}

\subsubsection{Cor e Opacidade}

Os parâmetros de cor $\left(L^{*}, a^{*}, b^{*} e \Delta E^{*}\right)$ e opacidade para os filmes à base de gelatina estão mostrados na Tabela 5. Foi possível observar dois comportamentos distintos nesta Tabela: primeiro, que não houve diferença estatística significativa $(p>0,05)$ entre os lados dos três filmes (lado ar e lado placa), para os diferentes parâmetros de cor e opacidade; e segundo, que os filmes de Gelatina e Gelatina/MMT não apresentaram diferenças entre si ( $p>0,05)$, sendo diferentes $(\mathrm{p}<0,05)$ dos filmes Gelatina/ATB. 
Tabela 5 - Parâmetros de cor $\left(L^{*}, a^{*}, b^{*}\right)$, diferença de cor $\left(\Delta E^{*}\right)$ e opacidade dos filmes à base de gelatina, lado "ar" e lado "placa"

\begin{tabular}{|c|c|c|c|c|c|}
\hline Filmes & $\mathbf{L}^{*}$ & $\mathbf{a}^{*}$ & $\mathbf{b}^{*}$ & $\Delta \mathbf{E}^{*}$ & Opacidade \\
\hline \multicolumn{6}{|c|}{ Lado ar } \\
\hline Gelatina & $91,3 \pm 0,0^{\mathrm{a}, \mathrm{A}}$ & $-0,77 \pm 0,02^{\mathrm{a}, \mathrm{A}}$ & $2,5 \pm 0,01^{, A}$ & $2,6 \pm 0,0^{\mathrm{a}, \mathrm{A}}$ & $0,1 \pm 0,1^{\mathrm{a}, \mathrm{A}}$ \\
\hline Gelatina/MMT & $91,4 \pm 0,0^{\mathrm{a}, \mathrm{A}}$ & $-0,80 \pm 0,01^{\mathrm{a}, \mathrm{A}}$ & $3,5 \pm 0,1^{\mathrm{a}, \mathrm{A}}$ & $3,1 \pm 0,1^{\mathrm{a}, \mathrm{A}}$ & $2,1 \pm 0,1^{\mathrm{a}, \mathrm{A}}$ \\
\hline Gelatina/ATB & $93,7 \pm 0,1^{\mathrm{b}, \mathrm{A}}$ & $-1,56 \pm 0,21^{\mathrm{b}, \mathrm{A}}$ & $7,4 \pm 0,9^{\mathrm{b}, \mathrm{A}}$ & $5,8 \pm 0,9^{\mathrm{b}, \mathrm{A}}$ & $43,7 \pm 1,8^{\mathrm{b}, \mathrm{A}}$ \\
\hline \multicolumn{6}{|c|}{ Lado placa } \\
\hline Gelatina & $91,3 \pm 0,01^{, A}$ & $-0,78 \pm 0,00^{\mathrm{a}, \mathrm{A}}$ & $2,5 \pm 0,1^{\mathrm{a}, \mathrm{A}}$ & $2.6 \pm 0.0^{\mathrm{a}, \mathrm{A}}$ & $0,2 \pm 0,1^{\mathrm{a}, \mathrm{A}}$ \\
\hline Gelatina/MMT & $91,4 \pm 0,0^{\mathrm{a}, \mathrm{A}}$ & $-0,78 \pm 0,00^{\mathrm{a}, \mathrm{A}}$ & $3,6 \pm 0,1^{\mathrm{a}, \mathrm{A}}$ & $3.1 \pm 0.1^{\mathrm{a}, \mathrm{A}}$ & $2,5 \pm 0,0^{\mathrm{a}, \mathrm{A}}$ \\
\hline Gelatina/ATB & $93,7 \pm 0,1^{\mathrm{b}, \mathrm{A}}$ & $-1,56 \pm 0,19^{\mathrm{b}, \mathrm{A}}$ & $7,3 \pm 0,8^{\mathrm{b}, \mathrm{A}}$ & $5.7 \pm 0.8^{\mathrm{b}, \mathrm{A}}$ & $44,1 \pm 1,8^{\mathrm{b}, \mathrm{A}}$ \\
\hline
\end{tabular}

Fonte: Própria autoria.

O filme de Gelatina produzido neste trabalho apresentou uma $\Delta \mathrm{E}^{*}$ similar aos filmes à base de gelatina suína elaboradas por Sobral (1999) e Vanin et al. (2005) $\left(\Delta \mathrm{E}^{*}=2,9\right)$. Além disso, o filme de Gelatina/MMT foi ligeiramente mais colorido $\left(\Delta \mathrm{E}^{*}\right)$ que o filme de gelatina; um comportamento similar também foi observado por outros autores, como Sothornvit et al. (2010), que trabalharam com filmes nanocompósitos de isolado proteico de soro, Alboofetileh et al. (2013) para filmes nacocompósitos de alginato, e Kanmani e Rhim (2014), para filmes nanocompósitos de gelatina. Para estes autores, a $\Delta \mathrm{E}^{*}$ foi devido principalmente ao aumento no valor do parâmetro $b^{*}$, devido à presença da MMT na matriz dos filmes.

Considerando-se os parâmetros de cor (Tabela 5), os filmes de Gelatina e Gelatina/MMT apresentaram uma ligeira coloração amarelada brilhante, caracterizada pelo valor do parâmetro b*. Enquanto que o filme de Gelatina/ATB apresentou o maior valor da $\Delta \mathrm{E}^{*}(5,8)$ com relação aos outros filmes. Este elevado valor de $\Delta \mathrm{E}^{*}$ para o filme de Gelatina/ATB foi devido ao maior valor positivo do parâmetro $b^{*}(7,4)$ (cor amarela), corroborando com o aspecto visual do filme (Figura 17). Este resultado era esperado, devido à coloração marrom clara da lecitina de soja utilizada como emulsificante na elaboração deste 
filme (ANDREUCCETTI; CARVALHO; GROSSO, 2009), mas também devido à presença de gotículas do plastificante dispersa na matriz biopolimérica.

Com relação à opacidade (Tabela 5), Carvalho et al. (2008) mencionaram que os filmes com uma opacidade menor que $1 \quad(\mathrm{Y}<1)$, são filmes transparentes. No presente trabalho, o filme de gelatina apresentou uma opacidade de 0,13 , o que indicou que se trata de filme altamente transparente (Figura 17). Outros autores também reportaram valores similares, como Sobral (1999) (Y=0,4), e Vanin et al. (2005) $(\mathrm{Y}=0,5)$. Por outro lado, o filme de Gelatina/MMT foi ligeiramente mais opaco que o filme de gelatina, que pode ser atribuído à dispersão da luz pela presença de MMT distribuída na matriz do filme (KANMANI; RHIM, 2014; NAGARAJAN et al., 2014), uma vez que a MMT não se dissolve na solução filmogênica (ALBOOFETILEH et al., 2013).

E, o filme de Gelatina/ATB apresentou a maior opacidade que os outros filmes. Andreuccetti, Carvalho e Grosso (2009) reportaram também elevados valores de opacidade para o mesmo tipo de filme. A elevada opacidade deste filme é devido à dispersão da luz, induzida pelas gotículas de caráter oleoso (ATB) distribuído na rede do filme. Resultados similares foram observados por autores como, Shojaee-Aliabadi et al. (2014), Acosta et al. (2015) e Acevedo-Fani et al. (2015), para filmes baseados em k-carragenana incorporados com dois óleos essenciais (Zataria multiflora Boiss e Mentha pulegium), filmes de amidogelatina incorporados de ésteres de ácidos graxos e filmes de alginato formados a partir de nanoemulsões de óleos essenciais (Thymus vulgaris, Cymbopogon citratus e Salvia officinalis). 


\subsubsection{Brilho}

O brilho é uma propriedade de superfície que tem escala arbitraria e é adimensional. Ele é relacionado à textura superficial, ou seja, ao grau de polimento dessa superfície (MORAES et al., 2008). No caso de superfícies lisas, a lei de refração é válida, sendo o ângulo de iluminação igual ao ângulo de refração. A intensidade de refração da luz é dependente do ângulo de iluminação e das propriedades do material. Entretanto, em superfícies rugosas, a luz é refletida na direção especular, mas também se difunde em outras direções. Sendo assim, a capacidade de refração da superfície do objeto reduz substancialmente. Quanto mais a luz é distribuída em todas as direções, menos intenso o ângulo de refração especular, que irá ser visualizado, portanto, menos brilhante será o material (KIGLE-BOECFLER, 1995).

Segundo Villalobos et al. (2005), ângulos menores (ex. 20²) são mais adequados para caracterizar materiais com maior brilho, enquanto que ângulos maiores (ex. 60 ), diferenciam melhor amostras com menos brilho. Os valores das medidas do brilho para os filmes são mostrados na Tabela 6, onde se encontram os resultados medidos para os ângulos de $20^{\circ} \mathrm{e}$ $60^{\circ}$

Tabela 6 - Valores de brilho $\left(20^{\circ}\right.$ e $\left.60^{\circ}\right)$ para os filmes à base de gelatina, lado "ar" e lado

$$
\text { "placa" }
$$

\begin{tabular}{lcccc}
\hline \multirow{2}{*}{ Filmes } & \multicolumn{2}{c}{$\mathbf{2 0}^{\circ}$} & \multicolumn{2}{c}{$\mathbf{6 0}^{\circ}$} \\
\cline { 2 - 5 } & Lado ar & Lado placa & Lado ar & Lado placa \\
\hline Gelatina & $124,2 \pm 4,0^{\mathrm{a}, \mathrm{A}}$ & $126,7 \pm 2,4^{\mathrm{a}, \mathrm{A}}$ & $160,3 \pm 0,4^{\mathrm{a}, \mathrm{A}}$ & $159,9 \pm 0,0^{\mathrm{a}, \mathrm{A}}$ \\
Gelatina/MMT & $49,4 \pm 3,0^{\mathrm{b}, \mathrm{A}}$ & $63,7 \pm 2,5^{\mathrm{b}, \mathrm{B}}$ & $87,9 \pm 1,8^{\mathrm{b}, \mathrm{A}}$ & $103,2 \pm 2,2^{\mathrm{b}, \mathrm{B}}$ \\
Gelatina/C.ATB & $33,4 \pm 3,3^{\mathrm{c}, \mathrm{A}}$ & $46,5 \pm 1,7^{\mathrm{c}, \mathrm{B}}$ & $77,3 \pm 1,6^{\mathrm{c}, \mathrm{A}}$ & $82,2 \pm 1,8^{\mathrm{c}, \mathrm{B}}$ \\
\hline
\end{tabular}

Letras minúsculas na mesma coluna indicam diferença significativa $(p<0,05)$ entre as medias de brilho dos filmes; letras maiúsculas diferentes na mesma linha indicam diferença significativa $(\mathrm{p}<0,05)$ entre as medias dos lados para cada filme. A diferença entre as medias foi obtida pelo teste de Tukey, utilizando-se o software STATGRAPHICS Centurion 16.1.

Fonte: Própria autoria. 
Os valores de brilho para o filme de Gelatina foram os mais elevados comparado aos outros filmes produzidos neste estudo. Isto significa que a superfície deste filme era lisa e homogênea (como se pôde verificar por MEV, Figura 18). Por outro lado, o filme de Gelatina/MMT apresentou um menor valor de brilho, com relação ao filme de Gelatina, seguido pelo filme de Gelatina/ATB.

No caso do filme de Gelatina/MMT a diminuição do brilho foi consequência da presença de MMT, na matriz do filme, formando aglomerados na sua superfície durante o processo de secagem (FLAKER et al., 2015, JORGE et al., 2014) (Figura 19), sendo por isso menor o valor do brilho do filme do lado ar que do lado placa.

Para o filme de Gelatina/ATB, o brilho foi consequência da maior irregularidade do filme, devido à coalescência e separação de fase das gotículas de ATB durante a secagem do filme, o qual diminuiu a reflectância especular e, por consequência o brilho (BONILLA; et al., 2011; JIMÉNEZ et al., 2010; VARGAS et al., 2009). A relação entre o incremento da rugosidade superficial e a diminuição do brilho dos filmes foi também observada por outros autores (FABRA et al., 2011; SÁNCHEZ-GONZÁLEZ et al., 2010; VILLALOBOS et al., 2005).

\subsubsection{Microestrutura dos filmes}

A microestrutura dos filmes à base de gelatina foi analisada por Microscopia Eletrônica de Varredura (MEV), com o intuito de observar sua morfologia superficial e seção transversal crio-fraturada. Além disso, a Microscopia de Força Atômica (AFM) foi utilizada para analisar a topografia superficial e determinar a rugosidade dos filmes. As análises foram realizadas nas duas superfícies do filme, aqui chamadas de lado ar e lado placa. 
5.1.5.1. Microscopia eletrônica de varredura (MEV)

O filme de Gelatina apresentou uma estrutura superficial (lado ar e lado placa) compacta, muito lisa e homogênea (Figura 18a,b). Assim como a seção transversal destes filmes também apresentou uma superfície homogênea sem presença de partículas (Figura 18c). A homogeneidade pode ser atribuída à presença de fases ordenadas e rede estrutural homogênea. Estruturas semelhantes foram obtidas em outros trabalhos (AHMAD et al., 2015; KANMANI; RHIM, 2014; MARTUCCI et al., 2015).

Figura 18 - Micrografias de MEV do filme de Gelatina: Lado ar (a), Lado placa (b), seção transversal (c)
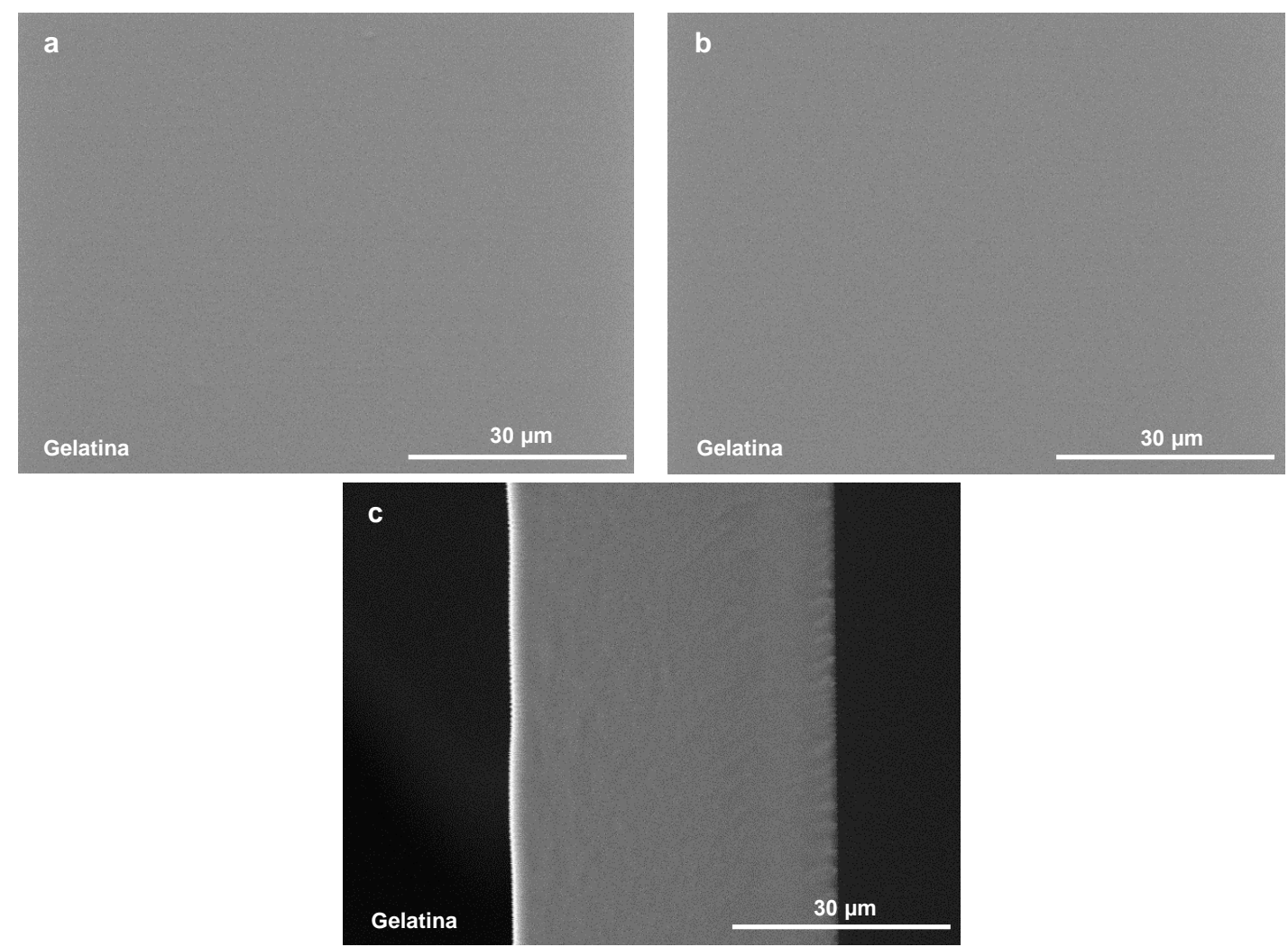

Fonte: Própria autoria.

Com relação ao filme de Gelatina/MMT, observou-se que estes apresentaram uma superfície irregular em ambos os lados do filme (Figura 19a,b), sendo bem mais irregular na 
superfície em contato com o ar, devido à formação de aglomerados causada pelas interações entre componentes na solução formadora de filmes (SFF) (JORGE te al., 2014), mas também pela eventual elutriação de material para a superfície durante o processo de secagem. A seção transversal também apresenta uma superfície menos lisa (Figura 19c), onde se observou que a formação dos aglomerados foi maior no lado do filme em contato com o ar. A modificação da textura superficial dos filmes devido à adição de MMT foi também reportada por outros autores (FLAKER et al., 2015; NAGARAJAN et al., 2014).

Figura 19 - Micrografias de MEV do filme de Gelatina/MMT: Lado ar (a), Lado placa (b), seção transversal (c)
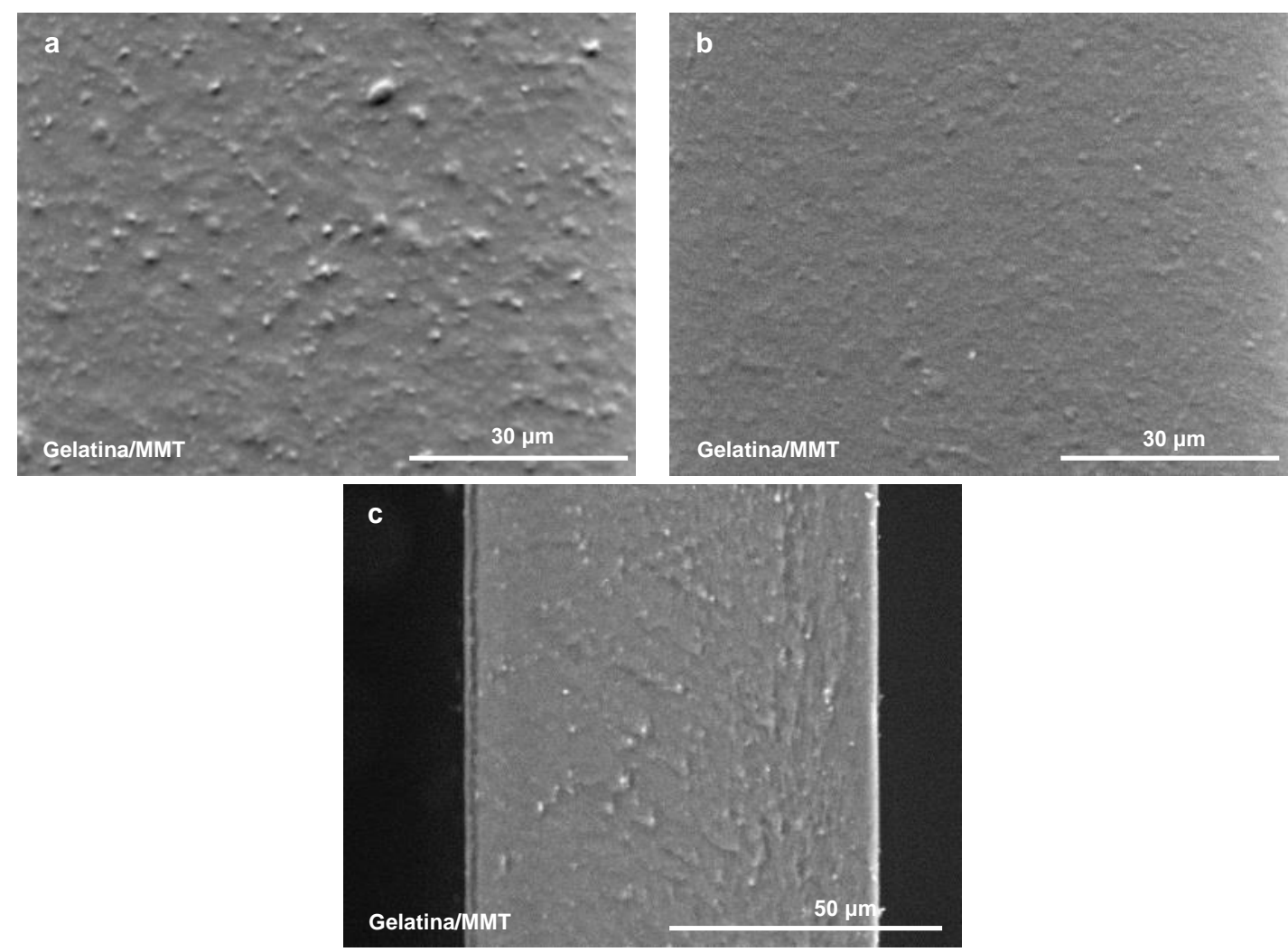

Fonte: Própria autoria.

A morfologia superficial do filme de Gelatina/ATB apresentou uma superfície muito heterogênea, irregular e com a presença de poros (Figura 20a,b), o qual foi mais visível do lado do filme em contato com o ar. Esta característica pode ser atribuída aos fenômenos de 
floculação, coalescência e separação de fase que ocorreram com o ATB durante o processo de secagem, onde as gotículas do ATB migraram à parte superior, originando a sua maior irregularidade superficial (BONILLA et al., 2012; SÁNCHEZ-GONZÁLEZ et al., 2010). Com a presença de ATB, a seção transversal deste filme tornou-se mais rugosa em comparação com o filme de Gelatina (Figura 20c). A adição do ATB no filme provavelmente interrompeu o alinhamento das moléculas de proteína na matriz do filme, o que reduziu a interação proteína-proteína, tornando ao filme mais rugoso.

Figura 20 - Micrografias de MEV do filme de Gelatina/ATB: Lado ar (a), Lado placa (b), seção transversal (c)
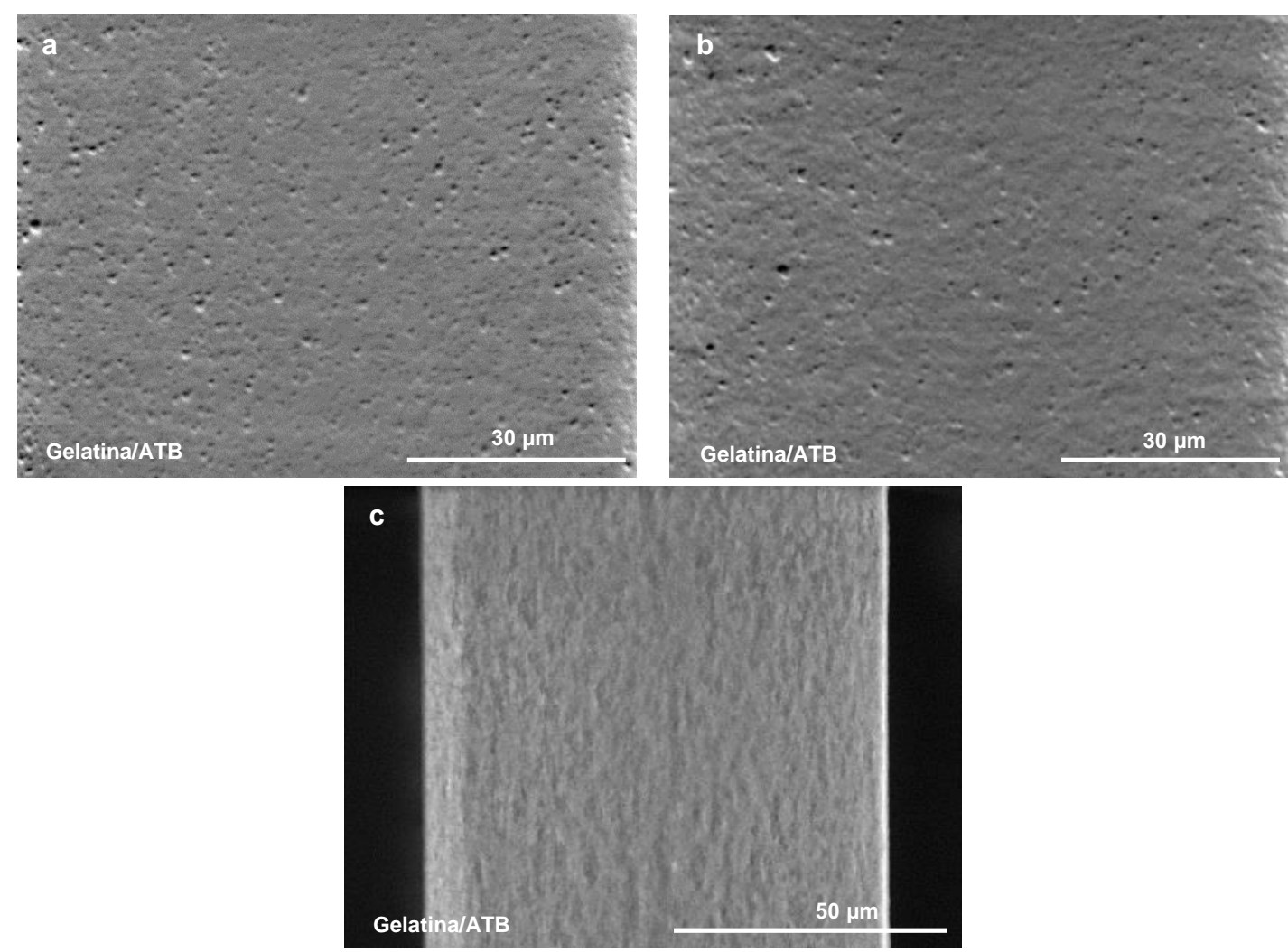

Fonte: Própria autoria. 


\subsubsection{Microscopia de força atômica (AFM)}

A topografia da superfície dos filmes à base de gelatina e os parâmetros de rugosidade $\left(\mathrm{R}_{\mathrm{a}}, \mathrm{R}_{\mathrm{q}}\right.$ ) (Tabela 7) foram obtidos a partir das micrografias obtidas por AFM (Figura 21). O filme de Gelatina apresentou uma topografia muito lisa, com baixos valores de $R_{a}$ e $R_{q}$ para ambos os lados do filme, não se observando diferença estatística significativa entre as superfícies ( $p>0,05)$, o que corrobora com as imagens obtidas por MEV. A rugosidade do filme de Gelatina, no presente trabalho, foi menor que o reportado por Farris et al. (2011) (7 nm). Já o filme de Gelatina/MMT apresentou uma superfície muito rugosa com altos valores de $\mathrm{Ra}$ e Rq para o lado ar e lado placa, observando-se maior rugosidade no lado ar do filme (Ra: 53,6 nm, Rq: 73,3 nm) devido à formação de aglomerados e ao processo de secagem que deslocaria as partículas à superfície, como já foi explicado na seção anterior (ver tópico 5.1.5.1). Flaker et al. (2015), apresentou valores próximos para filmes de gelatina com 5\% de $\operatorname{MMT}(64 \mathrm{~nm})$.

Tabela 7 - Valores de rugosidade $\mathrm{R}_{\mathrm{a}}(\mathrm{nm}), \mathrm{R}_{\mathrm{q}}(\mathrm{nm})$ para os filmes à base de gelatina, lado "ar" e lado "placa"

\begin{tabular}{lcccc}
\hline \multirow{2}{*}{ Filmes } & \multicolumn{2}{c}{$\mathbf{R}_{\mathbf{a}}(\mathbf{n m})$} & \multicolumn{2}{c}{$\mathbf{R}_{\mathbf{q}}(\mathbf{n m})$} \\
\cline { 2 - 5 } & Lado ar & Lado placa & Lado ar & Lado placa \\
\hline Gelatina & $1,1 \pm 0,0^{\mathrm{a}, \mathrm{A}}$ & $0,7 \pm 0,1^{\mathrm{a}, \mathrm{A}}$ & $2,2 \pm 0,2^{\mathrm{a}, \mathrm{A}}$ & $1,5 \pm 0,6^{\mathrm{a}, \mathrm{A}}$ \\
Gelatina/MMT & $53,5 \pm 2,5^{\mathrm{b}, \mathrm{A}}$ & $8,0 \pm 1,0^{\mathrm{b}, \mathrm{B}}$ & $73,3 \pm 4,2^{\mathrm{b}, \mathrm{A}}$ & $10,8 \pm 1,2^{\mathrm{b}, \mathrm{B}}$ \\
Gelatina/ATB & $32,4 \pm 1,4^{\mathrm{c}, \mathrm{A}}$ & $20,4 \pm 2,2^{\mathrm{c}, \mathrm{B}}$ & $40,9 \pm 1,9^{\mathrm{c}, \mathrm{A}}$ & $29,1 \pm 3,2^{\mathrm{c}, \mathrm{B}}$ \\
\hline
\end{tabular}

Letras minúsculas diferentes na mesma coluna indicam diferença significativa $(\mathrm{p}<0,05)$ entre as medias dos filmes; letras maiúsculas diferentes na mesma linha indicam diferença significativa $(\mathrm{p}<0,05)$ entre as medias dos lados para cada filme. A diferença entre as medias foi obtida pelo teste de Tukey, utilizando-se o software STATGRAPHICS Centurion 16.1.

Fonte: Própria autoria.

Para o filme de Gelatina/ATB as micrografias de AFM mostram uma superfície heterogênea e irregular, também corroborando com o observado por MEV, com um valor de 
rugosidade $\left(R_{a}, R_{q}\right)$ bem maior que o filme de Gelatina e menor ao filme de Gelatina/MMT. A topografia do lado ar do filme mostrou uma superfície muito complexa, com a presença de picos na sua estrutura (Figura 21). Esta estrutura complexa foi o que finalmente deu o maior valor de $R_{a}$ e $R_{q}(p<0,05)$ para a superfície em contato com o ar de secagem, devido aos fenômenos descritos anteriormente. Resultados similares foram observados para filmes de gelatina incorporados com óleo de oliva, onde a rugosidade se aumentou com o incremento da porcentagem de óleo na matriz do filme (MA et al., 2012). Além disso, Atarés, Bonilla e Chiralt (2010) também observaram resultados similares para filmes à base de caseinato de sódio incorporados com óleo essencial de gengibre, sendo que o óleo de gengibre formou agregados na etapa de secagem, o que provocou as irregularidades na superfície do filme. 
Figura 21 - Micrografias de AFM dos filmes à base de gelatina: Gelatina (a, b, g, h), Gelatina/MMT (c, d, i, j), Gelatina/ATB (e, f, k, l)

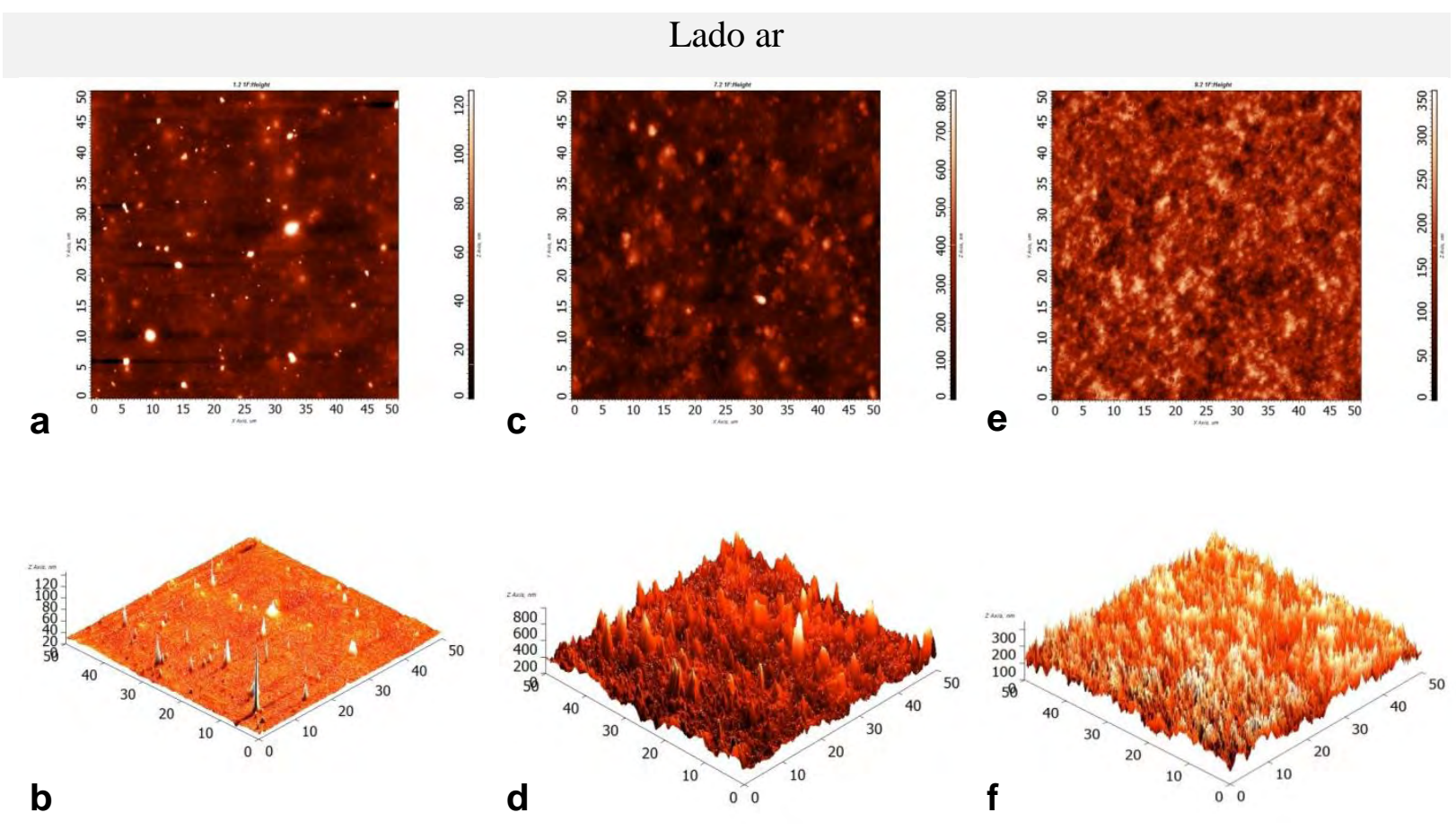

Lado placa
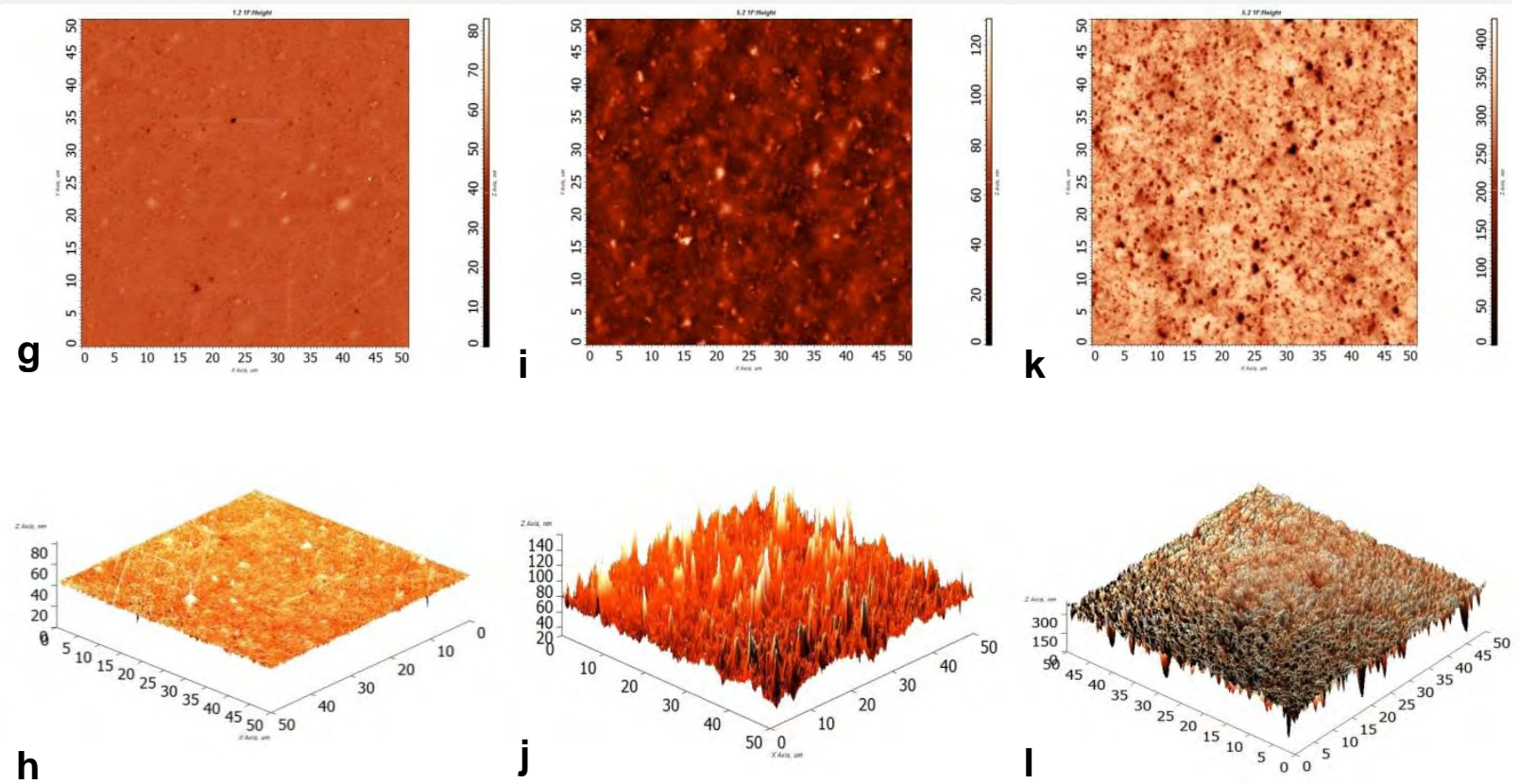

Fonte: Própria autoria. 


\subsubsection{Análise de imagem dos filmes}

Os parâmetros de textura extraídos a partir das imagens do MEV da superfície dos filmes (lado ar e lado placa) à base de gelatina encontram-se resumidos na Tabela 8. Para o lado ar, o filme Gelatina apresentou o maior valor para o parâmetro de energia $\left(4,0 \times 10^{-3}\right)$, em comparação com os filmes de Gelatina/MMT e Gelatina/ATB que apresentaram menores

valores $\left(2,0 \times 10^{-3}\right.$ e $1,6 \times 10^{-3}$ respectivamente), sendo que para esses dois últimos não houve diferença estatística significativa $(p>0,05)$. Altos valores de energia foram alcançados quando a distribuição dos níveis cinzas dos pixels apresentou uma constante ou uma forma periódica. Baixos níveis de energia indicam uma distribuição irregular dos pixels da imagem (ARZATEVÁZQUEZ et al., 2012; FERNÁNDEZ; CASTILLERO; AGUILERA, 2005; MENDOZA; DEJMEK; AGUILERA, 2007). Podem-se associar estas tendências com a superfície homogênea do filme de Gelatina e superfícies heterogêneas dos filmes de Gelatina/MMT (devido à formação de aglomerados) e Gelatina/ATB (devido aos fenômenos de floculação, coalescência e separação de fase acontecidos durante a secagem).

Além disso, os parâmetros de entropia e dimensão fractal apresentaram valores inversos com relação à energia, onde o filme de Gelatina teve os menores valores, enquanto que os filmes de Gelatina/MMT e Gelatina/ATB apresentaram os maiores valores. A entropia e a dimensão fractal para o filme de Gelatina foram 5,9 e 2,4, respectivamente. Em outras palavras, isto significa que a textura superficial do filme de Gelatina é mais homogênea e mais lisa que os outros dois filmes (Gelatina/MMT e Gelatina/ATB) corroborando com o discutido anteriormente. O filme de Gelatina/MMT apresentou um alto valor de dimensão fractal e um valor intermediário de entropia, quando comparado aos demais filmes, e isso pode ser atribuído à formação de aglomerados neste filme que resultou em um maior grau de complexidade e rugosidade. Finalmente o filme de Gelatina/ATB apresentou os maiores valores de entropia e um valor intermediário de dimensão fractal, indicando que este filme 
apresenta uma estrutura muito complexa e com rugosidade. Esta estrutura complexa pode ser observada na micrografia de AFM (Figura 21). É assim, que os valores dos parâmetros de textura obtidos neste lado dos filmes (lado ar) (Tabela 8) corroboram os valores de rugosidade apresentados na Tabela 7 para o mesmo lado.

Tabela 8 - Parâmetros de textura extraídos das micrografias de MEV dos filmes à base de gelatina

\begin{tabular}{lccc}
\hline \multirow{2}{*}{ Filmes } & \multicolumn{3}{c}{ Parâmetros de Textura } \\
\cline { 2 - 4 } & \multicolumn{2}{c}{ Lado "Ar" } & Entropia \\
Gelatina & $4,0 \pm 0,0^{\mathrm{a}, \mathrm{A}}$ & $5,9 \pm 0,0^{\mathrm{a}, \mathrm{A}}$ & $2,4 \pm 0,0^{\mathrm{a}, \mathrm{A}}$ \\
Gelatina/MMT & $2,0 \pm 0,0^{\mathrm{b}, \mathrm{A}}$ & $6,7 \pm 0,0^{\mathrm{b}, \mathrm{A}}$ & $2,5 \pm 0,0^{\mathrm{b}, \mathrm{A}}$ \\
Gelatina/ATB & $1,6 \pm 0,0^{\mathrm{b}, \mathrm{A}}$ & $6,9 \pm 0,2^{\mathrm{c}, \mathrm{A}}$ & $2,5 \pm 0,0^{\mathrm{b}, \mathrm{A}}$ \\
\hline & \multicolumn{1}{c}{ Lado "Placa" } & \\
Gelatina & $3,0 \pm 0,0^{\mathrm{a}, \mathrm{B}}$ & $6,3 \pm 0,0^{\mathrm{a}, \mathrm{B}}$ & $2,4 \pm 0,0^{\mathrm{a}, \mathrm{A}}$ \\
Gelatina/MMT & $3,0 \pm 0,0^{\mathrm{a}, \mathrm{B}}$ & $6,3 \pm 0,0^{\mathrm{a}, \mathrm{B}}$ & $2,4 \pm 0,0^{\mathrm{a}, \mathrm{B}}$ \\
Gelatina/ATB & $1,6 \pm 0,0^{\mathrm{b}, \mathrm{A}}$ & $7,0 \pm 0,1^{\mathrm{b}, \mathrm{A}}$ & $2,5 \pm 0,0^{\mathrm{b}, \mathrm{A}}$ \\
\hline
\end{tabular}

Letras minúsculas diferentes na mesma coluna em cada lado indicam diferença significativa $(p<0,05)$ entre as medias dos parâmetros de textura; letras maiúsculas diferentes entre os lados indicam diferença significativa $(\mathrm{p}<0,05)$ entre as medias dos lados para cada filme. A diferença entre as medias foi obtida pelo teste de Tukey, utilizando-se o software STATGRAPHICS Centurion 16.1.

Fonte: Própria autoria.

Com relação aos parâmetros de textura para o lado placa dos filmes, observou-se que, não houve diferença estatística significativa $(p>0,05)$ dos parâmetros de energia e entropia entre os filmes de Gelatina e Gelatina/MMT. Houve uma inversão de comportamento para os valores de energia e de entropia dos filmes de gelatina, uma vez que se esperava que a energia fosse maior na superfície em contato com a placa e a entropia nesta mesma superfície fosse menor, o que não ocorreu. Dessa forma, os resultados obtidos não corroboram com os dados obtidos para a rugosidade para este filme (Tabela 7). 
Comparando-se os as superfícies, aqui chamadas de lado ar e lado placa, para os filmes de Gelatina/MMT observou-se que o valor da energia foi maior para o lado placa e o valor da sua entropia foi menor para esta mesma superfície. Isso indica que a superfície do lado placa do filme foi mais homogênea que do lado ar, como já foi mencionado, e isso foi devido à formação de aglomerados na superfície do filme (lado ar), deixando, por conseguinte uma superfície mais homogênea no lado placa do filme. Para o filme de Gelatina/ATB, o valor da energia e entropia foi o mesmo que do lado ar ( $p>0,05)$, indicando que ambos os lados apresentam uma estrutura complexa.

A dimensão fractal para os filmes de Gelatina, Gelatina/MMT e Gelatina/ATB foi de 2,4, 2,4 e 2,5 respectivamente. Observou-se que a dimensão fractal do lado placa do filme de Gelatina foi igual à do lado ar, sendo então superfícies muito lisas. O valor da dimensão fractal para o filme de Gelatina/MMT foi menor no lado placa que no lado ar, o que indica que a superfície em contato com a placa foi mais lisa. O filme de Gelatina/ATB não mostrou diferença significativa $(\mathrm{p}>0,05)$ do valor de dimensão fractal em seus dois lados, os valores deste parâmetro indicam que as superfícies deste filme são heterogêneas e rugosas.

Com base nos resultados obtidos na análise de imagem, encontrou-se que houve uma relação entre os valores da dimensão fractal e os parâmetros de rugosidade, pois a dimensão fractal é um parâmetro que está associado diretamente com a rugosidade de uma imagem. Portanto, os filmes que tiveram altos valores de rugosidade (Gelatina/MMT e Gelatina/ATB) apresentaram altos valores de dimensão fractal, enquanto que no caso do filme de Gelatina, que exibiu um baixo valor de $R_{a}$ e $R_{q}$, apresentou um baixo valor de dimensão fractal com relação aos outros filmes. Em trabalhos prévios, uma relação entre parâmetros de rugosidade e valores de dimensão fractal já tinha sido reportada, Villalobos et al. (2005) mencionaram que os valores de dimensão fractal de filmes de hidroxipropilmetilcelulose (HPMC) contendo surfactantes apresentaram um patrão similar aos parâmetros de rugosidade $R_{a}$ e $R_{q}$. Assim 
também, Arzate-Vázquez et al. (2012) apresentaram a mesma relação entre a dimensão fractal e os parâmetros de rugosidade para filmes elaborados de quitosana e alginato.

A relação entre a dimensão fractal e os parâmetros de rugosidade para os filmes à base de gelatina, obtidos mediante AFM, no presente trabalho, pode ser observada na Figura 22, verificando-se uma relação linear entre aquelas propriedades.

Figura 22 - Relação Dimensão fractal (DF) - Rugosidade $\left(\mathrm{R}_{\mathrm{a}}, \mathrm{R}_{\mathrm{q}}\right)$ para os filmes à base de gelatina (G: Gelatina; G/MMT: Gelatina/MMT; G/ATB: Gelatina/ATB): Lado ar (a), Lado placa (b)
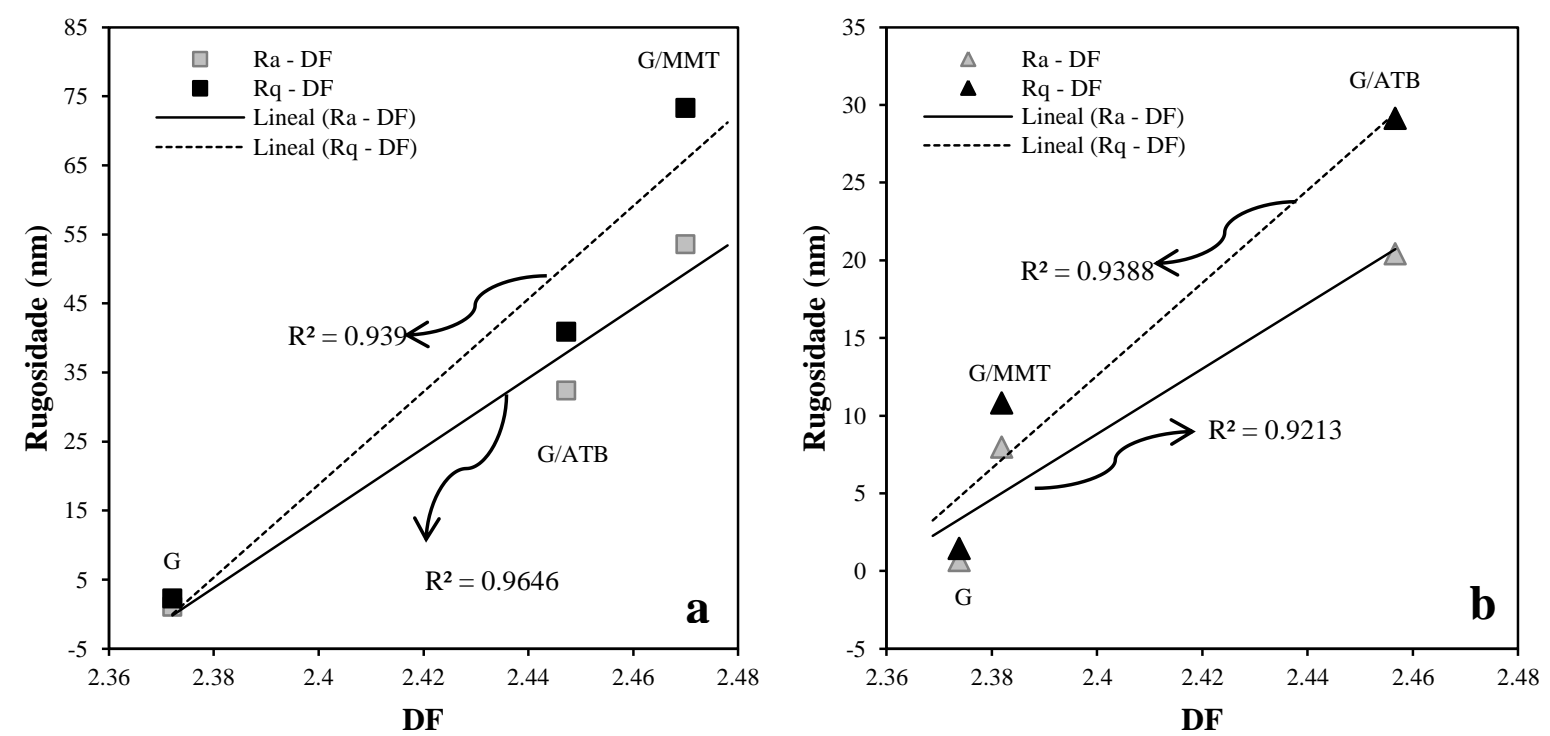

Fonte: Própria autoria.

\subsubsection{Propriedades superficiais dos filmes}

\subsubsection{1. Ângulo de contato}

O valor do ângulo de contato (AC) da gota de água pode indicar a hidrofobicidade/hidrofilicidade da superfície do filme. Na pratica, um AC grande (ou baixo valor para $\cos \theta$ ) representa uma superfície hidrofóbica, ao passo que, um AC pequeno (ou alto 
valor para $\cos \theta$ ) indica uma superfície hidrofílica. A diferença quantitativa entre superfícies "hidrofóbicas" e "hidrofílicas" é baseada no AC formado quando o solvente utilizado é a água, sendo $\theta>65^{\circ}$ equivalente à uma superfície hidrofóbica, e $\theta<65^{\circ}$ equivalente a uma superfície hidrofílica (VOGLER, 1998).

A molhabilidade, ou coeficiente de espalhamento, representa a capacidade de um determinado líquido de expandir-se sobre uma superfície sólida. O valor máximo que se pode obter para este coeficiente é zero (RIBEIRO, et al., 2007). Assim, na Tabela 9 encontram-se os valores do $\mathrm{AC}$, trabalho de adesão $\left(\mathrm{W}_{\mathrm{a}}\right)$ e o coeficiente de espalhamento $\left(\mathrm{S}_{\mathrm{e}}\right)$ da gota de água para os filmes à base de gelatina em um tempo de avaliação de 60 segundos. Foram analisados ambas as superfícies dos filmes, chamadas, lado ar e lado placa.

Tabela 9 - Dados de ângulo de contato $(\theta)$, trabalho de adesão $\left(\mathrm{W}_{\mathrm{a}}\right)$ e coeficiente de espalhamento $\left(\mathrm{S}_{\mathrm{e}}\right)$ dos filmes a base de gelatina para um tempo de 60 segundos

\begin{tabular}{|c|c|c|c|c|}
\hline Filmes & $\theta\left({ }^{\circ}\right)$ & $\mathrm{W}_{\mathrm{c}}(\mathrm{mN} / \mathrm{m})$ & $\mathrm{W}_{\mathrm{a}}(\mathrm{mN} / \mathrm{m})$ & $\mathrm{S}_{\mathrm{e}}(\mathrm{mN} / \mathrm{m})$ \\
\hline \multicolumn{5}{|c|}{ Lado ar } \\
\hline Gelatina & $98,9 \pm 2,0^{\mathrm{a}, \mathrm{A}}$ & 145,6 & $61,5 \pm 2,5^{\mathrm{b}, \mathrm{A}}$ & $-84,1 \pm 2,5^{\mathrm{b}, \mathrm{A}}$ \\
\hline Gelatina/MMT & $99,4 \pm 3,7^{\mathrm{a}, \mathrm{A}}$ & 145,6 & $61,0 \pm 4,6^{\mathrm{b}, \mathrm{A}}$ & $-84,6 \pm 4,6^{\mathrm{b}, \mathrm{A}}$ \\
\hline Gelatina/ATB & $79,9 \pm 1,9^{\mathrm{b}, \mathrm{A}}$ & 145,6 & $85,6 \pm 2,3^{\mathrm{a}, \mathrm{A}}$ & $-60,0 \pm 2,3^{\mathrm{a}, \mathrm{A}}$ \\
\hline \multicolumn{5}{|c|}{ Lado placa } \\
\hline Gelatina & $90,3 \pm 3,7^{\mathrm{b}, \mathrm{B}}$ & 145,6 & $72,4 \pm 4,7^{\mathrm{b}, \mathrm{B}}$ & $-73,2 \pm 4,7^{\mathrm{b}, \mathrm{B}}$ \\
\hline Gelatina/MMT & $108,4 \pm 0,3^{\mathrm{a}, \mathrm{B}}$ & 145,6 & $49,8 \pm 0,3^{\mathrm{c}, \mathrm{B}}$ & $-95,8 \pm 0,3^{\mathrm{c}, \mathrm{B}}$ \\
\hline Gelatina/ATB & $70,1 \pm 1,5^{\mathrm{c}, \mathrm{B}}$ & 145,6 & $97,6 \pm 1,8^{\mathrm{a}, \mathrm{B}}$ & $-48,0 \pm 1,8^{\mathrm{a}, \mathrm{B}}$ \\
\hline
\end{tabular}

Fonte: Própria autoria.

Observou-se que houve diferença estatística significativa $(\mathrm{p}<0,05)$ entre os lados dos diferentes filmes estudados. Além disso, para o lado ar dos filmes, somente o filme de Gelatina/ATB apresentou uma diferença estatística significativa com relação aos filmes de 
Gelatina e Gelatina/MMT, sendo que estes últimos apresentaram valores bastante semelhantes para o AC $\left(\sim 99^{\circ}\right)$. Considerando-se o lado placa, foi observada diferença estatística significativa $(\mathrm{p}<0,05)$ entre todos os valores de ângulo de contato dos filmes.

O filme de gelatina apresentou um valor de $\mathrm{AC}$ igual à $98,9^{\circ}$ para o lado ar e $90,3^{\circ}$ para o lado placa, observando-se claramente que o lado ar do filme foi mais hidrofóbico que o lado placa. Este comportamento pode estar associado com a reorientação das cadeias laterais das moléculas do polímero (seus aminoácidos hidrofóbicos: leucina, valina, fenilalanina, isoleucina e metionina), observando-se uma orientação preferida dos restos hidrofóbicos na interface filme-ar (BIALOPIOTROWICZ; JANCZUK, 2001; FARRIS et al., 2011). Outros autores também encontraram elevados valores de AC para filmes de gelatina, como Flaker et al. (2015) e Jorge et al. (2014), com $95,4^{\circ}$ e $90,4^{\circ}$, respectivamente.

O filme de Gelatina/MMT apresentou um valor de AC de $99,4^{\circ}$ para o lado ar e $108,4^{\circ}$ para o lado placa. Esse comportamento foi contrário ao observado no filme de Gelatina, uma vez que o lado placa do filme de Gelatina/MMT apresentou o maior valor de AC. Isso pode ser devido à migração do plastificante glicerol (plastificante altamente higroscópico), aliado à formação dos aglomerados de MMT na superfície do filme durante o processo de secagem, diminuindo, dessa forma, sua hidrofobicidade. Comportamentos similares foram observados para filmes de iota-carragena (KARBOWIAK et al., 2006) e filmes de quitosana (KUREK; GALUS; DEBEAUFORT, 2014), onde o lado do filme em contato com a placa teve os maiores valores de AC pela presença de glicerol no lado ar do filme. Por outro lado, Tunç e Duman (2010) mencionaram que a MMT tem um caráter hidrofílico, podendo sua adição implicar em uma diminuição do AC do lado ar do filme comparado ao lado placa. Jorge et al. (2014) observaram que a adição de MMT em filmes de gelatina não afetou os valores de AC e por consequência não afetou a sua hidrofobicidade. 
O filme de Gelatina/ATB apresentou o mesmo comportamento que o filme de Gelatina, pois, neste filme o AC do lado ar foi maior que do lado placa. Este comportamento também foi reportado por Matsakidou, Biliaderis e Kiosseoglou (2013), quando elaboraram filmes comestíveis à base de caseinato de sódio incorporados com óleo de gérmen de milho. Galus e Kadzińska (2016) estudaram a influência de óleos de amêndoas e nozes na matriz dos filmes de proteína de soro de leite, e também observaram que o AC da superfície em contato com o ar de secagem foi maior que o AC da superfície em contato com o suporte (placa). Esse comportamento pode estar ligado à acumulação de gotículas do ATB na superfície do filme como resultado do fenômeno de separação de fase durante o processo de secagem do filme de Gelatina/ATB.

Ao contrário do esperado, o filme de Gelatina/ATB apresentou os menores valores de AC (lado ar: $79,9^{\circ}$, lado placa: $70,1^{\circ}$ ) em relação aos outros filmes. O filme de Gelatina/ATB contém em sua matriz um plastificante hidrofóbico, o que sugeriria um comportamento mais hidrofóbico em relação aos outros filmes elaborados neste estudo. Entretanto, a presença do emulsificante (lecitina de soja), que possui caráter anfifílico, pode ter acarretado em uma diminuição do ângulo de contato dos filmes em ambas as superfícies, quando comparado aos demais filmes deste estudo. Na Figura 23 tem-se uma ilustração que esquematiza a arranjo estrutural das substâncias na presença de um agente surfactante, sendo que em (a) o filme encontra-se sem o agente surfactante e em (b) tem-se a presença do agente surfactante (TONGNUANCHAN; BENJAKUL; PRODPRAN, 2014). 
Figura 23 - Ilustração simplificada da matriz do filme de gelatina sem (a) e com óleo essencial (b) na presença de surfactante

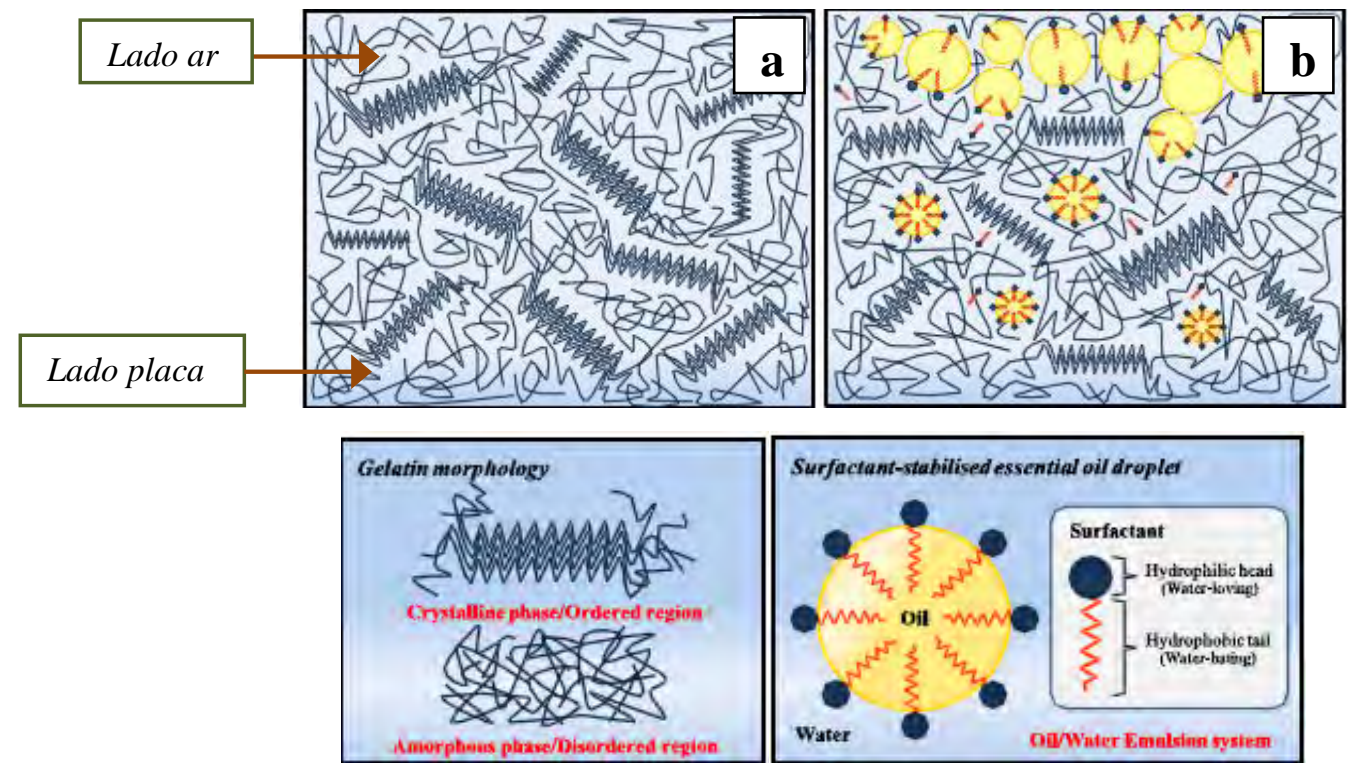

Fonte: Tongnuanchan, Benjakul e Prodpran (2014).

\subsubsection{Molhabilidade ou Coeficiente de Espalhamento $\left(\mathrm{S}_{\mathrm{e}}\right)$}

O trabalho de adesão $\left(\mathrm{W}_{\mathrm{a}}\right)$, que é definido como a energia por unidade de área requerida para separar duas fases (SLAVUTSKY; BERTUZZI, 2015), apresenta seu maior valor para o filme de Gelatina/ATB (Tabela 9 e Figura 24), sendo estes valores iguais à 85,6 $\mathrm{mN} / \mathrm{m}$ e $97,6 \mathrm{mN} / \mathrm{m}$ para o lado ar e lado placa, respectivamente. Isso indica que a água tem forte aderência por este filme em comparação aos outros filmes deste estudo, onde para o filme de Gelatina os valores de $\mathrm{W}_{\mathrm{a}}$ foram: lado ar $61,5 \mathrm{mN} / \mathrm{m}$; lado placa $72,4 \mathrm{mN} / \mathrm{m}$ e para o filme de Gelatina/MMT foram: lado ar, $61,0 \mathrm{mN} / \mathrm{m}$; lado placa, 49,8 mN/m.

Guettler, Moresoli e Simon (2013) trabalhando com materiais à base de soja reportaram valores de $\mathrm{W}_{\mathrm{a}}$ entre 78,2 a 120,2 mN/m sugerindo que esses materiais possuíram características hidrofílicas. Os valores de $\mathrm{W}_{\mathrm{a}}$ dos filmes de Gelatina/ATB estão dentro desta faixa. Basiak, Debeaufort e Lenart (2015) encontraram valores entre 118,1 a 126,8 mN/m para 
filmes de amido, sendo estes filmes com maior afinidade pela água que os filmes elaborados neste trabalho.

A tendência de um líquido a expandir-se sobre uma superfície e dada pelo coeficiente de espalhamento $\left(\mathrm{S}_{\mathrm{e}}\right)$. No caso dos filmes à base de gelatina elaborados neste estudo (Tabela 9 e Figura 25), o filme de Gelatina/ATB apresentou os valores do coeficiente de espalhamento menos negativos (lado ar: $-60,0 \mathrm{mN} / \mathrm{m}$ e lado placa: $-48,0 \mathrm{mN} / \mathrm{m}$ ), sugerindo que este filme apresentou características menos hidrofóbicas em comparação com os outros dois filmes elaborados (Gelatina e Gelatina/MMT) para ambos os lados.

Além disso, os filmes de Gelatina e Gelatina/MMT apresentaram os mesmos valores de $S_{e}$ no lado ar, reforçando as informações obtidas a partir dos valores para o ângulo de contato (AC). Avaliando-se o lado placa, o filme de Gelatina/MMT apresentou um valor mais negativo, indicando que este filme possui uma maior propriedade hidrofóbica $(-95,8 \mathrm{mN} / \mathrm{m})$, em relação ao filme de gelatina. Outros estudos, como por exemplo, Basiak, Debeaufort e Lenart (2015) que trabalharam com filmes de amido obtiveram valores de coeficiente de espalhamento que variaram de $-7,8$ a $-6,2 \mathrm{mN} / \mathrm{m}$. Slavutsky e Bertuzzi (2015) trabalharam com filmes de amido nanolaminados com óleo de girassol e encontraram valores de $S_{e}$ iguais à $-18,2$ mN/m. 
Figura 24 - Valores de Trabalho de Adesão, $\mathrm{W}_{\mathrm{a}}(\mathrm{mN} / \mathrm{m})$ e Coeficiente de Espalhamento, $\mathrm{S}_{\mathrm{e}}$ $(\mathrm{mN} / \mathrm{m})$ para os filmes à base de gelatina, lado ar e lado placa
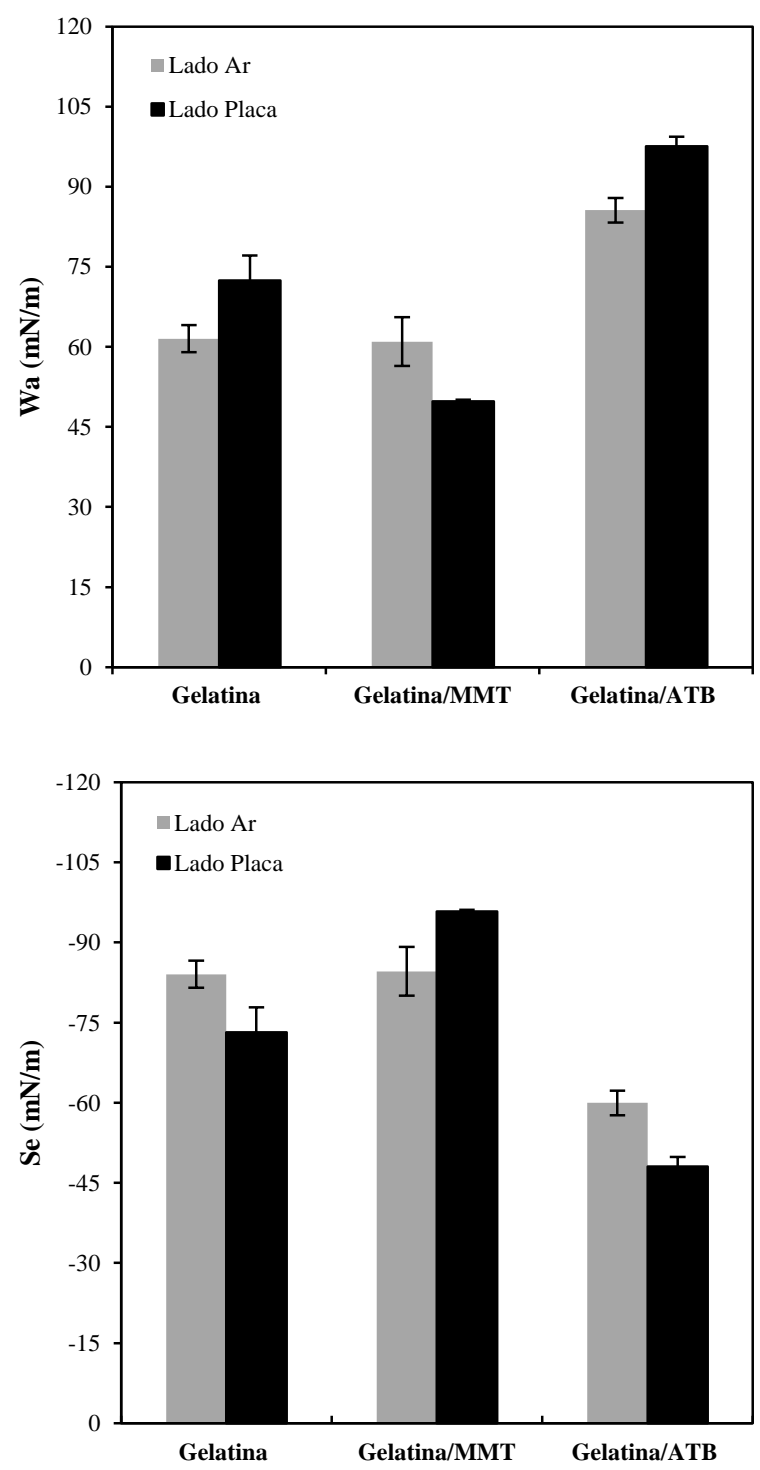

Fonte: Própria autoria.

As imagens capturadas para as gotas de água depositadas sobre os filmes em diferentes tempos estão representadas na Figura 25. Essa figura ilustra o comportamento para o ângulo de contato nos filmes (AC), corroborando com a discussão para as demais propriedades de superfície, como $\mathrm{W}_{\mathrm{a}}$ e o $\mathrm{S}_{\mathrm{e}}$. 
Figura 25 - Imagens das gotas de água capturadas imediatamente depois da deposição da gota $\left(\mathrm{t}_{0}\right)$, depois de $30 \mathrm{~s},\left(\mathrm{t}_{30}\right)$ e depois de $60 \mathrm{~s}\left(\mathrm{t}_{60}\right)$ de análise

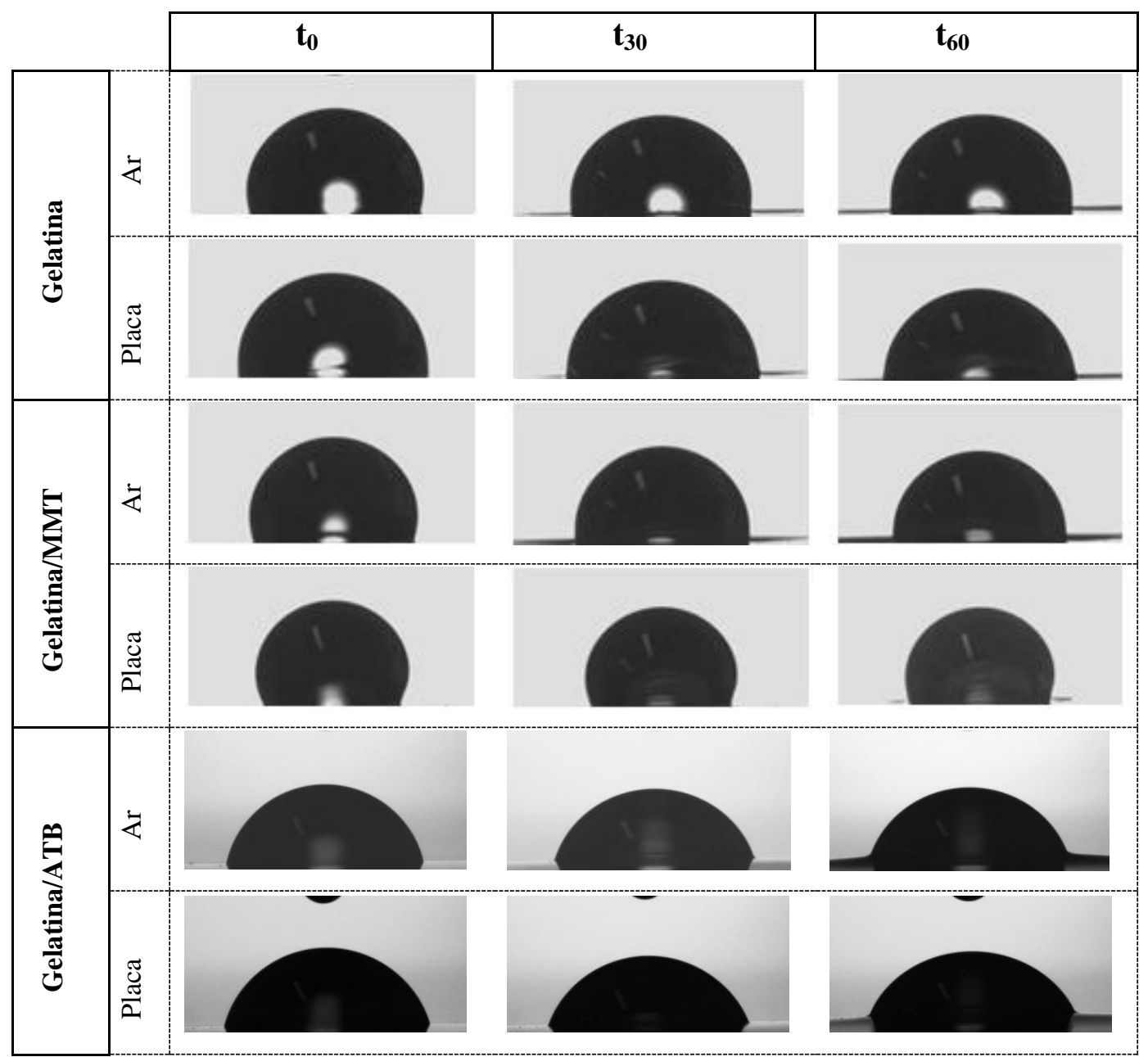

Fonte: Própria autoria

\subsubsection{Modelagem da cinética do ângulo de contato}

Os principais fenômenos envolvidos na interface da gota de água-filmes são: absorção, difusão, inchamento e evaporação (FARRIS et al., 2011). Assim, neste estudo, a contribuição da evaporação na cinética do comportamento do ângulo de contato foi examinada. A análise foi realizada mediante a medida direta do AC sobre um substrato plástico (Polietileno de baixa densidade, PEBD), de acordo com a metodologia proposta por Karbowiak et al. (2006). O AC da gota de água sobre o PEBD no momento da deposição, que é o tempo zero, foi de $93,0 \pm 1,5^{\circ}$ e no tempo de 60 segundos de $90,7 \pm 2,0^{\circ}$, não existindo diferença significativa ao 
longo do tempo de análise ( $\mathrm{p}>0,05)$. Considerando-se que o PEBD é hidrofóbico e portanto, não absorveu água, nem tampouco pode ter havido difusão na matriz polimérica, nem inchamento, a observada redução do AC só pode ter sido consequência da evaporação da água. Entretanto, considerando-se o resultado estatístico insignificante, pode-se sugerir que o efeito da evaporação foi desprezível.

Em relação aos resultados obtidos com os filmes de gelatina, observou-se que a maior variação do AC durante o período de avalição foi para os filmes de Gelatina pura (lado ar: 6,7\%; lado placa: -9,6\%) e Gelatina/MMT (lado ar: -10,3\%; lado placa: -7,3\%) (Tabela 10). Já o filme de Gelatina/ATB teve a menor variação em relação aos outros filmes deste estudo (lado ar: 2,6 \%, lado placa: 5,0 \%). Este comportamento sugere que os filmes de Gelatina e Gelatina/MMT foram mais afetados pelos fenômenos de absorção e espalhamento que o filme de Gelatina/ATB, muito possivelmente devido à presença do plastificante hidrofóbico.

Tabela 10 - Variação do ângulo de contato da gota de água sobre os filmes de gelatina durante o período de avaliação de 60 segundos

\begin{tabular}{lcccc}
\hline \multicolumn{1}{c}{ Filmes } & $\boldsymbol{\theta}\left({ }^{\circ}\right) / \mathbf{t}_{\mathbf{0}}$ & $\boldsymbol{\theta}\left({ }^{\circ}\right) / \mathbf{t}_{\mathbf{6 0}}$ & $\Delta \boldsymbol{\theta}\left({ }^{\circ}\right) / \mathbf{t}_{\mathbf{6 0}}-\mathbf{t}_{\mathbf{0}}$ & $\Delta \boldsymbol{\theta}^{*}(\boldsymbol{\%})$ \\
\hline \multirow{2}{*}{ Gelatina } & \multicolumn{1}{c}{ Lado $\mathbf{a r}$} \\
Gelatina/MMT & $106,0 \pm 2,6^{\mathrm{a}, \mathrm{A}, 1}$ & $98,9 \pm 2,0^{\mathrm{a}, \mathrm{A}, 2}$ & $7,1 \pm 2,6$ & 6,7 \\
Gelatina/C.ATB & $82,0 \pm 0,6^{\mathrm{b}, \mathrm{A}, 1}$ & $79,9 \pm 1,9^{\mathrm{b}, \mathrm{A}, 1}$ & $2,1 \pm 1,9$ & 2,6 \\
\hline
\end{tabular}

\section{Lado placa}

Gelatina

$$
99,9 \pm 3,9^{\mathrm{b}, \mathrm{B}, 1}
$$

$90,3 \pm 3,7^{\mathrm{b}, \mathrm{B}, 2}$

$9,6 \pm 1,0$

9,6

Gelatina/MMT

$$
116,9 \pm 2,3^{\mathrm{a}, \mathrm{B}, 1}
$$

$108,4 \pm 0,3^{\mathrm{a}, \mathrm{B}, 2}$

$8,5 \pm 2,4$

Gelatina/C.ATB

$$
73,8 \pm 0,1^{\mathrm{c}, \mathrm{B}, 1}
$$

$70,1 \pm 1,5^{\mathrm{c}, \mathrm{B}, 2}$

$3,7 \pm 1,4$

Letras minúsculas diferentes na mesma coluna em cada lado indicam diferença significativa $(p<0,05)$ entre as medias dos ângulos de contato; letras maiúsculas diferentes entre os lados indicam diferença significativa $(\mathrm{p}<0,05)$ entre as medias dos lados para cada filme; números diferentes na mesma linha em cada lado indicam diferença significativa $(p<0,05)$ entre as medias dos tempos. A diferença entre as medias foi obtida pelo teste de Tukey, utilizando-se o software STATGRAPHICS Centurion 16.1. * Percentual em relação a $\theta\left({ }^{\circ}\right) / \mathrm{t}_{0}$.

Fonte: Própria autoria. 
Contudo, ao final do período de observação dos filmes contendo $\mathrm{ATB}$, em relação à cinética do AC (Figura 26), observou-se que o AC aumentou e apresentou um comportamento irregular. Essa tendência foi mais evidente no lado ar do filme, e pode estar relacionada com o inchamento do filme em contato com a gota de água, e além disso, pode ter havido solubilização parcial do surfactante na gota de água. Este fenômeno de inchamento dos filmes emulsionados já tinha sido reportado por outros autores como Karbowiak et al. (2006), Kokoszka et al. (2010) e Galus e Kadzińska (2016).

Também se pode observar nas cinéticas do AC (Figura 26), os resultados dos ajustes da eq. (17) aos valores experimentais do ângulo de contato, obtidos por regressão não linear. Os coeficientes de ajuste $\left(\mathrm{r}^{2}\right)$ estão indicados na Tabela 11, onde se pode notar que houve uma boa correlação entre os dados experimentais de $\mathrm{AC}$ dos filmes à base de gelatina: maiores valores de $r^{2}$ para os filmes de Gelatina e Gelatina/MMT $\left(r^{2}>0,96\right)$, e menor $r^{2}$ para o lado ar do filme de Gelatina/ATB, muito possivelmente devido ao fenômeno de inchamento, ocorrido em maior quantidade neste lado do filme.

Tabela 11 - Parâmetros de ajuste da eq. (17) para a cinética de ângulo de contato dos filmes e valores da primeira derivada das curvas ajustadas

\begin{tabular}{|c|c|c|c|c|c|}
\hline \multirow{2}{*}{ Filmes } & \multicolumn{3}{|c|}{ Parâmetros* } & \multirow[b]{2}{*}{$\mathbf{r}^{2}$} & \multirow{2}{*}{$\begin{array}{l}\partial \theta / \partial t \\
\left({ }^{\circ} s^{-1}\right)\end{array}$} \\
\hline & $\boldsymbol{\theta}$ & $\mathbf{k}$ & $\mathbf{n}$ & & \\
\hline \multicolumn{6}{|c|}{ Lado ar } \\
\hline Gelatina & 106,9 & $-0,010$ & 0,51 & 0,98 & $-1,07$ \\
\hline Gelatina/MMT & 112,0 & $-0,010$ & 0,61 & 0,97 & $-1,15$ \\
\hline Gelatina/C.ATB & 82,6 & $-0,002$ & 0,79 & 0,88 & $-0,15$ \\
\hline \multicolumn{6}{|c|}{ Lado placa } \\
\hline Gelatina & 100,9 & $-0,005$ & 0,76 & 0,98 & $-0,54$ \\
\hline Gelatina/MMT & 118,4 & $-0,003$ & 0,81 & 0,96 & $-0,41$ \\
\hline Gelatina/C.ATB & 75,5 & $-0,003$ & 0,75 & 0,92 & $-0,26$ \\
\hline
\end{tabular}

*Ajuste a um nível significativo de 5\%.

Fonte: Própria autoria. 
Figura 26 - Cinética do ângulo de contato e seu ajuste para os filmes à base de gelatina
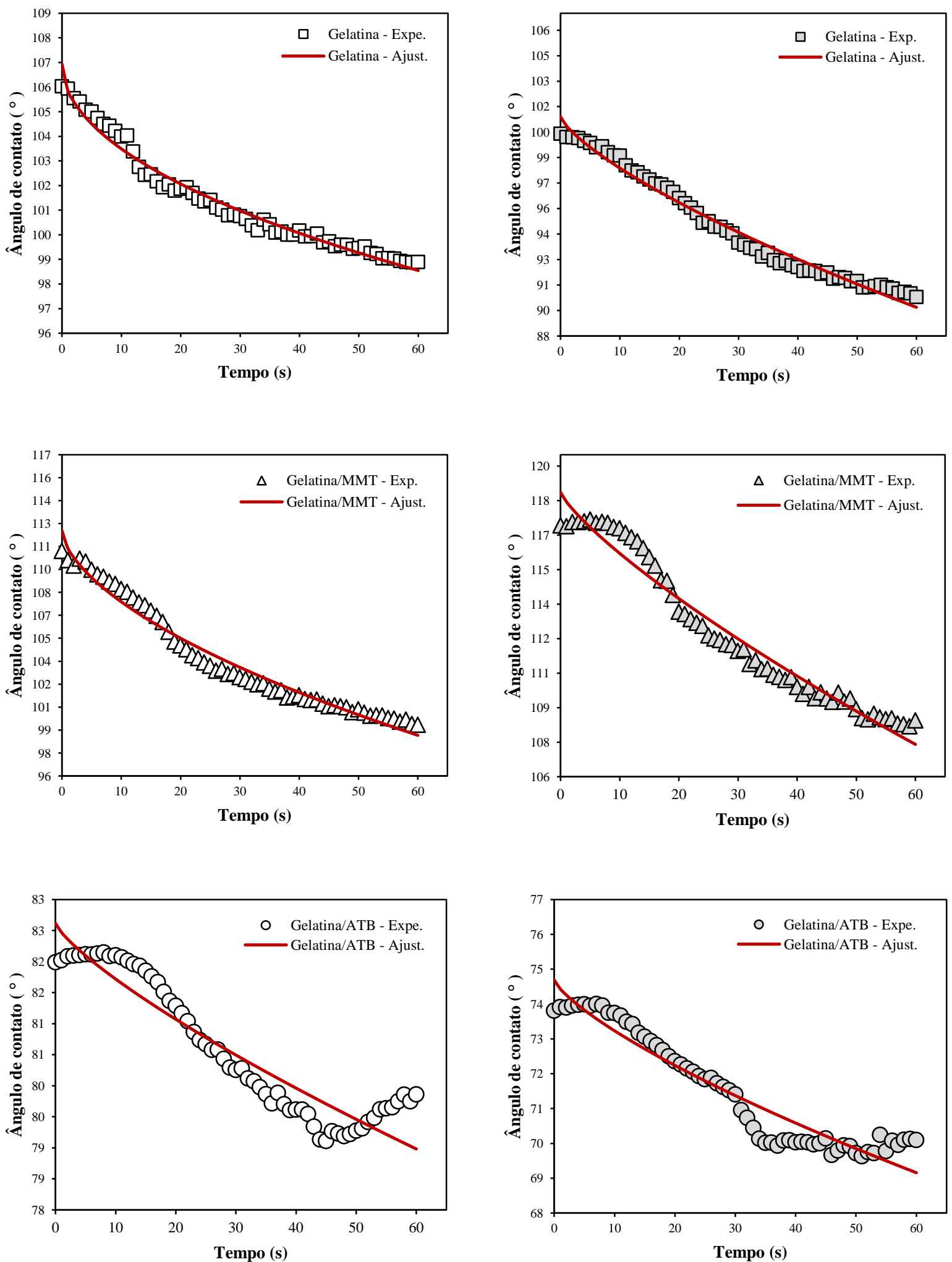

Fonte: Própria autoria. 
Em relação ao parâmetro "k", houve indícios de que existe uma correlação com a taxa de evolução do AC ( $\partial \theta / \partial \mathrm{t})$ para os filmes elaborados neste estudo. Farris et al. (2011) também obtiveram resultados semelhantes. Pode-se observar que para os filmes Gelatina e Gelatina/MMT, os valores foram muito superiores para o lado ar dos filmes.

O parâmetro " $n$ " está relacionado com os fenômenos de absorção e espalhamento (FARRIS et al., 2011). Teoricamente valores de $n=0$ e $n=1$ indicam uma absorção pura e espalhamento puro, respectivamente. Como os valores obtidos para "n" deste estudo (Tabela 11) ficaram mais próximos de 1 , pode-se sugerir que apesar de ter ocorrido ambos os fenômenos de absorção e espalhamento, este último foi mais predominante, durante o contato do filme com a gota de água.

\subsubsection{Correlação entre o ângulo de contato e a rugosidade}

As informações de ângulo de contato (AC), rugosidade e a estrutura dos filmes à base de gelatina elaborados neste estudo estão compiladas na Figura 27, onde se pode observar que não houve uma relação entre os valores da rugosidade dos filmes e seus respectivos $\mathrm{AC}$, não se encontrando, portanto uma correlação significativa segundo o mostrado na Tabela 12. Contrariamente, Resa, Jagus e Gerschenson (2014) estudaram o efeito da adição de natamicina, nisina (agentes antimicrobianos) e glicerol sobre as propriedades físico-químicas, rugosidade e hidrofobicidade de filmes de amido de mandioca e observaram que maiores valores do AC foram relacionados com uma maior rugosidade desses filmes. 
Figura 27 - Valores de ângulos de contato e rugosidade dos filmes à base de gelatina

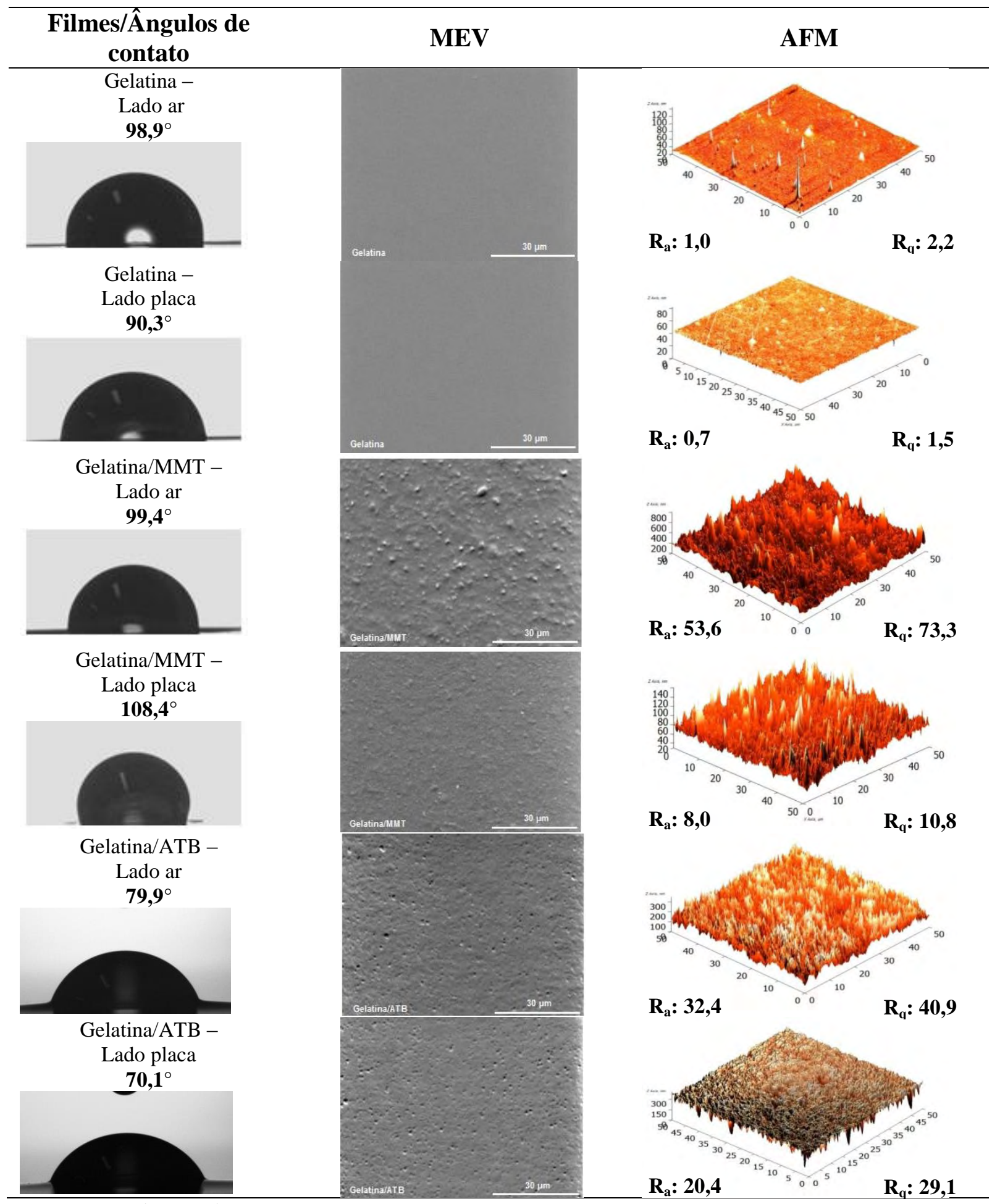

Fonte: Própria autoria.

O mesmo foi observado por Muscat et al. (2013) que estudaram a hidrofobicidade de filmes de amido com alto teor de amilose adicionados de três diferentes ceras naturais (cera de abelha, cera de candelila e cera de carnaúba) com e sem Tween-80. Esses autores observaram 
que altos valores de AC foram obtidos nos filmes contendo cera de carnaúba e Tween-80, e que este comportamento foi relacionado com a alta rugosidade dos filmes.

Tabela 12 - Correlação entre os valores de Rugosidade e Ângulo de contato

\begin{tabular}{lcc}
\hline Ângulo de contato $\left({ }^{\circ}\right)$ & $\mathbf{R a}(\mathbf{n m})$ & $\mathbf{R q}(\mathbf{n m})$ \\
\hline Lado ar & $-0,091$ & $-0,031$ \\
& $\mathbf{0 , 9 4 2} \mathrm{ns}$ & $\mathbf{0 , 9 8 1} \mathrm{ns}$ \\
Lado placa & $-0,648$ & $-0,674$ \\
& $\mathbf{0 , 5 5 1} \mathrm{ns}$ & $\mathbf{0 , 5 2 9} \mathrm{ns}$ \\
\hline
\end{tabular}

A significância estatística é apresentada em negrito.

* Coeficientes significativos $(\mathrm{p}<0,05)$.

ns: Coeficientes não significativos.

Fonte: Própria autoria.

\subsubsection{Energia livre superficial}

Os valores de energia livre superficial para os filmes à base de gelatina estão apresentados na Tabela 13. Está evidente os baixos valores obtidos para a componente polar $\left(\gamma_{\mathrm{S}}^{\mathrm{P}}\right)$, podendo assim, justificar os resultados obtidos para o $\mathrm{AC}$ da gota de água para os filmes deste estudo. $\mathrm{O}$ valor da $\gamma_{\mathrm{S}}{ }^{\mathrm{P}}$ para o filme de Gelatina teve um valor de $0,24 \mathrm{nN} / \mathrm{m}$ para o lado ar e 1,41 mN/m para o lado placa, sendo menores que os reportados por Farris et al. (2011) $(2,23 \mathrm{mN} / \mathrm{m})$ para filmes de gelatina.

Os baixos valores da componente polar da energia livre superficial obtidos neste estudo podem explicar o caráter hidrofóbico do filme de Gelatina, como já foi observado nos AC $\left(98,9^{\circ}\right.$ lado ar e $90,3^{\circ}$ lado placa), sugerindo que os grupos hidrofóbicos da gelatina se orientaram na superfície do filme (BIALOPIOTROWICZ; JANCZUK, 2001). Os valores (Tabela 13) para a componente dispersa $\left(\gamma_{\mathrm{S}}^{\mathrm{D}}\right)$ estão de acordo com o reportado por Farris et al. (2011) $(35,16 \mathrm{mN} / \mathrm{m})$ para filmes de gelatina. 
Tabela 13 - Valores de energia livre superficial $\left(\gamma_{S}\right)$ e seus componentes polar $\left(\gamma_{S}{ }^{\mathrm{P}}\right)$ e dispersa $\left(\gamma_{\mathrm{S}}{ }^{\mathrm{D}}\right)(\mathrm{mN} / \mathrm{m})$ mediante o método de Owens e Wendt para os filmes à base de gelatina

\begin{tabular}{lccc}
\hline Filmes & \multicolumn{1}{c}{$\gamma_{\mathbf{S}}$} & $\gamma_{\mathbf{s}}^{\mathbf{p}}$ & $\gamma_{\mathbf{S}}^{\mathbf{D}}$ \\
\hline Gelatina & $36,2 \pm 0,3^{\mathrm{a}, \mathrm{A}}$ & $0,24 \pm 0,08^{\mathrm{a}, \mathrm{A}}$ & $36,0 \pm 0,4^{\mathrm{a}, \mathrm{A}}$ \\
Gelatina/MMT & $39,5 \pm 0,4^{\mathrm{b}, \mathrm{A}}$ & $0,13 \pm 0,10^{\mathrm{a}, \mathrm{A}}$ & $39,4 \pm 0,3^{\mathrm{b}, \mathrm{A}}$ \\
Gelatina/ATB & $42,7 \pm 1,0^{\mathrm{c}, \mathrm{A}}$ & $3,27 \pm 0,71^{\mathrm{b}, \mathrm{A}}$ & $39,4 \pm 0,3^{\mathrm{b}, \mathrm{A}}$ \\
\hline & \multicolumn{2}{c}{ Lado placa } \\
Gelatina & $39,6 \pm 0,6^{\mathrm{a}, \mathrm{B}}$ & $1,41 \pm 0,79^{\mathrm{a}, \mathrm{A}}$ & $38,2 \pm 0,2^{\mathrm{a}, \mathrm{AB}}$ \\
Gelatina/MMT & $37,9 \pm 1,3^{\mathrm{a}, \mathrm{AB}}$ & $0,29 \pm 0,08^{\mathrm{a}, \mathrm{A}}$ & $37,6 \pm 1,2^{\mathrm{a}, \mathrm{AB}}$ \\
Gelatina/ATB & $44,3 \pm 0,1^{\mathrm{b}, \mathrm{A}}$ & $7,54 \pm 0,16^{\mathrm{b}, \mathrm{B}}$ & $36,7 \pm 0,0^{\mathrm{a}, \mathrm{B}}$ \\
\hline
\end{tabular}

Letras minúsculas diferentes na mesma coluna em cada lado indicam diferença significativa $(\mathrm{p}<0,05)$ entre as medias de $\gamma_{\mathrm{S}}$, $\gamma_{\mathrm{S}}^{\mathrm{P}}$ e $\gamma_{\mathrm{S}}{ }^{\mathrm{D}}$; letras maiúsculas diferentes entre os lados indicam diferença significativa $(\mathrm{p}<0,05)$ entre as medias dos lados para cada filme. A diferença entre as medias foi obtida pelo teste de Tukey, utilizando-se o software STATGRAPHICS Centurion 16.1.

Fonte: Própria autoria.

Para os filmes elaborados neste estudo, de maneira geral, os valores da componente polar da energia livre superficial $\left(\gamma_{\mathrm{S}}{ }^{\mathrm{P}}\right)$ foram maiores para a superfície em contato com a placa (lado placa) do que para a superfície em contato com o ar de secagem (lado ar). Dessa forma, esses resultados de $\gamma_{S}{ }^{P}$ refletiram nos resultados para os ângulos de contato dos filmes (AC). A $\gamma_{\mathrm{S}}{ }^{\mathrm{P}}$ para o filme de Gelatina/MMT teve ainda menores valores com relação ao filme de Gelatina. A interação entre a gelatina e a MMT ocorreu por ligações de hidrogênio entre os grupos NH da gelatina e Si-O da MMT (RHIM, 2011). Assim, as ligações intermoleculares (pontes de hidrogênio) formadas pelos componentes da gelatina e a MMT foram mais fortes que as ligações formadas por a MMT, gelatina e a água. Isso evitou a interação dos filmes com a água e reduziu a hidrofilicidade do filme. Comportamento similar foi observado por outros autores (ECHEVERRÍA; EISENBERG; MAURI, 2014; SLAVUTSKY; BERTUZZI, 2012; TUNÇ; DUMAN, 2010). 
No caso do filme de Gelatina/ATB, observou-se valores de $\gamma_{\mathrm{S}}{ }^{\mathrm{P}}$ maiores que dos outros dois filmes, $3,27 \mathrm{mN} / \mathrm{m}$ e $7,54 \mathrm{mN} / \mathrm{m}$, para o lado ar e lado placa, respectivamente. Isso pode estar relacionado à presença dos grupos polares do surfactante (lecitina de soja) que migraram para a superfície do filme.

Altos valores de energia livre superficial implicam em baixos valores de AC, o que corrobora com os resultados obtidos para as medições de ângulo de contato. No caso deste filme, os valores para o AC foram $77,8^{\circ}$ para o lado ar e $68,1^{\circ}$ para o lado placa. Dessa forma, o lado ar do filme apresentou um menor valor de $\gamma_{\mathrm{S}}{ }^{\mathrm{P}}$, isso porque pode ter havido migração do ATB na superfície do filme provocado pelos fenômenos de floculação, coalescência e separação de fase (BONILLA et al., 2012; SÁNCHEZ-GONZÁLEZ et al., 2010). 


\section{CONCLUSÕES}

Em geral, os filmes à base de gelatina elaborados nesta tese apresentaram uma boa aparência visual, com espessura, umidade, brilho, cor e opacidade em acordo com a literatura, tanto para os filmes de gelatina, como para os filmes adicionados de montmorillonita (MMT) e plastificados com o citrato de acetiltributila (ATB).

A adição de montmorillonita e o citrato de acetiltributila na matriz da solução filmogênica de gelatina provocou uma relevante mudança na sua estrutura, topografia e rugosidade, sendo mais evidente nos filmes de Gelatina/MMT.

Os parâmetros de textura da análise de imagem, especialmente a dimensão fractal (DF) mostrou ser uma ferramenta útil para a caracterização da textura superficial dos filmes à base de gelatina, encontrando-se uma correlação entre a DF e os valores de rugosidade.

Os três filmes apresentaram características hidrofóbicas $\left(\theta>65^{\circ}\right)$, sendo o filme de Gelatina/MMT o de maior hidrofobicidade, em relação aos filmes deste estudo. Ou seja, apresentou maior ângulo de contato, menores valores de coeficiente de adesão e coeficiente de espalhamento, seguido do filme de Gelatina e filme de Gelatina/ATB.

Por outro lado, o filme de Gelatina/ATB apresentou menores valores de hidrofobicidade, contrariamente ao esperado, por se utilizar um plastificante hidrofóbico, contudo concluiu-se que os baixos valores para o ângulo de contato foram atribuídos à migração do surfactante (lecitina de soja).

A equação empírica utilizada para modelar os valores da cinética de ângulo de contato dos filmes à base de gelatina apresentou uma boa correlação, o que pôde ser observado pelos altos valores de coeficiente de ajuste $\left(r^{2}=0,88\right.$ à 0,98$)$. Não foi encontrada uma correlação entre os valores do ângulo de contato e a rugosidade dos filmes à base de gelatina. 
Os valores da componente polar dos filmes refletiram os valores encontrados na determinação do ângulo de contato, sendo que os filmes com maiores valores de componente polar apresentaram os menores valores de ângulo de contato. 


\section{REFERÊNCIAS}

ARVANITOYANNIS, I. S. Formation and properties of collagen and gelatin films and coatings. In: GENNADIOS, A. Protein-based films and coatings. Boca Raton: CRC Press, 2002. cap. 11, p. 275304.

ACEVEDO-FANI, A. et al. Edible films from essential-oil-loaded nanoemulsions: Physicochemical characterization and antimicrobial properties. Food Hydrocolloids, Amsterdam, v. 47, p. 168-177, 2015.

ACOSTA, S. et al. Physical properties and stability of starch-gelatin based films as affected by the addition of esters of fatty acids. Food Hydrocolloids, Amsterdam, v. 49, p. 135-143, 2015.

AHMAD, M. et al. Optical and thermo-mechanical properties of composite films based on fish gelatin/rice flour fabricated by casting technique. Progress in Organic Coatings, Amsterdam, v. 84, p. 115-127, 2015.

ALBOOFETILEH, M. et al. Effect of montmorillonite clay and biopolymer concentration on the physical and mechanical properties of alginate nanocomposite films. Journal of Food Engineering, London, v. 117, n. 1, p. 26-33, 2013.

ANDRADE, R. et al. Wettability of gelatin coating formulations containing cellulose nanofibers on banana and eggplant epicarps. LWT - Food Science and Technology, London, v. 58, n. 1, p. 158$165,2014$.

ANDREUCCETTI, C.; CARVALHO, R. A.; GROSSO, C. R. F. Effect of hydrophobic plasticizers on functional properties of gelatin-based films. Food Research International, Kidlington, v. 42, n. 8, p. 1113-1121, 2009.

ARZATE-VÁZQUEZ, I. et al. Microstructural characterization of chitosan and alginate films by microscopy techniques and texture image analysis. Carbohydrate Polymers, Kidlington, v. 87, n. 1, p. 289-299, 2012.

ATARÉS, L.; BONILLA, J.; CHIRALT, A. Characterization of sodium caseinate-based edible films incorporated with cinnamon or ginger essential oils. Journal of Food Engineering, London, v. 100, n. 4, p. 678-687, 2010.

BASIAK, E.; DEBEAUFORT, F.; LENART, A. Effect of oil lamination between plasticized starch layers on film properties. Food Chemistry, In press. 2015. doi:10.1016/j.foodchem.2015.04.098.

BENBETTAÏEB, N. et al. Impact of electron beam irradiation on fish gelatin film properties. Food Chemistry, In press. 2015. doi:10.1016/j.foodchem.2015.03.034.

BERGO, P.; MORAES, I. C. F.; SOBRAL, P. J. A. Infrared spectroscopy, mechanical analysis, dielectric properties and microwave response of pigskin gelatin films plasticized with glycerol. Food Bioscience, Amsterdam, v. 1, p. 10-15, 2013.

BIALOPIOTROWICZ, T.; JANCZUK, B. The changes of the surface free energy of the adsorptive gelatin films. European Polymer Journal, Kidlington, v. 37, p. 1047-1051, 2001.

BONILLA, J. et al. Effect of essential oils and homogenization conditions on properties of chitosanbased films. Food Hydrocolloids, Amsterdam, v. 26, n. 1, p. 9-16, 2012. 
BONILLA, J. et al. Physical properties of chitosan-basil essential oil edible films as affected by oil content and homogenization conditions. Procedia Food Science Amsterdam, v. 1, p. 50-56, 2011.

CARVALHO, R. A. et al. Development of edible films based on differently processed Atlantic halibut (Hippoglossus hippoglossus) skin gelatin. Food Hydrocolloids, Amsterdam, v. 22, n. 6, p. 1117-1123, 2008.

CHOI, W. Y. et al. Wettability of Chitosan Coating Solution on " Fuji " Apple Skin. Journal of Food Science, Hoboken, v. 67, n. 7, p. 3-7, 2002.

ECHEVERRÍA, I.; EISENBERG, P.; MAURI, A. N. Nanocomposites films based on soy proteins and montmorillonite processed by casting. Journal of Membrane Science, Amsterdam, v. 449, p. 15-26, 2014.

FABRA, M. J. et al. Influence of the homogenization conditions and lipid self-association on properties of sodium caseinate based films containing oleic and stearic acids. Food Hydrocolloids, Amsterdam, v. 25, n. 5, p. 1112-1121, 2011.

FARRIS, S. et al. Wetting of biopolymer coatings: Contact angle kinetics and image analysis investigation. Langmuir, Washington, v. 27, p. 7563-7574, 2011.

FERNÁNDEZ, L.; CASTILLERO, C.; AGUILERA, J. M. An application of image analysis to dehydration of apple discs. Journal of Food Engineering, London, v. 67, n. 1-2, p. 185-193, 2005.

FERREIRA, A. S. et al. Influence of grape pomace extract incorporation on chitosan films properties. Carbohydrate Polymers, Kidlington, v. 113, p. 490-9, 2014.

FLAKER, C. H. C. et al. Gelatin-based nanocomposite films: a study on montmorillonite dispersion methods and concentration. Journal of Food Engineering, London, v. 167, Part A, p. 65-70, 2015.

GALUS, S.; KADZIŃSKA, J. Whey protein edible films modified with almond and walnut oils. Food Hydrocolloids, Amsterdam, v. 52, p. 78-86, 2016.

GONTARD, N.; GUILBERT, S.; CUQ, J. L. Edible wheat gluten film: Influence of the main variable on film properties using response methodology. Journal of Food Science, Chicago, v. 57, n. 1, p. 190-195, 1992.

GUETTLER, B. E.; MORESOLI, C.; SIMON, L. C. Contact angle and surface energy analysis of soy materials subjected to potassium permanganate and autoclave treatment. Industrial Crops and Products, Amsterdam, v. 50, p. 219-226, 2013.

JONGJAREONRAK, A. et al. Characterization of edible films from skin gelatin of brownstripe red snapper and bigeye snapper. Food Hydrocolloids, Amsterdam, v. 20, n. 4, p. 492-501, 2006.

JORGE, M. F. C. et al. Viscoelastic and rheological properties of nanocomposite-forming solutions based on gelatin and montmorillonite. Journal of Food Engineering, London, v. 120, n. 1, p. 81-87, 2014.

KANMANI, P.; RHIM, J. W. Physicochemical properties of gelatin/silver nanoparticle antimicrobial composite films. Food Chemistry, Amsterdam, v. 148, p. 162-169, 2014.

KARBOWIAK, T. et al. Wetting properties at the surface of iota-carrageenan-based edible films. Journal of Colloid and Interface Science, Maryland Heights, v. 294, n. 2, p. 400-410, 2006. 
KARBOWIAK, T.; DEBEAUFORT, F.; VOILLEY, A. Importance of surface tension characterization for food, pharmaceutical and packaging products: a review. Critical Reviews in Food Science and Nutrition, New York, v. 46, n. 5, p. 391-407, 2006.

KOKOSZKA, S. et al. Liquid and vapour water transfer through whey protein/lipid emulsion films. Journal of the Science of Food and Agriculture, Chichester, v. 90, n. 10, p. 1673-1680, 2010.

KUJAWA, J. et al. The influence of surface modification on the physicochemical properties of ceramic membranes. Colloids and Surfaces A: Physicochemical and Engineering Aspects, Amsterdam, v. 443, p. 567-575, 2014.

KUREK, M. et al. Carvacrol affects interfacial, structural and transfer properties of chitosan coatings applied onto polyethylene. Carbohydrate Polymers, Kidlington, v. 97, n. 1, p. 217-225, 2013.

KUREK, M.; GALUS, S.; DEBEAUFORT, F. Surface, mechanical and barrier properties of bio-based composite films based on chitosan and whey protein. Food Packaging and Shelf Life, Amsterdam, v. 1, n. 1, p. 56-67, 2014.

MA, W. et al. Characterization of gelatin-based edible films incorporated with olive oil. Food Research International, Kidlington, v. 49, n. 1, p. 572-579, 2012.

MARTUCCI, J. F. et al. Oregano and lavender essential oils as antioxidant and antimicrobial additives of biogenic gelatin films. Industrial Crops and Products, Amsterdam, v. 71, p. 205-213, 2015.

MATSAKIDOU, A.; BILIADERIS, C. G.; KIOSSEOGLOU, V. Preparation and characterization of composite sodium caseinate edible films incorporating naturally emulsified oil bodies. Food Hydrocolloids, Amsterdam, v. 30, n. 1, p. 232-240, 2013.

MENDOZA, F.; DEJMEK, P.; AGUILERA, J. M. Colour and image texture analysis in classification of commercial potato chips. Food Research International, Kidlington, v. 40, n. 9, p. 1146-1154, 2007.

MUSCAT, D. et al. The physicochemical characteristics and hydrophobicity of high amylose starchglycerol films in the presence of three natural waxes. Journal of Food Engineering, London, v. 119, n. 2, p. 205-219, 2013.

NAGARAJAN, M. et al. Characteristics of bio-nanocomposite films from tilapia skin gelatin incorporated with hydrophilic and hydrophobic nanoclays. Journal of Food Engineering, London, v. 143, p. 195-204, 2014.

RESA, C. P.; JAGUS, R. J.; GERSCHENSON, L. N. Effect of natamycin, nisin and glycerol on the physicochemical properties, roughness and hydrophobicity of tapioca starch edible films. Materials Science \& Engineering C: Materials for Biological Applications, Amsterdam, v. 40, p. 281-287, 2014.

PACKHAM, D. Surface energy, surface topography and adhesion. International Journal of Adhesion and Adhesives, London, v. 23, n. 6, p. 437-448, 2003.

RAMÍREZ, C. et al. Study of contact angle, wettability and water vapor permeability in carboxymethylcellulose (CMC) based film with murta leaves (Ugni molinae Turcz) extract. Journal of Food Engineering, London, v. 109, n. 3, p. 424-429, 2012.

RHIM, J. W. Effect of clay contents on mechanical and water vapor barrier properties of agar-based nanocomposite films. Carbohydrate Polymers, Kidlington, v. 86, n. 2, p. 691-699, 2011. 
RIBEIRO, C. et al. Optimization of edible coating composition to retard strawberry fruit senescence. Postharvest Biology and Technology, Amsterdam, v. 44, n. 1, p. 63-70, 2007.

RUDAWSKA, A.; JACNIACKA, E. Analysis for determining surface free energy uncertainty by the Owen-Wendt method. International Journal of Adhesion and Adhesives, London, v. 29, n. 4, p. 451-457, 2009.

SÁNCHEZ-GONZÁLEZ, L. et al. Physical and antimicrobial properties of chitosan-tea tree essential oil composite films. Journal of Food Engineering, London, v. 98, n. 4, p. 443-452, 2010.

SHOJAEE-ALIABADI, S. et al. Characterization of nanobiocomposite kappa-carrageenan film with Zataria multiflora essential oil and nanoclay. International Journal of Biological Macromolecules, Amsterdam, v. 69, p. 282-289, 2014.

SLAVUTSKY, A. M.; BERTUZZI, M. a. Formulation and characterization of nanolaminated starch based film. LWT - Food Science and Technology, London, v. 61, n. 2, p. 407-413, 2015.

SOBRAL, P. J. A. et al. Mechanical, water vapor barrier and thermal properties of gelatin based edible films. Food Hydrocolloids, Amsterdam, v. 15, n. 4-6, p. 423-432, 2001.

SOBRAL, P. J. A.; HABITANTE, A. M. Q. B. Phase transitions of pigskin gelatine. Food Hydrocolloids, Oxford, v. 15, n. 4-6, p. 377-382, 2001.

SOBRAL, P. J. A. Influência da espessura de biofilmes feitos à base de proteínas miofibrilares sobre suas propriedades funcionais. Pesquisa Agropecuária Brasileira, Rio de Janeiro, v. 35, n. 6, p. 1251$1259,2000$.

SOBRAL, P. J. A. Propriedades funcionais de biofilmes de gelatina em função da espessura. Ciência e Engenharia, Uberlândia, v. 8, n. 1, p. 60-67, 1999.

SOTHORNVIT, R. et al. Effect of clay content on the physical and antimicrobial properties of whey protein isolate/organo-clay composite films. LWT Food Science and Technology, London, v. 43, n. 2, p. 279-284, 2010.

THOMAZINE, M.; CARVALHO, R. A.; SOBRAL, P. J. A. Physical properties of gelatin films plasticized by blends of glycerol and sorbitol. Journal of Food Science, Chicago, v. 70, n. 3, p. 172$176,2005$.

TONGNUANCHAN, P.; BENJAKUL, S.; PRODPRAN, T. Structural, morphological and thermal behaviour characterisations of fish gelatin film incorporated with basil and citronella essential oils as affected by surfactants. Food Hydrocolloids, Amsterdam, v. 41, p. 33-43, 2014.

TUNÇ, S.; DUMAN, O. Preparation and characterization of biodegradable methyl cellulose/montmorillonite nanocomposite films. Applied Clay Science, Amsterdam, v. 48, n. 3, p. 414-424, 2010.

VANIN, F. M. et al. Effects of plasticizers and their concentrations on thermal and functional properties of gelatin-based films. Food Hydrocolloids, Amsterdam, v. 19, n. 5, p. 899-907, 2005.

VARGAS, M. et al. Characterization of chitosan-oleic acid composite films. Food Hydrocolloids, Amsterdam, v. 23, n. 2, p. 536-547, 2009.

VOGLER, E. A. Structure and reactivity of water at biomaterial surfaces. Advances in Colloid and Interface Science, Amsterdam, v. 74, p. 69-117, 1998. 
WIĄCEK, A. E. Effect of surface modification on starch biopolymer wettability. Food Hydrocolloids, Amsterdam, v. 48, p. 228-237, 2015.

YIN, Y. C. et al. Surface modification of sodium caseinate films by zein coatings. Food Hydrocolloids, Amsterdam, v. 36, p. 1-8, 2014. 